\title{
A Correlational Study to Evaluate the Effectiveness of Behavior- Based Safety in an Offshore Oil Production Facility
}

Zinga Martine Branco

West Virginia University

Follow this and additional works at: https://researchrepository.wvu.edu/etd

\section{Recommended Citation}

Branco, Zinga Martine, "A Correlational Study to Evaluate the Effectiveness of Behavior-Based Safety in an Offshore Oil Production Facility" (2013). Graduate Theses, Dissertations, and Problem Reports. 519. https://researchrepository.wvu.edu/etd/519

This Thesis is protected by copyright and/or related rights. It has been brought to you by the The Research Repository @ WVU with permission from the rights-holder(s). You are free to use this Thesis in any way that is permitted by the copyright and related rights legislation that applies to your use. For other uses you must obtain permission from the rights-holder(s) directly, unless additional rights are indicated by a Creative Commons license in the record and/ or on the work itself. This Thesis has been accepted for inclusion in WVU Graduate Theses, Dissertations, and Problem Reports collection by an authorized administrator of The Research Repository @ WVU. For more information, please contact researchrepository@mail.wvu.edu. 


\title{
A Correlational Study to Evaluate the Effectiveness of Behavior-Based Safety in an Offshore Oil Production Facility
}

\author{
Zinga Martine Branco
}

Thesis Submitted to the Benjamin M. Statler College of Engineering and Mineral Resources at West Virginia University in partial fulfillment of the requirement for the degree of

Master of Science in

Safety Management

Gary Winn, Ph.D., Chair

Michael Klishis, Ph.D.

Majid Jaridi, Ph.D.

Department of Industrial and Management Systems Engineering Morgantown, West Virginia

2013

Keywords: Intervention effectiveness; Behavior-Based Safety; Safety interventions; Incident Prevention; Occupational Safety Program Evaluation

Copyright 2013 Zinga M. Branco 


\begin{abstract}
A Correlational Study to Evaluate the Effectiveness of Behavior-Based Safety in an Offshore Oil Production Facility
\end{abstract}

Zinga Martine Branco

For many countries, oil production constitutes a large part of their economic resources. It is also one of the most hazardous activities with high incident rates. Workplace safety has remained a challenge for these industries which strive to operate injury free. Behavior-Based Safety (BBS) is used as a safety intervention approach to minimize the frequency and severity of workplace incidents and injuries. Many companies assume BBS is effective in reducing injuries and losses. However, only anecdotal evidence is usually presented to support the effectiveness of BBS in decreasing incident rates.

This study explores the relationship between Behavior-Based Safety (BBS) outcomes and incident rates in an oil production offshore facility located in West Africa. Quantitative analyses were performed using company historical data during a period of five years. Pearson productmoment correlation coefficients were calculated. Significant relationships (p value $<0.05$ ) were found in correlation analyses between the rates of unsafe behaviors and total incidents; safe behaviors and total incidents; and observations sessions and total incidents. Linear regression models were used to assess the predictability of incident rates from BBS outcomes. These models revealed that only about three to nine percent of the variances in total incident rates could be explained by BBS outcomes, suggesting the existence of other organizational factors impacting incident rates' variations.

These findings suggested that BBS process could improve safety-related behaviors in workplaces; however, it had little effect on incident rates because BBS process outcomes were not good predictors of incident rates. Therefore, companies should not focus on BBS alone to decrease incident rates. Other safety programs should be given attention and resources allocated into BBS activities should be reconsidered. Further research is recommended to explore causal relationships of the significant correlations and to investigate the effects of BBS on incident rates when considered together with other existing safety programs. 


\section{Dedications}

This thesis is dedicated to my heavenly Father who blessed me abundantly.

To my family who always supported me along the journey of my life.

To my friends and mentors who always believed in me.

Finally to all the people who strive to make this world a better place. 


\section{Acknowledgement}

This work was conducted under the direction of Dr. Gary Winn, and Dr. Michael Klishis who are to be recognized for their dedication and advising time. Special thanks go to the oil production company located in West Africa for the information provided in order to perform this work.

The author, also gratefully acknowledges direct support for this research from Dr. Majid Jaridi.

Finally, it is fitting to recognize many other people who have promoted this research in many different ways; without all of you this work would not have been possible. 


\section{Table of Contents}

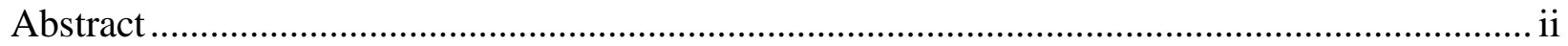

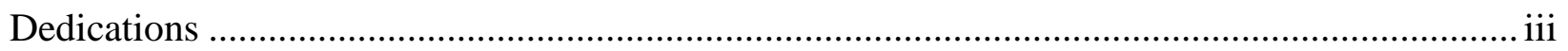

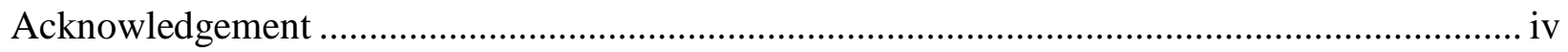

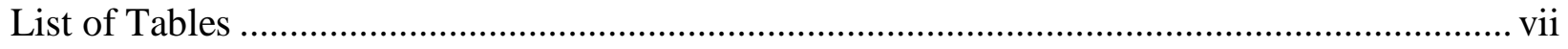

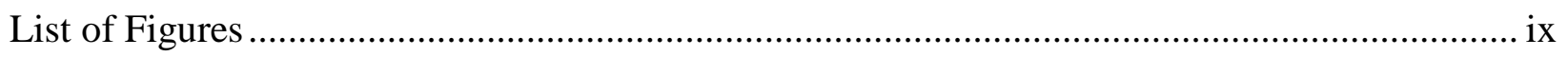

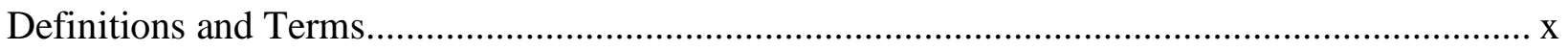

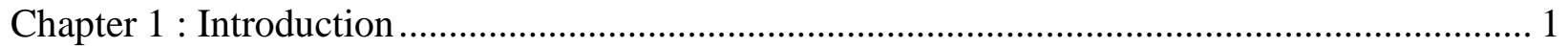

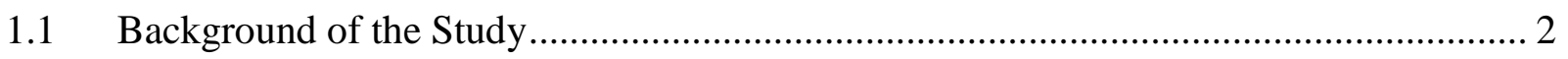

1.2 Behavior-Based Safety in XYZ Oil Company ........................................................ 3

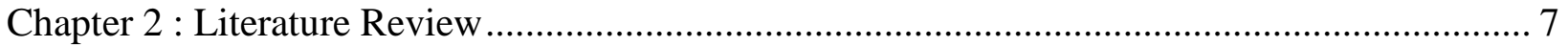

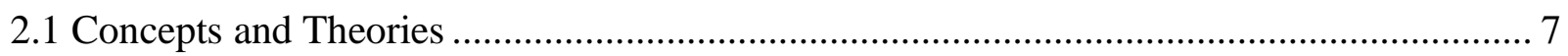

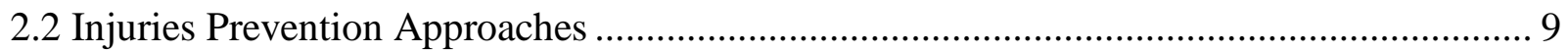

2.2.1 Traditional Approaches to Incident Preventions .................................................. 9

2.2.2 The Shift in Incident Preventions Approaches ...................................................... 10

2.3 Behavioral Interventions and Other Incident Prevention Approaches............................. 12

2.4 Behavioral Interventions and Organizational Behaviors Change ................................... 13

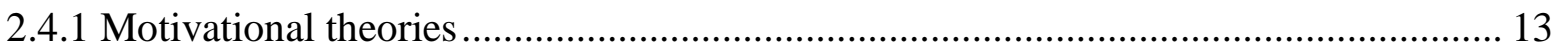

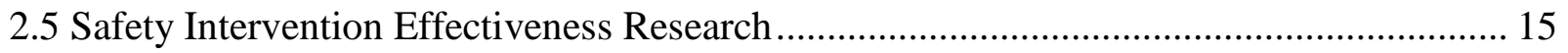

2.5.1 The need for intervention effectiveness research ................................................ 15

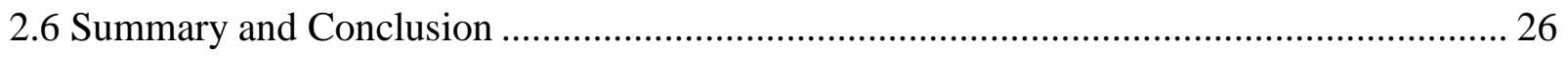

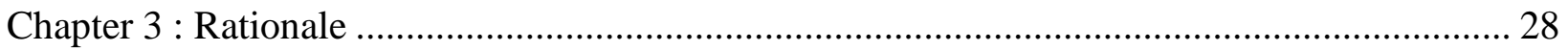

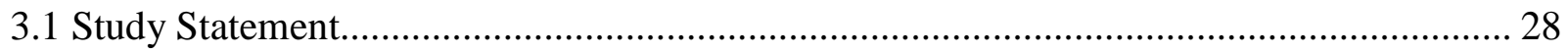

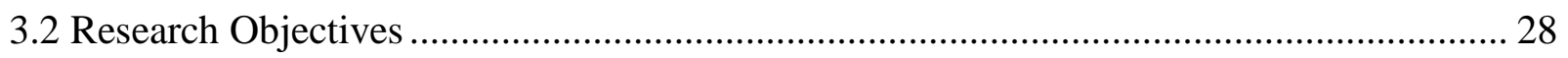

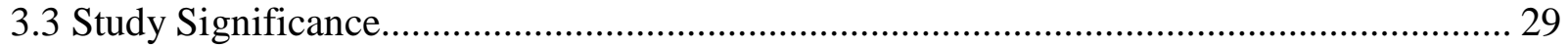

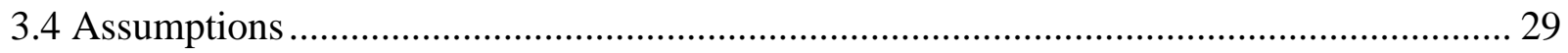

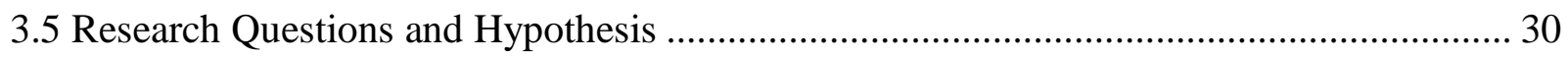

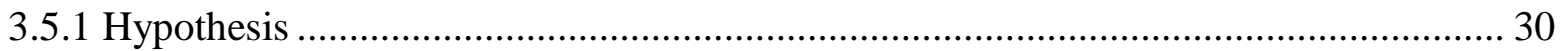

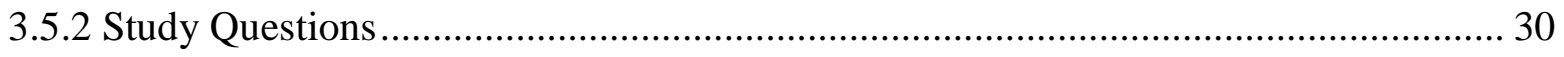

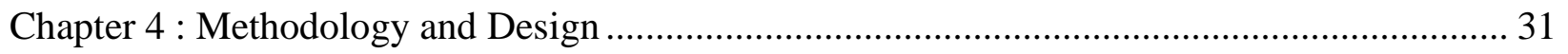




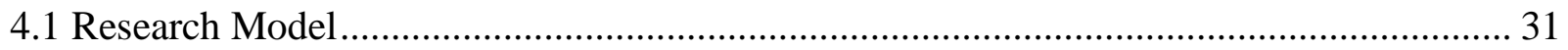

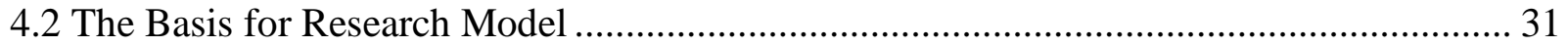

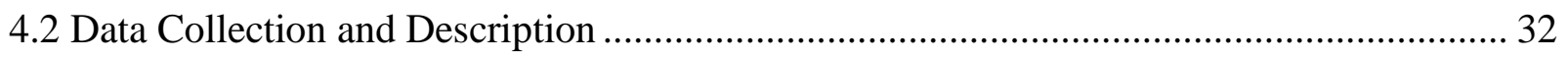

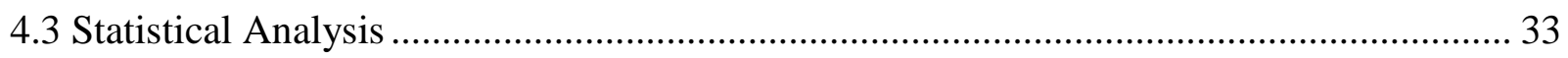

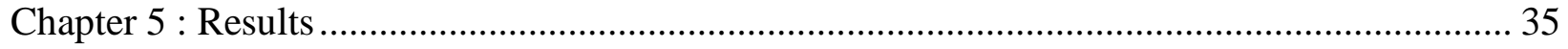

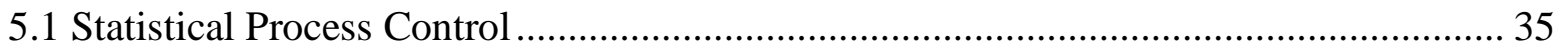

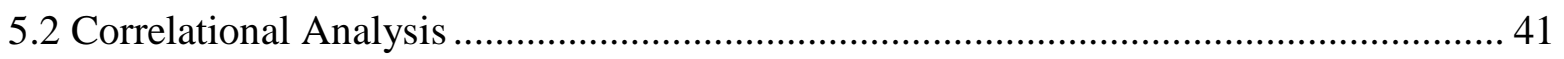

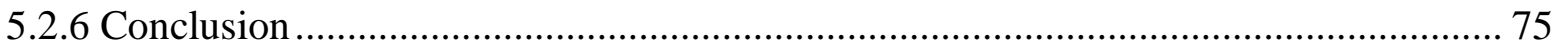

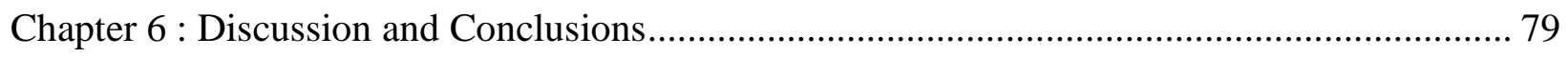

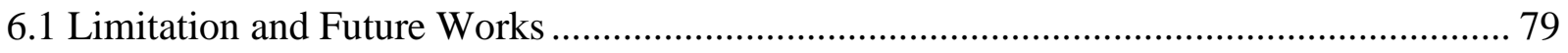

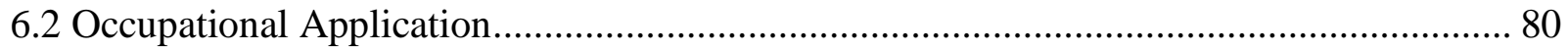

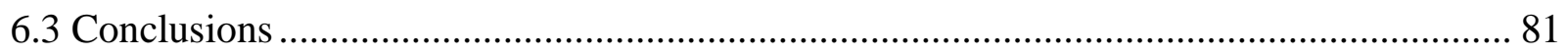

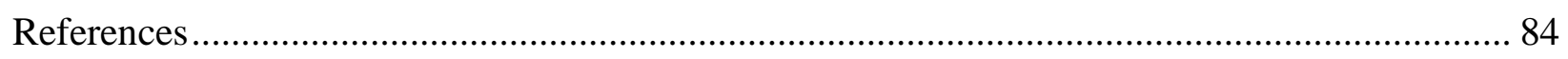

Appendix A: Five Years BBS Outcomes Spreadsheet ....................................................... 91

Appendix B: XYZ Oil Company Incident Rates from 2008-2005 ........................................ 95

Appendix C: Sample of BBS Observation Sheet.............................................................. 97

Appendix D: Sample of Critical Behaviors Inventory and Definitions in XYZ Oil Company .... 98 


\section{List of Tables}

Table 5.1: Descriptive Statistics of Total Incident Rates....................................................... 35

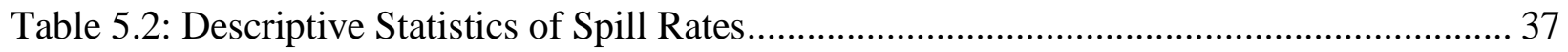

Table 5.3: Descriptive Statistics of Injury and Illness Rates ................................................ 38

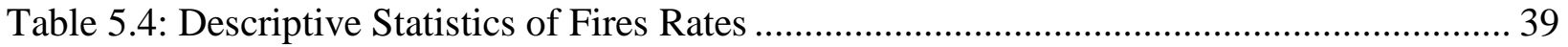

Table 5.5: Descriptive Statistics of Near-Miss Rates ........................................................... 40

Table 5.6: Correlation Results between Total Incident Rates and Safe Behaviors ...................... 42

Table 5.7: R-Values of the Correlation between Total Incidents and Safe Behaviors ................ 42

Table 5.8: ANOVA Results between Total Incident Rates and Safe Behaviors ........................ 43

Table 5.9: Regression Coefficients of Total Incident Rates on Safe Behaviors ......................... 43

Table 5.10: Correlation Results Between Total Incident Rates and At-Risk Behaviors .............. 44

Table 5.11: R-Values of the Correlation Between Incident Rates and At-Risk Behaviors .......... 44

Table 5.12: ANOVA Results between Total Incident Rates and At-Risk Behaviors.................. 45

Table 5.13: Regression Coefficients of Total Incident Rates on At-Risk Behaviors .................. 45

Table 5.14: Correlation Results between Incident Rates and Observation Sessions ................... 46

Table 5.15: R- Values of the Correlation between Total Incidents and Observation Sessions .... 47

Table 5.16: ANOVA Results between Total Incident Rates and Observation Sessions .............. 47

Table 5.17: Regression Coefficients of Total Incident Rates on Observation Sessions.............. 48

Table 5.18: Correlation Results between Near-Miss Rates and At-Risk Behaviors.................... 49

Table 5.19: R-Values of the Correlation between Near-Miss Rates and At-Risk Behaviors ....... 49

Table 5.20: ANOVA Results between Near-Miss Rates and At-Risk Behaviors ...................... 49

Table 5.21: Regression Coefficients of Near-Misses on At-Risk Behaviors.............................. 50

Table 5.22: Correlation Results Between Near-Miss and Safe Behavior Rates ......................... 51

Table 5.23: R-Values of the Correlation between Near-Miss and Safe Behaviors ..................... 51

Table 5.24: The ANOVA Results between Near-Miss and Safe Behavior Rates ....................... 52

Table 5.25: Regression Coefficients of Near-Misses on Safe Behaviors .................................. 64

Table 5.26: Correlation Results between Near-Misses and Observation Sessions..................... 53

Table 5.27: R-Values of the Correlation between Near-Misses and Observation Sessions ......... 53

Table 5.28: ANOVA Results between Near-Misses and Observation Sessions ........................ 54

Table 5.29: Regression Coefficients of Near-Misses on Observation Sessions ........................ 54

Table 5.30: Correlation Results between Injuries/Illness and At- Risk Behaviors..................... 55

Table 5.31: R-Values of the Correlation between Injuries/Illnesses and At-Risk Behaviors...... 55

Table 5.32: ANOVA Results between Injuries/Illnesses and At-Risk Behaviors ..................... 56

Table 5.33: Regression Coefficients of Injuries/Illnesses on At-Risk Behaviors...................... 56

Table 5.34: Correlation Results between Injuries/Illnesses and Observation Sessions............... 57

Table 5.35: R-Values of the Correlation between Injuries/Illnesses and Observation Sessions .. 57 
Table 5.36: ANOVA Results Between Injuries/Illnesses and Observation Sessions .................. 58

Table 3.37: Regression Coefficients of Injuries/Illnesses and Observation Sessions .................. 58

Table 5.38: Correlations Results between Injuries/Illnesses and Safe Behaviors ...................... 59

Table 5.39: R-Values of the Correlation between Injuries/Illnesses and Safe Behaviors ............ 59

Table 5.40: ANOVA Results between Injuries/Illnesses and Safe Behaviors............................ 60

Table 5.41: Regression Coefficients of Injuries/Illnesses on Safe Behaviors ............................ 60

Table 5.42: Correlation Results between Spills and Safe Behaviors....................................... 61

Table 5.43: R-Values of the Correlation between Spills and At-Risk Behaviors........................ 61

Table 5.44: ANOVA Results between Spill and At-Risk Behavior Rates ............................... 62

Table 5.45: Regression Coefficients of Spill Rates on At-Risk Behavior Rates ........................ 62

Table 5.46: Correlation Results between Spills and Observation Sessions............................... 63

Table 5.47: R-Values of the Correlations between Spills and Observation Sessions.................. 63

Table 5.48: ANOVA Results between Spills and Observation Sessions................................... 64

Table 5.49: Regression Coefficients of Spills on Observation Sessions ................................... 64

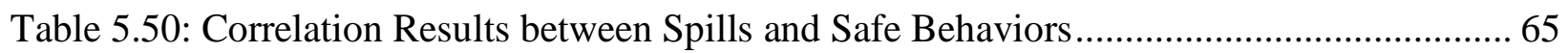

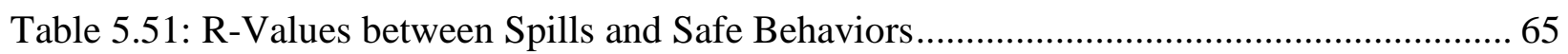

Table 5.52: ANOVA Results between Spills and Safe Behaviors ........................................... 66

Table 5:53: Regression Coefficients of Spills on Safe Behaviors ........................................... 66

Table 5.54: Correlation Results between Fires and At-Risk Behaviors .................................... 67

Table 5.55: R-Values of the Correlation between Fires and At-Risk Behaviors......................... 68

Table 5.56: ANOVA Results between Fires and At-Risk Behaviors ......................................... 68

Table 5.57: Regression Coefficients of Fires on At-Risk Behaviors........................................ 69

Table 5.58 Correlation Results between Fires and Observation Sessions Behaviors.................. 70

Table 5.59: R-Values of the Correlation between Fires and Observation Sessions .................... 70

Table 5.60: ANOVA Results between Fires and Observation Sessions................................... 71

Table 5.61: Regression Coefficients of Fires on Observation Sessions ................................... 71

Table 5.62: Correlation Results between Fire and Safe Behaviors .......................................... 72

Table 5.63: R-Values of the Correlation between Fires and Observation Sessions ..................... 72

Table 5.64: ANOVA Results between Fires and Safe Behaviors.............................................. 73

Table 5.65: Regression Coefficients of Fires on Safe Behaviors ........................................... 73

Table 5.66: Correlation Results between Observation sessions and Safe Behavior Rates........... 75 


\section{List of Figures}

Figure 1.1: XYZ Oil Company’s BBS Framework ........................................................... 6

Figure 2.1: Modified Reason's Accident Causation Model...................................................... 9

Figure 2.2: Accident Triangle ....................................................................................... 20

Figure 5.1: Process Control Chart of Incident Rates ............................................................. 36

Figure 5.2: Process Control Chart of Spill Rates ..................................................................... 37

Figure 5.3: Process Control Chart of Injuries and Illness Rates .............................................. 38

Figure 5.4: Process Control Chart of Fire Rates ................................................................. 40

Figure 5.5: Process Control Chart of Near-Misses ......................................................... 41

Figure 5.6: Scatter Plots of the Relations between Safe Behaviors and Observations Sessions .. 74 


\section{Definitions and Terms}

- ANOVA: Analysis of Variance.

- At- Risk behaviors: Unsafe work practice in a facility (Krause, 1995).

- BBS: Behavior-Based Safety is an employee-driven process that consists of changing workers’ safety-related behaviors (Krause, 1995).

- Incident: Any unplanned event resulting in a loss whether injuries occur or not. For the purpose of this study, accidents and incidents will be used interchangeably (Brauer, 2006, p.23).

- Incident rates: A U.S. standardized measurement computed by multiplying the number of injuries (incidents) by 200,000 and then dividing the result by the total hours worked (Petersen, 2003).

- Intervention Effectiveness: Consists of determining whether a safety initiative has had the intended effect (Robson et al., 2001).

- Leading indicators: Leading metrics typically representing self-assessment ratings of a company's exposure to safety hazards (Wurzelbacher \& Jin, 2011).

- NIOSH: National Institute for Occupational Safety and Health.

- Safety Intervention: any attempt to change how things are done in order to improve safety. 
- Summative Evaluation: Same as effectiveness evaluation. That is, did the intervention work in terms of impact on the dependent variable? (Robson et al., 2001).

- Trailing Indicators: typically measures the frequency and severity of past injuries/ illnesses, such as injury rates and worker compensation costs. These types of metrics are reflective of what has occurred (Wurzelbacher \& Jin, 2011). 


\section{Chapter 1: Introduction}

Behavior-Based Safety (BBS) has become very popular as a proactive safety intervention approach to deterring workplace incidents and injuries in the last two decades. Many industries around the world are investing tremendous resources to implement and sustain BBS processes in the workplace. Some scholars also consider BBS process outcomes as important indicators of organizational safety performance. However, little has been done to establish the effectiveness or impact of this process in lowering incident rates in workplace settings. In many of these organizations there is competition for financial resources which are usually limited. However, it appears that many safety consulting companies, who usually design these behavioral safety processes, overly inflate the potential of BBS to decrease incident rates by presenting evidences which are merely anecdotal. Therefore, it becomes important to empirically clarify whether or not these companies are buying into an unproven concept.

XYZ Oil Company has applied different approaches in order to decrease incident rates and to sustain an injury-free operation culture. A little more than a decade ago, the company adopted BBS as a proactive safety process in their safety system. It is strongly believed that the company's safety performance improved due to the implementation of the BBS process, which, since then, has been given far more attention than other loss prevention strategies. Substantial resources have been put into this process. However, while there are indications of XYZ Oil Company’s safety performance improvement, the relationship between BBS activities and the company's incident rates is yet to be established. This study will examine the relationship 
between BBS process outcomes and incident rates in order to establish whether its attributed impact on incident rates is a mere perception or a fact.

\subsection{Background of the Study}

The aim of this study is not to analyze functional elements of Behavioral-Based Safety process or to assess their applicability; such types of studies have been extensively featured in the safety literature and are generally performed during the development and implementation phases of BBS which are precursors to the effectiveness evaluation which is the concern of this study. The objective of this work is to explore the effect of BBS interventions in a realistic setting by using final performance outcomes measurement such as incident rates. Sometimes referred to as summative evaluation, effectiveness evaluations need to be systematically done because they are generally more useful than other types of evaluations (LaMontagne \&Needleman, 1996).

A large portion of BBS effectiveness studies published in the safety literature has used proxy-outcomes or substitutes for incident and injury rates. One reason given is that the typical low frequency of major and recordable incidents and injuries in the workplace may lessen the study's power. Additionally, possible unreliability of an organization's incident tracking systems was also mentioned as one of the concerns (Geller, 1996; Johnston \& Hayes, 2005). However, in order to establish objectively the effectiveness of an intervention, final outcomes measurements such as incident rates should be considered (Sulzer-Azaroff \& Austin, 2000; Hermann et al., 2010). In addition, the very few studies that have considered final outcomes measurement have seldom applied objective methods (Haynes et al., 1982). 


\subsection{Behavior-Based Safety in XYZ Oil Company}

Company overview. Located southwest of the African Coast, XYZ Oil Company is a subsidiary of a multinational oil company headquartered in the United States. Its activities involve exploration, production, shipment of crude oil, gas and other petroleum products. Founded in 1956, it has been one of the most successful oil companies in Africa. XYZ Oil Company is divided into many departments; these include Production, Finances, Human Resource and Legal, Supply Chain and Health Environment. The company employs more than six thousand employees, working in different departments. Oil production is one of the most hazardous industrial activities with high incident rates. According to the U.S. Bureau of Labor Statistics 2011 report, the incident rate is estimated at 0.9 for 100 full time workers in oil and gas explorations. Therefore, promoting safe operations and environmentally sound production is a challenge for many oil production companies.

In XYZ Oil Company, the production department has experienced a considerable number of incidents. In fact, the production department is the most exposed to incidents due to the hazardous and complex nature of the production activities performed. In the effort to reduce incident rates many safety initiatives have been implemented including slogans, policies, rules, safety meetings, safe work practices, safety trainings, process hazard analysis (PHA), incident investigations, safety audits and employees’ disciplinary process. While these strategies may have contributed to decreasing incidents at one time, they were not effective in sustaining good safety performance and ensuring continuous improvement.

In 2000, the company implemented Behavior-Based Safety (BBS) as a means to decrease incident rates and sustain continuous improvement. Considerable company resources, time and 
efforts were invested into training people and applying BBS concepts. After more than a decade of implementation, XYZ Oil Company's safety performance has been better at least anecdotally, and it is believed that BBS has helped in decreasing the number of incidents. The average workers in this company spend about 15 minutes/day participating in BBS processes. Considering the 6,000 workers involved with this process, the man-power needed is substantial. Therefore, it is worth questioning how well this process is working and how to measure its effectiveness. Is it just that people have bought into to an unproved concept or is BBS's impact on accident rates a fact? This study considers a correlational approach to evaluate the effectiveness of Behavior-Based Safety process within the XYZ Oil Company by using a statistical analysis of the company's historical data.

Behavior-Based Safety description. Organizational behavior analysis has been around for a century, beginning with Frederick Taylor in the late 1800s. However, it became industryoriented and based on principles of operant conditioning about three decades ago under the proprietary name of Behavior Science Technology (BST). Nonetheless, the term Behavior-Based Safety (BBS) was coined by Dr. Scott Geller (Petersen, 2003; Krause, 1995). The BBS process consists of observing workers' behaviors while performing their tasks and giving constructive feedback to them. A sample of critical behaviors to be observed is included in Appendix D. Feedback is the core of the whole observation activity; it is a friendly peer to peer discussion about specific safe and risky behaviors observed. The result of the conversation is captured in writing on an observation worksheet especially designed for this process. A sample of observation sheets is shown in Appendix C. 
While it can be adapted to fit specific companies’ needs, BBS principles remain founded on the "ABC" analysis (Geller, 2005). This consists of identifying the antecedents (A) to targeted behaviors (B) and applying either encouraging or deterring consequences (C). In the BBS process, it is believed that consequences drive behaviors while antecedents influence behaviors. Consequences may be classified into two main categories: positive reinforcements, which consist of giving stimulus (verbal reinforcement for example) in order to encourage safe behaviors, and negative reinforcements, which consist of removing a stimulus in order to discourage risky behaviors.

Conceptual Framework of BBS Process in XYZ. The BBS process at XYZ Oil Company follows the corporation design from the United States. It consists of observing people while carrying out their daily activities and requires that feedback between observers and observees occur objectively and promptly. The most important thing is to capture what drives specific behaviors in order to correct (when risky) or repeat them (when safe). In order to complete an observation, users must go through the following steps: ask permission, perform observation, provide/lead feedback and collect information in writing to be input into the organization's database. A typical BBS observation generally should take about 10-15 minutes (Cooper \& Philips, 2004). On a by-weekly basis, a specific team of employees, called a Steering Committee, will analyze the information provided, update the team on performance and come up with corrective actions to address any opportunity that may arise. In addition, a BBS champion is elected to lead friendly BBS competitions among teams on a monthly basis. It is important to note that this process is employee-driven where punishment and repercussions for reported behaviors are not allowed. For these reasons, BBS observations are reported anonymously. 
However, as in any other safety intervention process, BBS needs management support in order to be successful. XYZ`s BBS conceptual framework is illustrated in Figure 1.1.

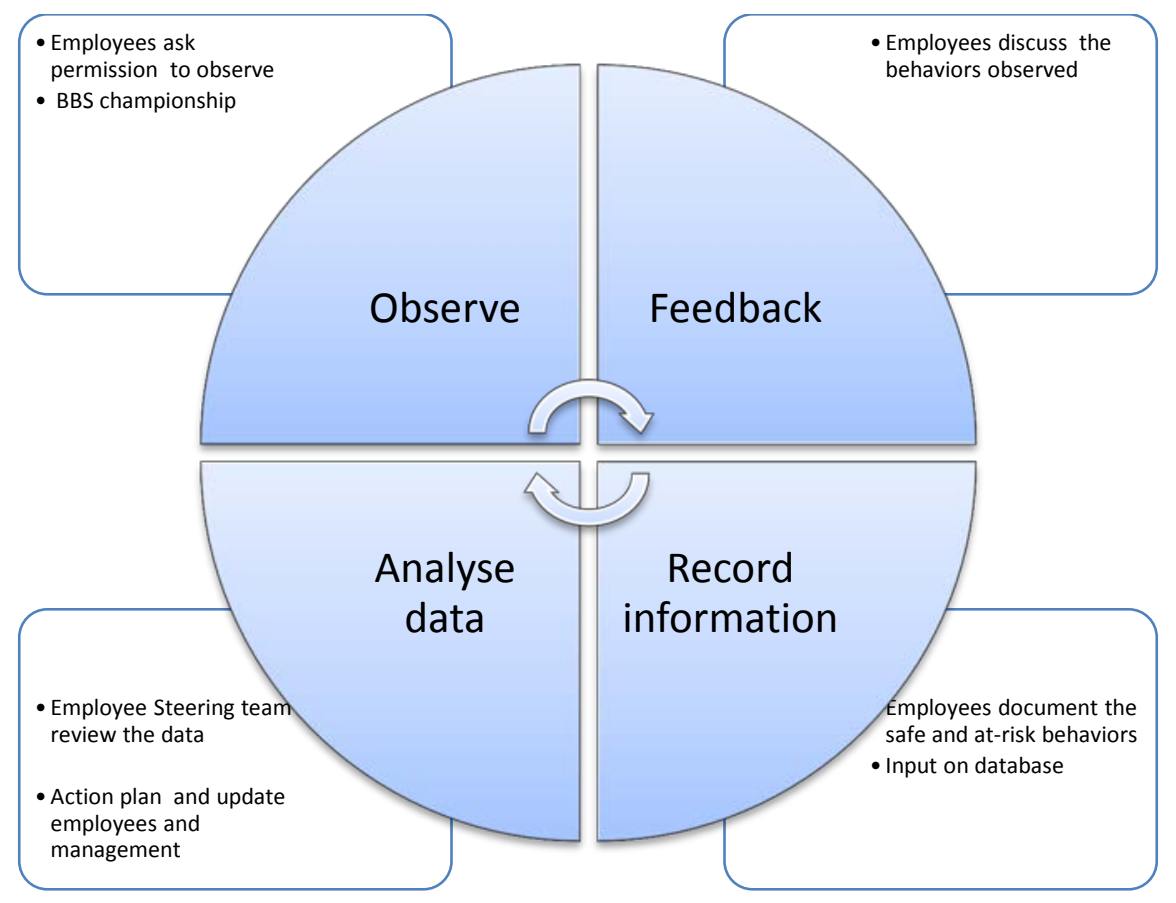

Figure 0.1: XYZ Oil Company’s BBS Framework Summarized for this Study.

The conceptual theory supported Behavior-Based Safety process is presented in chapter two. This chapter also reviews the injuries and prevention strategies as well as BBS effectiveness studies featured in the safety literature. 


\section{Chapter 2: Literature Review}

\subsection{Concepts and Theories}

This literature review provides a background into occupational accident prevention approaches in terms of their history and both traditional and progressive perspectives. Primarily, the underlying theories and concepts relevant to occupational accidents and prevention strategies are explored here. Second, the conceptual framework of BBS process design is analyzed here in order to understand the dynamic in which BBS is supposed to work and empirical evidences supporting this framework in the safety literature are also extensively reviewed.

History of accident prevention programs. In the early 1800’s, employers were little concerned with worker's safety (Goetsch, 2008). With the industrial development in the United States, occupational casualties increased due to new manufacturing technologies and man-power demographic changes. Much later, these events, in addition to labor shortage due to World War II deployments, raised serious concerns for worker safety which then became the subject of much higher interest than in early decades (Goetsch, 2008). However, "the advent of organized industrial safety programs is accredited to the Pittsburgh Survey” (Petersen, 2003) which was performed by the Russell Sage Foundation and published in 1907. This survey revealed that work related incidents claimed 562 lives and 500 serious and permanent disabilities per year in a single county (Petersen, 2003). In 1916, industrial safety programs were modeled by the American Occupational Medical Association to include occupational health.

Accident causation theories. In the early 1900s occupational accidents were generally regarded as a matter of fate. The notion of work-related accident unavoidability was notably 
challenged by Sidney Williams in his Industrial Safety Manual (1927), where he claimed that accidents were predictable events which can be prevented (Petersen, 2003; Kidd P. et al., 2003). Thus, in an effort to prevent workplace incidents, safety and health practitioners focused on uncovering their causes. Many theories of accident causations were then proposed and some of them have framed modern accident prevention approaches. They include Heinrich’s Domino theory and axioms, human factor theory, Petersen theory and behavioral theory, among the most notable.

H.W. Heinrich’s Domino theory of accidents suggested that there are five factors in a chain reaction ending up in accidents (Petersen, 2003). In his axioms, Heinrich claimed that unsafe acts constitute 88 per cent of causes of accidents while ten per cent are caused by unsafe conditions and the remaining two per cent are attributed to unrecognized causes (Heinrich, 1931; Heinrich, Petersen, \& Roos, 1980). He also proposed the concept of the 3 E’s of safety which are engineering, education, and enforcement. Many modern injury prevention approaches are based on Heinrich’s works.

Heinrich’s accident causation theory was later challenged by more comprehensive views of accident causations; the most relevant is the multiple causations theory, which held that accidents are seldom a matter of a single cause. Rather, many causes and sub-causes may contribute together in order for an accident to happen. These contributing factors were grouped into two main categories which involve human and environmental factors. A typical accident causation model evolved from this theory is the Reason's accident causation model (Hopkins, 2006). In this model, the common accident triangle was modified to include other 
contributing factors to incidents deviating from the common pathway to incidents. What he called “the latent condition’s pathways.” The model is pictured in Figure 2.1.

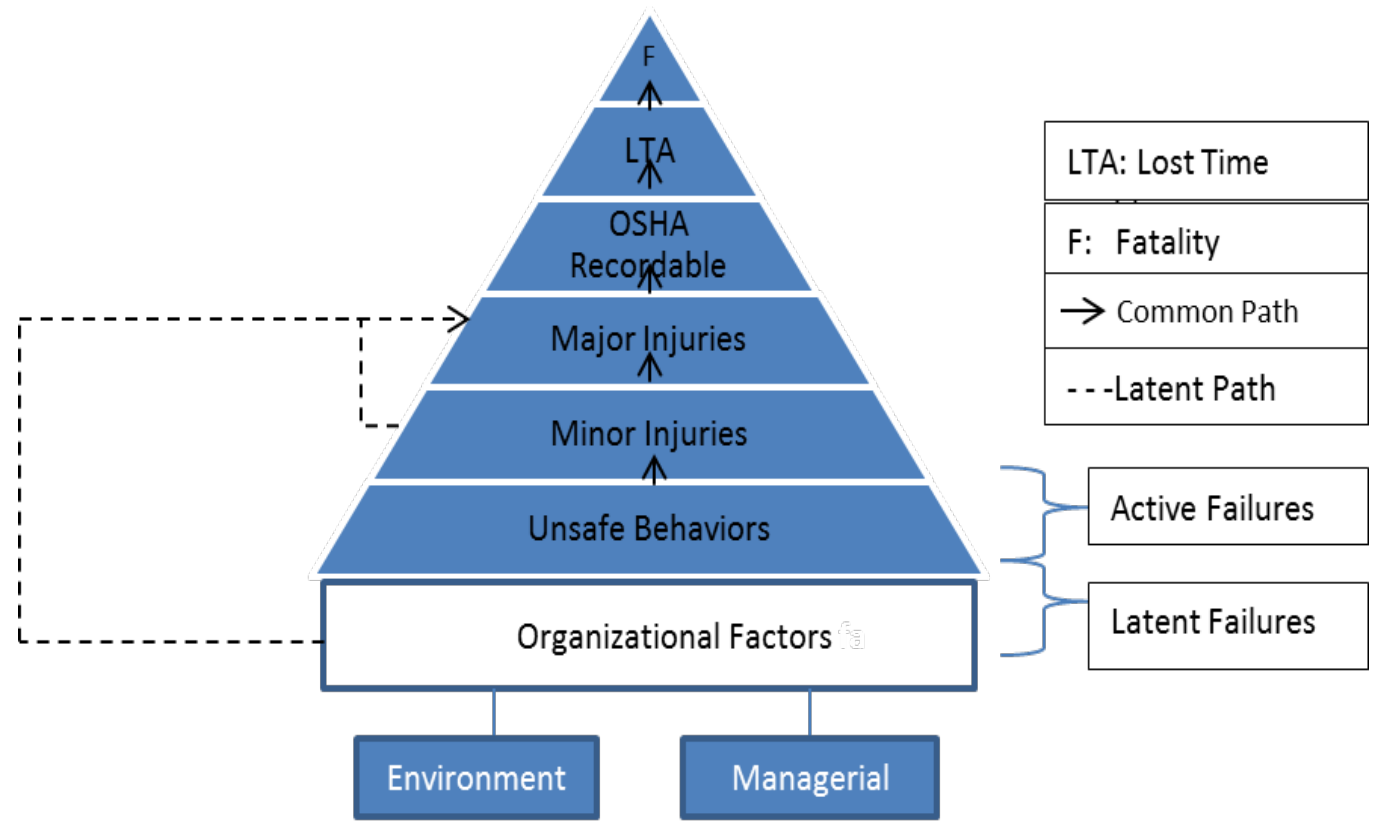

Figure 0.1: Modified Reason’s Accident Causation Model (Source, Hopkins, 2006, p. 9).

\subsection{Injuries Prevention Approaches}

\subsubsection{Traditional Approaches to Incident Preventions.}

Traditional incident prevention approaches were mainly design and administrative oriented, with little to no emphasis on human factors. The 3 E’s of safety have been the core of early safety programs which hold that incidents can be addressed by engineering, education and enforcement. Advocates of this approach believed that process hazards can be eliminated through engineering design; then, through education, safe work practices could be inculcated to workers and safety expectations emphasized. Finally, through enforcement organizations may ensure that safety policies, procedures, rules and regulations are in place and followed accordingly. Another relevant concept of traditional incident prevention approaches is the hierarchy of controls, socalled because of its ranking order of effectiveness. From the highest to the least effective, a 
typical model of controls suggested by NIOSH (2010) includes elimination, substitution, engineering controls, administrative controls and finally, personal protective equipment (PPE).

\subsubsection{The Shift in Incident Preventions Approaches.}

From top-down management to broad participation approaches, early safety intervention approaches were mostly driven by management and disseminated to the workers. Despite some safety improvement accredited to these management-driven approaches, performance sustainability was hardly achieved because these interventions were less likely to get employee commitment. Thus, the need for employee's participative approaches became evident (Paul \&Maiti, 2007). This was illustrated by the work of Neal and Griffin (2006) that examined the effects of top-down and bottom-up safety processes on safety performance. The study concluded that sustainable improvement in workers' safety behaviors was associated with incident reduction in bottom-up processes. Consequently, worker commitment becomes paramount in safety interventions. The idea of broad participation in safety interventions emerged from total quality management (TQM) strategies introduced by Edward Deming in 1982 (Brauer, 2006; Carder \& Ragan, 2003). The TQM approach sought to improve process quality through the participation of every layer of the organization (Brauer, 2006). This approach shifted the direction of organizational safety management focus from top-down to bottom-up directed approaches. 
From Anecdotal to Scientific Evidence. With TQM, scientific approaches to process improvement were also introduced. TQM methods focus on reducing error rates by identifying opportunities for improvement and correcting them before the finished products. These methods are known to have influenced modern safety performance management. The argument was that if safety can be regarded as a process characteristic similar to quality, then similar techniques can be applied (Carder, 1994; Carder \& Ragan, 1994 \& 2003). For instance, TQM methods could be applied to intervention strategies such as Behavior-Based Safety "because behaviors can be observed, measured and subject to extended statistical analysis techniques” (Weinstein, 1997). In the BBS case, incident rates represent error rates, which are regarded as defective products of the work process.

Scientific methods applied to safety intervention studies have been noticeably featured in the safety literature for the last two decades (Chen \& Tian, 2012; Carder \& Ragan, 1994 \& 2003) demonstrating the practicability of statistical analysis tools in evaluating safety interventions. Similarly, scientific-based evaluative concepts developed in other fields were also applied to safety management. For example, Evidence-Based Intervention approaches developed in medical fields were applied in safety studies (Shannon et al., 1999). Other studies suggested that the Transtheoretical Model of Change (TMC), widely used in other human oriented fields, may be used to determine the effectiveness of injury prevention interventions (Kidd et al., 2003; DeJoy, 1996).

From trailing to leading indicators. Traditional performance indicators were based on trailing factors. For example, at the end of a year, companies usually compare incident rates against targeted numbers to establish safety performance. The problem with this approach lies in its powerlessness to produce change. In fact, by the time incident rates are reported, it is too late 
to act. Actually, this is a reactive approach to safety performance and unlikely to sustain injury free operation's goals. The adaptation of TQM methods to safety management helped switch the gear from trailing to leading indicators. Consequently, proactive safety interventions such as

Behavior-Based Safety process, which yield leading indicators, gained popularity. Behavioral theorists advocate that eliminating risky (at-risk) behaviors in the workplace may lead to safety improvement, and suggested that in order to sustain these improvements, as with TQM, safety interventions should be driven by employees.

\subsection{Behavioral Interventions and Other Incident Prevention Approaches}

Behavior-Based Safety and the 3E's Model. As a widely accepted accident prevention approach, the 3E's model of safety suggests that incidents can be prevented through Education, Enforcement and Engineering. However, providing education, engineering and enforcement may not necessarily decrease undesirable behaviors (Hart et al., 2009). Consider, for example, how many incidents involve removing a machine guard or a very experienced worker taking short cuts. Also, the number of fines for exceeding speed limits despite surveillance cameras and warning signs could be an illustrative example of the limitations of safety enforcement. (Kidd et al. 2003) suggested that knowledge that is not translated into practice has little value. BehaviorBased Safety process is designed to drive workers into this translation. Numerous studies have identified the lack of safe behavioral motivation as a substantial contributor to workers' unsafe acts; this is an important aspect addressed in BBS intervention but not recognized in the 3E's Model.

BBS and the traditional hierarchy of control. Behavioral interventions can be designed to fit into any level of the hierarchy of controls for performance sustainability (Wirth and 
Sigurdsson, 2008). BBS can be involved in many of these control levels. For example, observing the use of PPE is usually part of the behaviors sampling process. Likewise, components of administrative controls such as safety meetings and management commitment are also recorded during BBS observations. As mentioned about the 3E's model, prevention strategies based on the hierarchy of controls alone may not address worker's unsafe behaviors. In fact, most of the protective devices can be easily removed or tampered with. For example, people may just choose to bypass a safety device to speed up production or remove their seatbelts while driving to feel more comfortable. This usually occurs when the consequences of such risky behaviors appear to be more rewarding than the safer ones. Hence, behavior change should accompany successful implementation of the hierarchy of controls; this is where the BBS process may fit in.

\subsection{Behavioral Interventions and Organizational Behaviors Change}

\subsubsection{Motivational theories.}

Some studies have associated motivation and change in individual safety behaviors (Neal \& Griffin, 2006). Popular motivational theories contend that people need to be motivated in order to perform well. For example, Maslow's theory looks at the internal motivators to performance via the hierarchy of needs; similarly, Herzberg's theory looks at rewards and recognitions associated with one’s work as external motivators, affecting behavior outcomes (Brauer, 2006). The well-known Hawthorne Effect suggests that when people know that they are being observed, the desired behaviors improve. Another study identified feedback as behavior motivator. All these theories, as distinct and complex as they may be, have mostly agreed that people need to be motivated in order to perform desired behaviors. BBS may promote both intrinsic and extrinsic employee motivation forces because its elements include observations and feedbacks. 


\section{Behavior-Based Safety as a model of organizational behavioral modification.}

Behavioral-Based Safety interventions derive from the argument that most of the occupational incidents are related to unsafe acts and unsafe acts evolve from unsafe behaviors (Paul \& Maiti, 2007; Heinrich, 1931; Wirth \& Sigurdsson, 2008). Therefore, focusing on behavior modification would address workplace incidents. Geller (2005) suggested four basic types of Behavior-Based Interventions related to three stages of behavior modification. They are instructional, supportive, motivational and self-management interventions and all four are associated with other- directed, self-directed and self-motivated behaviors stages of change.

The first type, the instructional intervention, is regarded as an activator, aimed at raising worker awareness about the consequences of unsafe behaviors by instructing them on safe work practices related to targeted behaviors. Safety training will fit into this category. A supportive intervention includes recognitions and feedbacks to support learned safe behaviors, and the idea is people like to know that they are doing good things in order to continue doing them. It is a path to turning the learned behaviors fluent (Geller, 2005). In Geller’s model of behavior change, the two previous interventions are related to other directed behaviors stage of change. The third type of behavioral intervention and perhaps the most challenging is motivational. In this scenario, workers usually choose to engage in risky behaviors because of perceived benefits. In this case, the reinforcement aspect of Behavior-Based approaches in addition to suggested incentives and rewards can be used as extrinsic motivators to behavior change. The latter type of intervention is associated with the self-directed stage of change.

A major characteristic of Behavior-Based Safety interventions consists of bringing about behavior's transition from the other-directed to the self-directed stage. At the latter stage of 
behaviors, "the employee is constantly self-motivated to act safety" (Geller, 2005). This is the last stage of behavior modification where the motivation is actually intrinsic. At this stage, safe behaviors become inherent and self-accountability for safety is developed. Understanding the association between behavioral interventions and stages of change is relevant to evaluating organizational Behaviors-Based interventions. A study performed by Kidd et al. (2003), suggested a covariate relationship between the strength of an intervention and the stage of change and emphasized the need to observe individual stages of change in response to intervention's inputs when assessing intervention effectiveness. This is an important aspect of safety intervention effectiveness research.

\subsection{Safety Intervention Effectiveness Research}

\subsubsection{The need for intervention effectiveness research.}

Organizations around the world are investing substantial resources in well-advertised modern safety intervention programs. Most of the time, however, these are without solid evidence of their effectiveness in realistic conditions. Effectiveness here means their impact on work processes. Ineffective safety interventions may lead to waste of resources and in some cases they may negatively impact workplaces (Shannon et al., 1999). Hence, intervention evaluation studies are invaluable to organizational performance. In addition, results of intervention effectiveness studies may serve as guidance in the decision-making process related to resource allocation (Haddix et al., 2003); therefore these studies must be subjected to strict scientific standards (Wirth and Sigurdsson, 2008).

Safety Intervention Evaluation Models. The National Institute for Occupational Safety and Health (NIOSH) defines "safety intervention as measures deliberately applied to decrease 
the frequency and the severity of incidents” (Dyreborg et al., 2011). NIOSH suggests a fourphase model of safety intervention evaluation; they are implementation, development, monitoring and effectiveness assessment. Many aspects of the first three phases have been substantially studied over the last 30 years. However, research on effectiveness assessments are fairly recent and constitute one of the growing research focuses in the area of safety interventions.

Intervention effectiveness assessment can be performed in numerous ways, however it is generally outcomes-oriented rather than process focused (Haddix et al., 2003); it seeks to analyze whether the goals of the intervention are achieved (McDavid, 2005; Wirth and Sigurdsson, 2008) by providing a direct link between the intervention and "the outcomes of interest." A review of the safety literature suggested that safety interventions may follow three main perspectives. They can be performed at organizational, technical and human levels (Dyreborg et al., 2011; Robson et al., 2001). Regardless of their orientation, this type of research usually strives to answer the following questions: "Does the program work?” and “At what extent it has an impact?” (Komaki \& Goltz, 2001). Answering these questions requires a systematic impact assessment rather than merely assuming that a popular process would normally work. When assessing intervention effectiveness, it is critical to select proper methodologies and measurement factors while considering the intervention's objectives (Robson et al., 2001). For instance, evaluation models suitable for compliance-oriented interventions may not be appropriate for behavior-oriented interventions simply because behavioral approaches are more complex and more subjective than regulatory approaches. 
Outcomes measurement factors. Measurement factors generally stem from safety performance indicators which can be classified as leading or lagging. The most common ones are illustrated in the accidents triangle Figure 2.2. These factors can also be grouped in terms of dimensions as individual factors (injuries, first aids, LTA and DAW) and process safety factors (fires, spills, toxic releases and property damage) (Skogdalen et al., 2011). Guidance on the selection of appropriate measurement factors is scarcely available in the safety literature (Shannon et al., 1999; Wirth and Sigurdsson, 2008). However, Wirth and Sigurdsson advised that these factors should be sector-specific, objective and easily quantifiable. Measurement factors are primarily determined by the intervention's objectives. In this regard, the review of safety literature distinguishes two main tendencies of intervention effectiveness studies. The ones that use substitutes for incidents as outcomes measurement and the ones that use incident rates directly as outcome measurements. The outcomes measurement commonly used as substitute for incident rates include safety climate, culture, saving costs and safety behaviors indexes.

Substitute Outcomes. Also called proxy outcomes, these are proximate indicators of incidents which may lead to indirect evidence of intervention effectiveness. Many researchers in occupational safety literature have considered these substitutes. Some of them have explored the relationship between Behavior-Based interventions and the change in organizational factors such as safety climate (Flin et al., 2000; Mearns, 2009), safety culture and safety leadership. Few works have focused on direct and indirect saving costs resulting from BBS interventions. For example,( Iyer et al., 2004) studied the relationship between incident rates and "intervention's application rate” defined as the total man-hours invested. Other studies such as Cooper and Phillips (2004) used safety indexes (percent safe score) as measures of effectiveness. Interestingly, very few studies included “at-risk" behavior rates, also referenced by (Krause 
2006) as "the critical mass" in their effectiveness analysis, and this, despite widely accepted theories identifying them as a common path to injuries and incidents in general (Heinrich, 1931; Wirth and Sigurdsson, 2008).

However, NIOSH cautioned researchers about the use of these substitutes and suggested that if the objective of an intervention is to decrease incident rates; then the latter should constitute the outcome measurements unless a causal path to incidents is established (Robson et al., 2001). Unfortunately, many studies that had used substitute outcomes measurement have failed to provide empirical evidence of a significant correlational link between these substitutes and incident rates (Height \& Thomas, 2003; Saari, 1994). Additionally, predictive validity is hard to establish when using substitutes (Mearns, 2009). Moreover, it should be noted that incident rates are still regarded as critical outcomes measurement for safety performance by many organizations and regulatory agencies.

Short-Term Outcomes. Some studies have focused on undesirable events close to incidents and regarded as precursors of serious injuries. They are usually called short-term outcomes. The typical ones are near- misses and minor injuries. A possible argument is that in the traditional safety pyramid, near misses and minor injuries usually precede major injuries characterized by low frequency and high severity; therefore, by focusing on incident patterns evolving from near-miss and minor injury patterns, major incidents may be prevented because these patterns can uncover potential weaknesses involved in the occurrence of major incidents. It is important to notice that despite their positions on the safety incidents pyramid, their value as leading indicators may be questionable. 
On the other hand, major incidents at offshore oil production facilities such as fires, explosions and toxic releases are not frequent; these precursors may be useful when evaluating interventions' effectiveness. However, in other types of organizations their use may not be practical. Even in the former case, as already mentioned above, a systematic relationship between these precursors and the outcomes of interest should be established. Many studies have explored the relationship between the near-misses reported and major incidents (Guastello, 1993; Jones et al., 1999; Nielsen et al., 2006). Jones et al. (1999) found an increase of reported nearmisses and minor injuries which resulted in a decrease of lost time accidents (LTA) and major injuries in a Danish metal plant.

Final Outcomes. Final outcome measurements result from the ultimate intervention objectives. They are practical outcomes of the intervention establishing direct evidences of effectiveness. They are usually trailing indicators listed as elements of organizational safety performance. These include incident and injury rates. In behavioral safety literature, non-survey based intervention studies considering these factors as outcomes measurements are scarce. (Haight et al., 2007) appears to be a unique study of this kind. It explored the variation of incident rates as dependent variables in response to behavioral safety outcomes as independent variables. The accident's triangle in Figure 2.2 illustrates the dynamic between the different types of outcomes. 


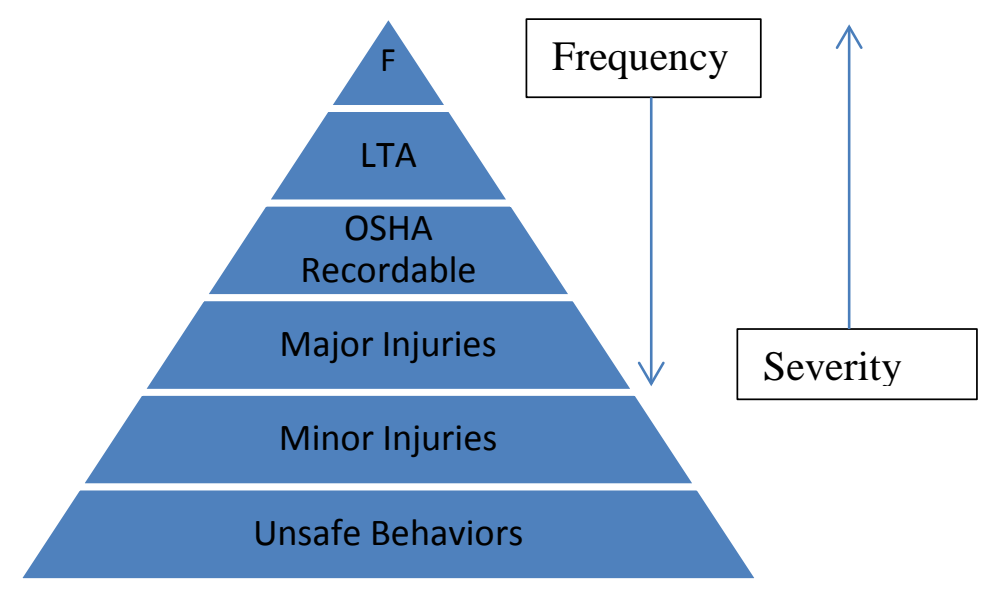

F: Fatalities

LTA: Lost Work

Time Accident

OSHA: Occupational

Safety and Health

Administration

Figure 0.2: Accident Triangle Modified from Krause, 1995

Evaluation methodologies. As mentioned above, selecting a proper methodology is critical when performing intervention evaluation studies. In the safety literature, this type of research has taken multiple directions, however the methodology used can be quantitative, qualitative or mixed. Qualitative analyses are generally used for descriptive purposes whereas quantitative analyses are more useful in intervention effectiveness studies because they determine the nature of the correlation between the intervention inputs and performance outcomes and can also be used for performance trending and forecasting (Janicak, 2003). BBS evaluation research featured in the safety literature usually involves experiment design, survey questionnaires and statistical models.

Experimental design. Generally, research based on experiments is more relevant and favored. However, in some cases, experiments may not be possible due to legal, ethical and organizational reasons. In other cases, intervention effectiveness assessment based on experiment may not be feasible because pre-intervention data are either non reliable or simply nonexistent. In these situations, non-experimental designs may be used for effectiveness evaluation. This is 
oftentimes the case in high hazards organizations with long term BBS history such as XYZ Oil Company.

Survey-based design. Much BBS intervention effectiveness research featured in the safety literature is survey-based. For example, safety perception surveys (SPS) are widely used to assess safety interventions. While these works may involve some data analysis, their results are not objectively determined because they involve perception-based evidence. For example, BBS evaluation based on surveys actually "measures the level of participant's satisfaction” and how they perceive the intervention impact on incident rates (Fullarton \&Stokes, 2006). Quantifying the effectiveness of safety interventions such as BBS involves applying statistic on numerical data (Fullarton \&Stokes, 2006 ; Haight and Thomas, 2003). These data should include both intervention and performance outcomes. In addition, survey methods were not validated as a good instrument to predict work place incident rates (Wirth and Sigurdsson, 2008; Fullarton \& Stokes, 2006).

Statistical models. Safety and health programs may be hard to quantify and their effectiveness difficult to measure by survey methods. One way to achieve this is to use statistical models because they generally quantify output variation in response to input applications (Iyer et al., 2004). These models usually include mathematical relationships and provide quantifiable objective evidences. In addition, they allow for making predictions useful to guide decision-making processes (Haddix et al., 2003). One of the very rare studies that used quantitative supported evidence to establish the relationship between BBS outcomes as independent variables and incident rates as dependent variables was performed by (Haight et al., 2007). He attempted to express this relationship in terms of mathematical functions. In this form, 
the extent at which the intervention works can be determined. The study concluded that there was no significant relationship between BBS and incident rates.

\subsubsection{A Theoretical Analysis of Behavior-Based Safety Effectiveness.}

Assessing the effectiveness of Behavior-Based Safety involves answering the two core questions of any intervention effectiveness study mentioned above. The intent of BBS intervention in the workplace is to decrease incident rates by increasing safe behaviors and decreasing at-risk behaviors. This functional statement identifies the process by which the program is supposed to work. In this context, it becomes relevant to assess the ability of BBS interventions to perform as such. As a pre-evaluation study, the core question—does BBS work?—may be answered by breaking down this functional statement into its key components and questioning them. This is a common tactic used in many theory-driven evaluation approaches (Pawson and Tilley, 2004). This perspective led to three theory-based sub questions which constitute the framework of this study: a) do BBS interventions increase safe behaviors? b) does increasing safe behaviors decrease incident rates? c) to what extent does BBS process impact incident rates?

\section{Do Behavior-Based Safety interventions increase safe behaviors? The use of} behavioral approaches to occupational incident prevention was first recognized in the work of (Komaki \& Goltz, 2001). Advocates of these approaches contend that Behavior-Based interventions may foster safe behaviors in the workplace. A fairly decent number of works featured in the safety literature had sought to verify this argument. Many of these studies have concluded that the percentage of safe behaviors had increased after behavioral interventions. Among them, Figures a study performed by ( Godbey, 2006). In this study, BBS intervention was implemented in order to induce specific behavioral changes in a manufacturing facility. In 
the early stage of the intervention, an increase of about 20 per cent of safely performed activities was observed in relation to the performance baseline. Similarly, Cooper \& Newbold's (1994) study showed an increase in safe behaviors frequency in response to behavioral safety interventions in a small manufacturing facility. Also, Cooper's (2006) study reported a small but not statistically significant positive relationship between observation frequency and the rate of safe behaviors. Congruently, a study performed by Alvero \& Austin (2004) suggested that performing BBS observations to a peer changes the observer's safety-related behaviors as well.

Reber et al. (1984) explored safety behavior trends after a behavioral intervention was applied in a sugar factory plant in the US. The study examined the effect of Behavior-Based Safety observations on workers' performance through "safety score," defined as the ratio of the number of employees observed working completely safely and the number of total employees in a department. The study concluded that the safety score of the department improved from a baseline of 62 per cent to more than 90 percent. Another study performed by (Chen \& Tian, 2012) concluded that the total safety index (SI), defined as the ratio of safe behaviors observed and the total number of observations made, had increased by 10 per cent during 35 weeks of BBS experiments in a Chinese construction company. A similar intervention study performed by (Saari, 1994) reported that safety indexes in two of the targeted departments had increased from 70 and 78 percent to 96 and 99 per cent respectively.

Do increasing safe behaviors decrease incident rates? The proactive merit of BBS approaches lies in the fact that unsafe behaviors which occur before accidents are eliminated (Godbey, 2006; Krause and Russel, 2004); however, many intervention studies have focused on safe behaviors as a strategy to incident prevention (Paul \& Maiti, 2007; Godbey, 2006). In 
Godbey's (2006) study, an increase of safe targeted behaviors had a positive impact on incident rates; reportedly, the total case incident rates (TCIR) was cut by more than 50 per cent in one of the facilities under experiment.

Conversely, other studies have come to different conclusions. For example, (Cooper \& Philips, 2004) explored the relationship between safety climate and behavior change and their impact on incident rates, and "the study revealed that lower percent of safe behaviors were recorded as the number of incident rates decreased," upholding therefore their previous study's conclusion that the percentage of safe behaviors observed and incident rates are not necessary directly correlated (Cooper et al., 1994). It worth noting that similar to both the Cooper and Godbey studies above, much effectiveness evaluation research featured in the safety literature does not include the index of at-risk behaviors in their analysis.

To What Extent Does BBS Process Impact Incident Rates? This question can be answered by observing how well BBS outcomes can predict incident rates. In fact, the predictability of incident rates through applied behavioral approaches is one of the recent focuses of behavioral safety intervention research. Prediction about people's actions can be made "from the information about their past, their surrounding or their internal attributes" (Brauer, 2006). The same reasoning can be applied to an organization's safety performance. Early safety performance predictive studies had focused on internal organizational attributes such as attitudes and beliefs because some behavioral theorists believed that they are predictors of safety-related behaviors. However, these views were somewhat undermined when the concept of cognitive dissonance had suggested that these internal attributes may not be good predictors of human behaviors (Brauer, 2006). 
Other studies have attempted to predict incident rates from organizational safety culture. A typical example would be the study performed by Razi (2006) where organizational safety culture was measured by using a Likert type scale survey model. The study hypothesized that "unavoidable" accident rates could be predicted by the culture of an organization. A linear regression analysis revealed that 9 per cent of the variance was predicted by the organization's safety culture with $\mathrm{R}$ square $=0.092$. The standard coefficients were negative, suggesting the existence of an inverse relationship. Although a quantitative methodology was used to assess this relationship through a safety culture survey, it is worth noting that the opinions of the survey's participants are somewhat subjective; therefore the generality of this model may be questionable.

Another factor believed to affect safety performance was work experience. Paul and Maiti (2007) designed a theoretical accident model exploring the relationship between safety performance and four human factors, including work experience in underground coal mining sites (p. 453). The hypothesis was that these variables could predict work related injuries; three of these human factors indicated a statistically significant positive relationship with work-related injuries. However, this study dealt with factors in relation to performing safety-related behaviors and does not actually determine the relationship between safety behaviors and work injuries.

(Haight et al., 2007) analyzed the relationship between Behavior-Based Safety and incident rates in an offshore oil production facility. The study looked at dependent variables such as the number of observation worksheets collected, total behaviors observed, at-risk behaviors and safe behaviors percentage. The independent variables included the number of total incidents, injuries, fires and near-misses. Ordinal logistic regression models were used and the authors concluded that the relationship between the variables was not statically significant. However, it 
is worth noting that the percentage of variability explained by all the variables in the regression models, expressed by the values of Nagelkerke's R square, was about 1 to 3 per cent, with the best model explaining 39.8 percent of the variances with a p-value of 0.069 . This best model involved all the independent variables together as input and the total incident rates as the dependent variable. This was one of the rare non survey-based studies using incident rates directly as outcome variables. However, the authors recognized that the relatively short period of time considered may have impacted the study's results.

\subsection{Summary and Conclusion}

The principle objective of organizational safety intervention approaches is to protect and preserve the people and efficacy of resources. As (Pawson \& Tilley, 2004) suggested, interventions are theories- incarnated, therefore understanding their underlining theories and concepts is critical to successful intervention's evaluations. One cannot successfully prevent accidents if their causes are not uncovered and systematically addressed. Many accident causation theories have been devised and have brought about different safety prevention approaches. Traditional safety interventions were mostly design and administrative oriented with little emphasis on human factors. The few human approaches to accident prevention were heavily management focused and their results were seldom sustainable because of the lack of employee commitment. Behavior-Based Safety came about as addressing this gap by promoting worker's behavioral change and fostering a continuous safety performance improvement. That is, mitigating incident rates at a point where safety performance is sustained. Since then, BBS processes have been widely adopted by organizations sometimes even without evidence of their effectiveness in realistic conditions. 
Many of these organizations cannot afford to invest in ineffective safety programs. Therefore the effectiveness of these safety interventions should be established. Understanding the dynamic between Behavior-Based Safety interventions and the stage of changes is the starting point of identifying potential successful strategies. The literature review has suggested that, conceptually, safety-related behaviors can be modified through the BBS process and possibly impact incident rates. However, BBS's practicability in decreasing incidents rates in realistic settings still needs to be objectively established. Intervention evaluation research offers systematic approaches to establishing BBS process effectiveness. Evaluative research on BBS has been decently represented in occupational safety literature. However, many of them are process-oriented. The few outcomes-oriented evaluations featured have considered the relationship between BBS outcomes and substitute outcomes instead of incident rates. Also, many of these studies were based on perception surveys. A large number of these studies suggested the existence of significant relationships between BBS and the substitute outcomes considered. However, as (Robson et al., 2007) pointed out in his systematic review of safety intervention effectiveness research, "the significance of these results for final outcomes remains unknown.” On the other hand, the rare studies which were not based on surveys and have considered final outcomes such as incident rates revealed none to little statistically significant relationships. In the light of this controversy, more non survey-based effectiveness studies considering the relationship between BBS and incident rates need to be undertaken to give further insights to the impact of Behavior-Based Safety interventions on occupational incident rates. 


\section{Chapter 3: Rationale}

\subsection{Study Statement}

The aim of this study was to evaluate the effectiveness of the BBS process in decreasing incident rates. The main argument of this study is that there is a statistically significant relationship between BBS process outcomes and incident rates in XYZ Oil Company. Therefore, the resources invested in this process are justified. This relationship can be established through statistical analyses of historical data of both BBS outcomes and incident rates over a period of five years. These data are shown in Appendix A and Appendix B. Furthermore, this study also seeks to explore how well BBS outcomes can predict incident rates in XYZ Oil Company. It is expected that, if XYZ Oil Company can predict incident rates, it would be possible to assess and adjust its safety intervention activities, such as BBS process, in order to meet safety performance targets.

\subsection{Research Objectives}

The purpose of this study was to evaluate the effectiveness of Behavior-Based Safety intervention in decreasing incident rates in realistic settings. Generally, assessing the effectiveness of a safety intervention involves answering two basic questions related to whether or not the intervention works and to what extent it impacts desired outcomes. Answering these questions constitutes the framework of this study and it can be achieved the following ways. The relationship between BBS process and incident rates will be examined through statistical correlation approaches. Secondly, regression analyses will be used to quantify the extent of BBS's impact and, therefore, develop predictive models which may be used to adjust the effort 
put into the BBS process in order to meet company performance targets. This study may help to identify effective safety intervention strategies and optimize the use of an organization's resources.

\subsection{Study Significance}

The relevance of this work can be emphasized from two main perspectives. From a business standpoint, the results of this work may support the investment made by XYZ Oil Company into Behavior-Based Safety process. This study's results may also be used as decision making guidance for resource allocation in similar industrial settings. From an organizational safety research perspective, BBS intervention effectiveness studies seem to be decently represented in the safety literature; however, a considerable number are based on perception surveys and use substitute (surrogated) outcomes measurement instead of incident rates making it rather difficult to objectively relate these studies' results to incident rates. In addition, the handful of non-survey based studies that have considered final outcomes measurement such as incident rates have inconsistently revealed the existence of a statistically significant relationship between Behavior-Based Safety processes and incident rates bringing about the need for more research of this genre. The present study may contribute to both the purpose of filling the gap in the safety literature and providing more insights into the impact of the BBS process on incident rates because this study relies on objective approaches and uses incident rates as final outcomes.

\subsection{Assumptions}

It is assumed in this study that incident data resulting from XYZ Oil Company's safety reports are reliable and that the BBS process was performed accordingly. The study also assumes 
that BBS intervention activities and quality were held constant throughout the time frame considered.

\subsection{Research Questions and Hypotheses}

Two main hypotheses are considered in this study which are framed around the questions stated thereafter.

\subsubsection{Hypothesis}

- Null Hypothesis \#1.

$\mathrm{H}_{1}$ : A significant positive relationship exists between BBS process outcomes and incident rates (alternative hypothesis).

$\mathrm{H}_{01}$ : There is no significant positive relationship between BBS process outcomes and incident rates.

\section{- Null Hypothesis \#2}

$\mathrm{H}_{2}$ : Behavior-Based Safety can predict incident rates (alternative hypothesis).

$\mathrm{H}_{02}$ : Behavior-Based Safety cannot predict incident rates.

\subsubsection{Study Questions}

- Q1. Does performing BBS observations increase work related safe behaviors?

- Q2. What is the extent of the impact of Behavior-Based Safety processes on incidents rates?

The methodology used to test the hypotheses and to answer the study questions are explained in Chapter 4. 


\section{Chapter 4: Methodology and Design}

\subsection{Research Model}

The main purpose of this study was to assess the effectiveness of Behavior-Based Safety Process on incident rates in realistic settings. Data collected from BBS process and company’s incident reports were analyzed using some statistical techniques. Statistical Package for the Social Sciences (SPSS) software was used to perform a descriptive analysis of both safetyrelated behaviors and incident rates. Also, linear regressions were used to develop predictive models. The research is based on the analysis of historical data provided by XYZ Oil Company administrative reports and company databases. The nature of the relationship between BBS intervention and incident rates was explored. In addition, the literature review of previous works and research performed on Behavior-Based Safety and safety performance measurement were considered in order to establish the study's variables.

\subsection{The Basis for Research Model}

This methodology was selected because of the difficulty of having a control group that is not performing BBS. In fact, the BBS process is already implemented companywide and it was not practical to suggest having a non-BBS group within XYZ Oil Company. Additionally, this would have required making an operational group stop doing BBS, exposing the company to potential safety performance threats. In addition, company historical data on incidents prior to BBS interventions were not readily available, leaving the author with no baseline for considering any quasi-experiment or longitudinal design. Therefore, a correlational study was deemed more appropriate. As it was suggested by Whitley \& Kite (2012), “correlational strategies allow [researchers] to test hypotheses that are not amenable to the experimental strategy. 


\subsection{Data Collection and Description}

This correlation research is based on the analysis of historical data provided by XYZ Oil Company. These data were collected through software used to document BBS observations and company incidents data retrieved from company monthly safety performance reports and checked by the author against XYZ Oil Company’s incident investigation database for additional reliability. Five years of BBS historical data were analyzed. Actually, a total of 567,900 observations performed by a daily average of 150 employees were input into the database during the selected period. These observations were grouped on a monthly basis. At the end of each month, data were selected and compared to the number of incidents registered for the same period of time to establish correlations and determine to what extent BBS impacts incident rates in the organization. For this study, the following variables are considered.

Dependent variables. These are the number of incidents per man-hours worked. The US Occupation Safety and Health Association (OSHA) standardized incident rates calculation was applied. It consists of multiplying the number of incidents by 200,000 (100 full time employees working 40 hours/day during 50 weeks) then dividing the result by the number of man-hours worked during the period considered. The review of XYZ Oil Company’s incidents historical data and previous studies performed in the oil industry led to the selection of the following operational variables for incident rates (Wurzelbacher \& Jin, 2001).

- $\quad$ The Rate of Near-Misses (NN) reported per employees -months.

- The Rate of Injuries \& Illnesses, including first aids (IN) per employees -months.

- $\quad$ The Rate of Fires reported (FI) per employees -months. 
- The Rate of Spills, including oil spills in water, lands and secondary containments reported (SP) per employees -months.

- The Total Incident Rates (TE) per employees -months.

Independent variables. Behavior-Based safety process is data driven and the data provided by this process may be used to quantify employees' safety level within an organization. For consistency, these data are considered in terms of rates by dividing them by the man-hours worked. The review of the safety literature led to identifying the following BBS operational variables.

- The Rate of Safe Behaviors observed (KSafe) per employees -months.

- The Rate of At-Risk Behaviors Observed (KRisk) per employees -months.

- The Rate of Observation Sessions Performed (Obsheet) per employees -months.

Obsheet consists of the number of the observation worksheets collected through the BBS tracking system. The frequency of observation sessions is important because it quantifies employees' participation in the BBS process.

\subsection{Statistical Analysis}

Applied statistics to research may be either differential or associational. The former is generally applied when researchers are seeking to explore the difference between groups whereas the latter seeks to explore relationships between variables. This study, however, hypothesizes the existence of a significant relationship between variables; therefore associational tests would be more appropriate (Morgan et al., 2012). This study falls into the group recognized as correlation 
research by Creswell (2008) and can be performed by using correlations and regressions analysis.

The incident data collected were analyzed to determine whether the process was in control because out of range data may indicate problems with the data collection process. Also, process variations may indicate the existence of special events, which may have occurred during the time period considered for this work. Such events may impact the research's results. Therefore, they should be identified and dealt with prior to any correlation or regression analysis being performed. For this purpose, descriptive analysis and statistical process control (SPC) were performed to examine all the dependent variables in order to identify any process variations due to special causes. The results of this analysis are presented in Chapter 5. 


\section{Chapter 5: Results}

The dependent variables were explored through descriptive statistics and Pearson moment correlation coefficients were computed to explore the relationship between BBS variables and incident rates, and the impact of the BBS process on incident rates was assessed through regression analyses as presented in this chapter.

\subsection{Statistical Process Control}

\section{Total Incident Rates (TE)}

Table 5.1: Descriptive Statistics of Total Incident Rates

\begin{tabular}{|c|c|c|c|c|c|c|}
\hline \multicolumn{7}{|c|}{ Descriptive Statistics } \\
\hline & $\mathrm{N}$ & Range & Minimum & Maximum & Mean & Std. Deviation \\
\hline TE & 60 & 23.81 & .00 & 23.81 & 8.2582 & 6.81394 \\
\hline Valid N & 60 & & & & & \\
\hline
\end{tabular}

The Total Incident Rates (TE) registered monthly during a period of 5 years was analyzed; the variables range from 0 to 23.81 with the mean of 8.25 Incident Rate per month. The process control chart of Total Incident Rates is shown in Figure 5.1. 


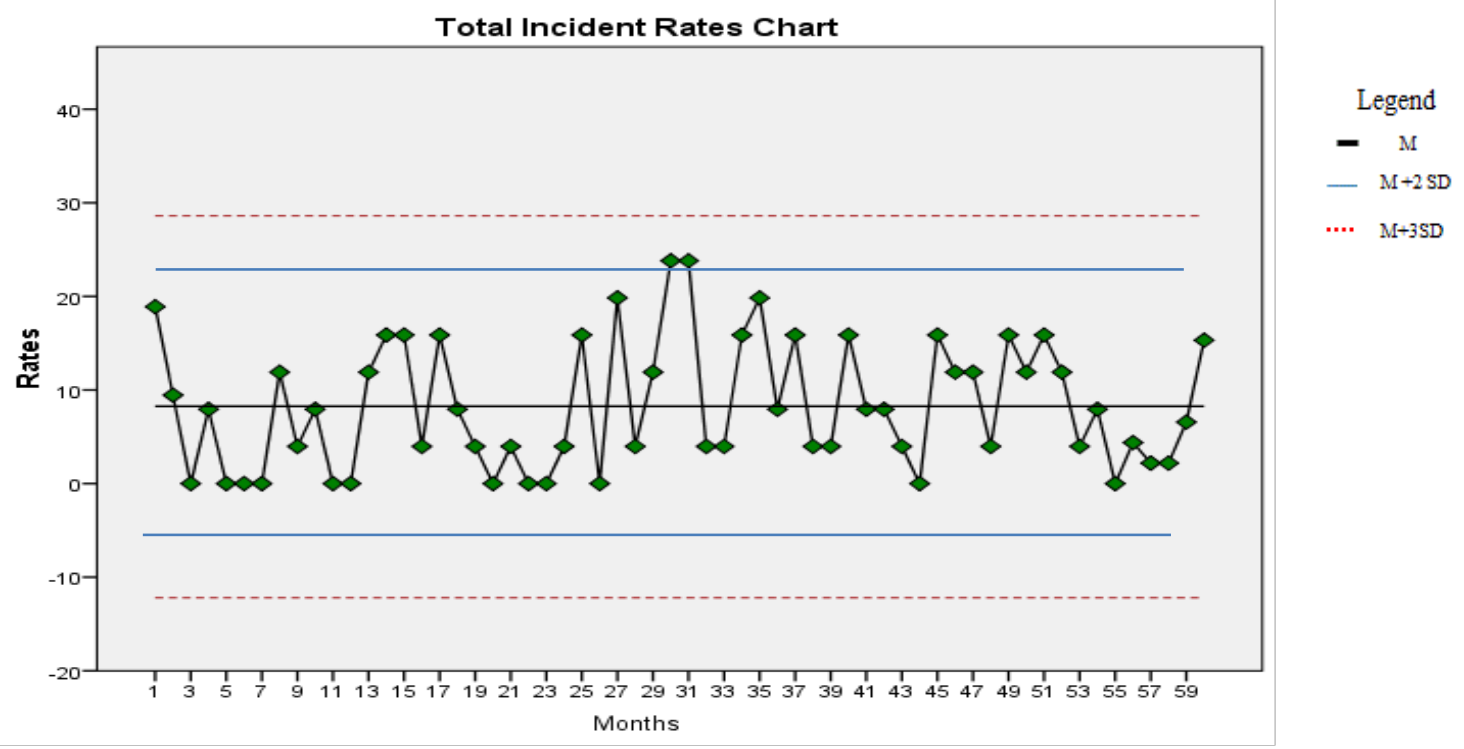

Figure 0.1: Process Control Chart of Incident Rates

The process is fairly in control and there are no points above 3 standard deviations, suggesting that most of the variation was common causes. However, a pattern can be seen in case \# 7 corresponding to the period of April to July 2008 where there were no incidents. Another pattern can be seen in case 31 and 32 corresponding to months of June and July 2010 where there was a high rate of incidents. Nonetheless, the latter case indicated the existence of common causes which may need to be investigated internally so the process can be regarded as under control.

\section{Spill Rates (SP)}

Descriptive statistics were performed in order to examine the variation of Spill Rates and the results are illustrated in the Table 5.2. 
Table 5.2 Descriptive Statistics of Spill Rates

\begin{tabular}{|c|c|c|c|c|c|c|c|}
\hline & $\mathrm{N}$ & Range & Minimum & Maximum & Mean & Std. Deviation & Variance \\
\hline SP & 60 & 15.87 & .00 & 15.87 & 2.9853 & 3.97880 & 15.831 \\
\hline Valid N (listwise) & 60 & & & & & & \\
\hline
\end{tabular}

Spill Rates (SP) registered monthly during a period of 5 years were analyzed; the variables range from 0 to 15.87 Incident Rates with the mean of 2.985 Incident Rate per month. The Spill Rates process control chart is shown in Figure 5.2.

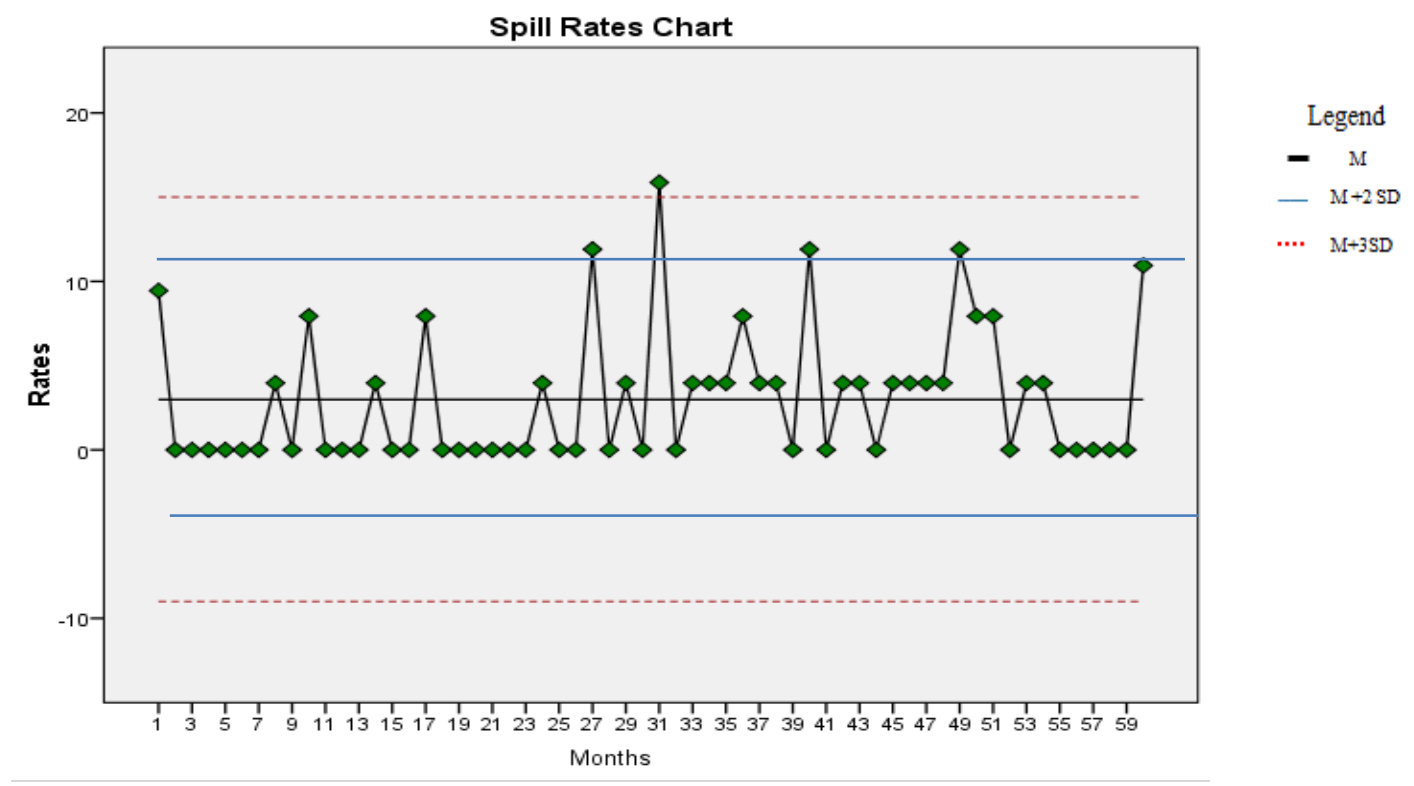

\section{Figure 0.2: Process Control Chart of Spill Rates}

The process is fairly in control and most of the data are around 1 to 2 standard deviations except for case 31 which corresponds to July 2010, where the company actually registered a higher numbers of spills. This case may need to be investigated internally; however it does not appear to make the process out of control. 


\section{Injuries and Illnesses Rates (IN)}

The Rate of Injuries and Illnesses (IN) registered monthly during a period of 5 years were analyzed; the variables range from 0 to 7.94 Injuries Rates with the mean of 0.713 Injuries Rate per month. The result of the descriptive statistic is shown in Table 5.3 and the process control chart is illustrated in Figure 5.3

Table 5.3: Descriptive Statistics of Injury and Illness Rates

\begin{tabular}{|c|c|c|c|c|c|c|}
\hline & $\mathrm{N}$ & Minimum & Maximum & Mean & Std. Deviation & Variance \\
\hline IN & 60 & .00 & 7.94 & .7173 & 1.71170 & 2.930 \\
\hline Valid N (listwise) & 60 & & & & & \\
\hline
\end{tabular}

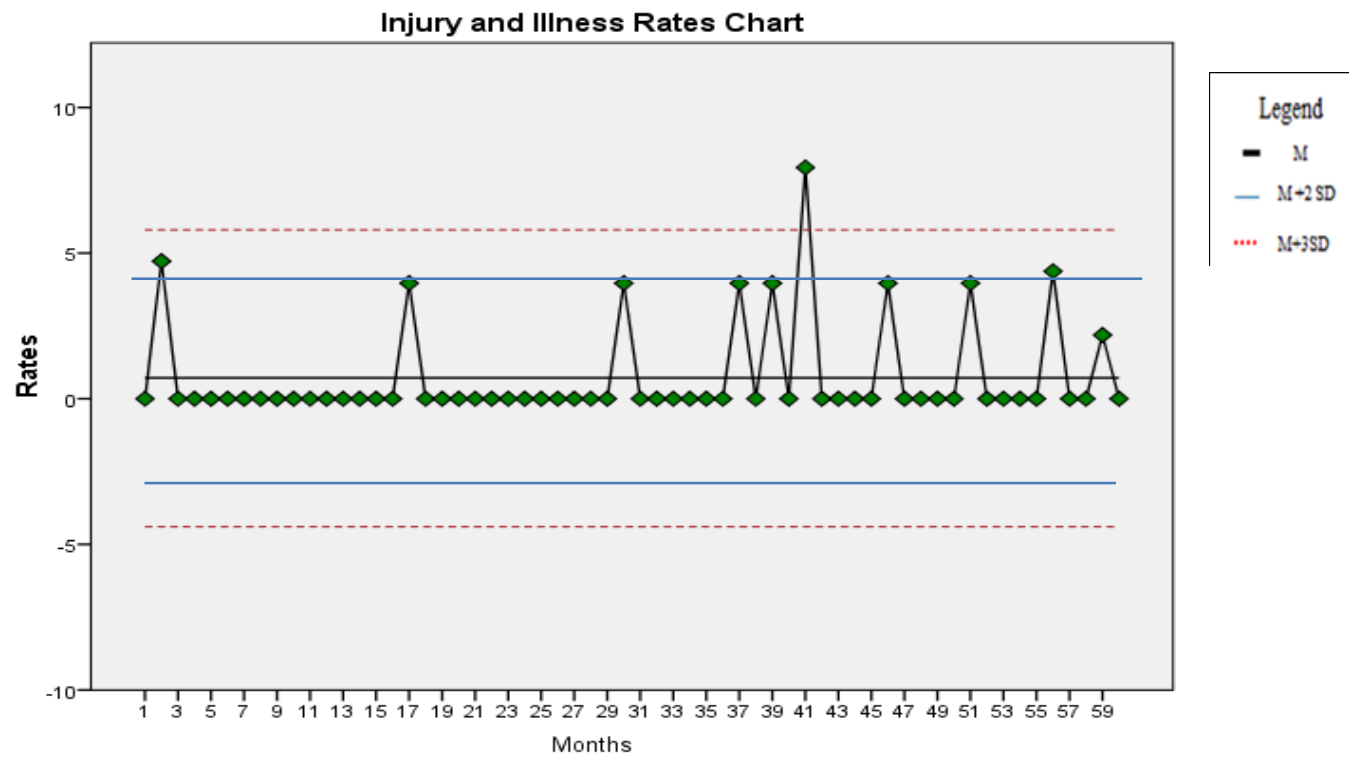

Figure 0.3: Process Control Chart of Injuries and Illness Rates

The process is fairly in control and most of the data are around 1 to 2 standard deviations except 
for Case \#2, located just beyond 2 standard deviations and Case \#41 located out of 3 standard deviations. However, Case \#2 may still be considered common causes because it is still located close to the other points on the graph. On the other hand, Case \#41 which corresponds to the month of May 2011 when Injuries Rates were a bit higher than normal may suggest the existence of special causes that need to be internally investigated. In addition, some patterns could be seen on case \#37 and \#39 where two of three successive data were at 2 standard deviations. These latter cases correspond to months of March and May 2011 where the number of injuries was a little higher than normal and may require to be investigated internally. However, they still could be considered common causes because they are not out of 3 standard deviations and are still close to the other points on the graph.

\section{Fire Rates (FI)}

The Rate of Fires was examined by using descriptive statistics and process control analyses. The results are shown on Table 5.4.

Table 5.4: Descriptive Statistics of Fires Rates

\begin{tabular}{|c|c|c|c|c|c|c|}
\hline & $\mathrm{N}$ & Minimum & Maximum & Mean & Std. Deviation & Variance \\
\hline FI & 60 & .00 & 4.72 & .4459 & 1.26164 & 1.592 \\
\hline Valid N & 60 & & & & & \\
\hline
\end{tabular}

Fire Rates (FI) registered monthly during a period of 5 years were analyzed. The variables range from 0 to 4.72 Fire Rates with the mean of 0.445 Fire Rates per month. Figure 5.4 illustrates a process control chart of Fire Rates. 


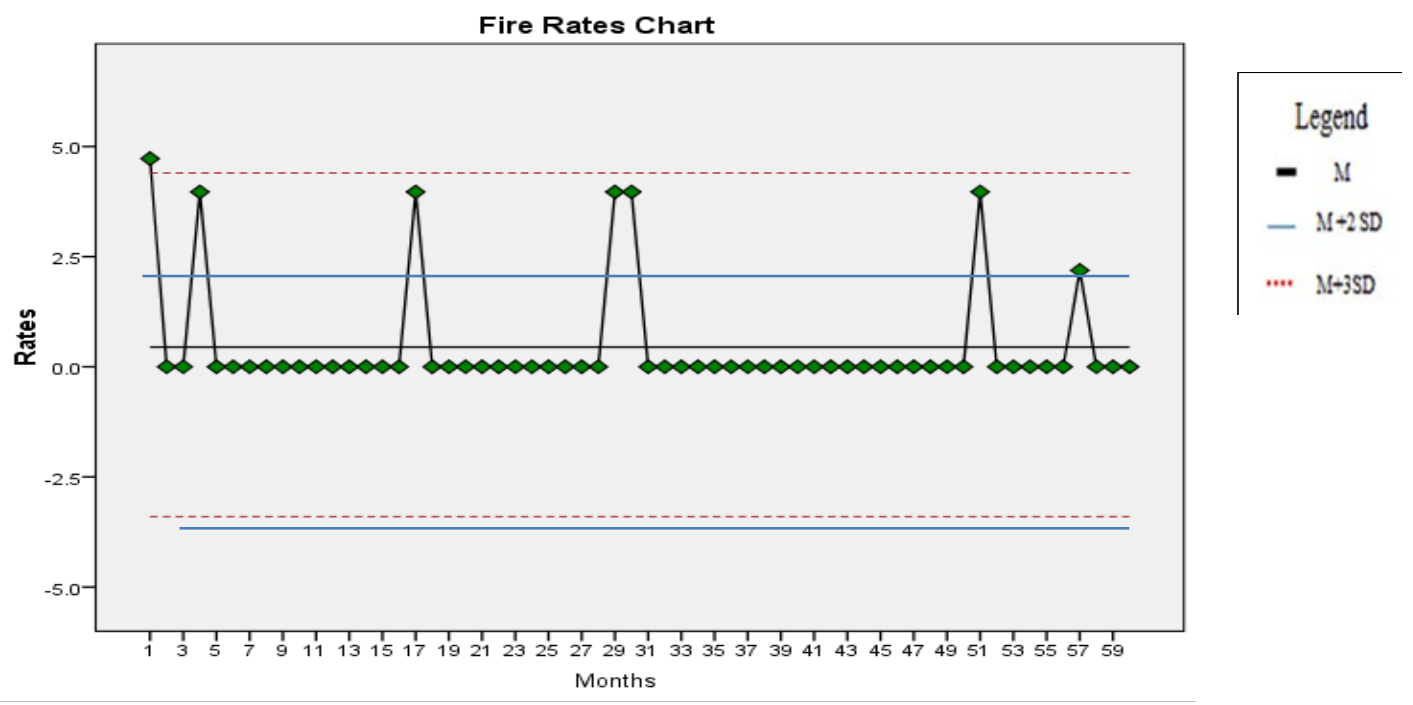

Figure 0.4: Process Control Chart of Fire Rates

Because $10 \%$ of the data are above $2 \mathrm{SD}$, it can be suggested that the process is not in control. However, it is worth noting that fire incidents are generally not common. There are generally either one or no fires per month making the process appear as out of control even when it is really not.

\section{Near-Miss Rates (NN)}

Table 5.5: Descriptive Statistics of Near-Miss Rates

\begin{tabular}{|c|c|c|c|c|c|c|c|}
\hline & $\mathrm{N}$ & Range & Minimum & Maximum & Mean & Std. Deviation & Variance \\
\hline $\mathrm{NN}$ & 60 & 15.87 & .00 & 15.87 & 3.3696 & 4.67516 & 21.857 \\
\hline Valid N & 60 & & & & & & \\
\hline
\end{tabular}

Near-Miss Rates (NN) registered monthly during a period of 5 years was analyzed; the variables range from 0 to 15.87 Near-Miss Rates with the mean of 3.3696 Near-Miss Rate per month. The process control chart is illustrated on Figure 5.5. 


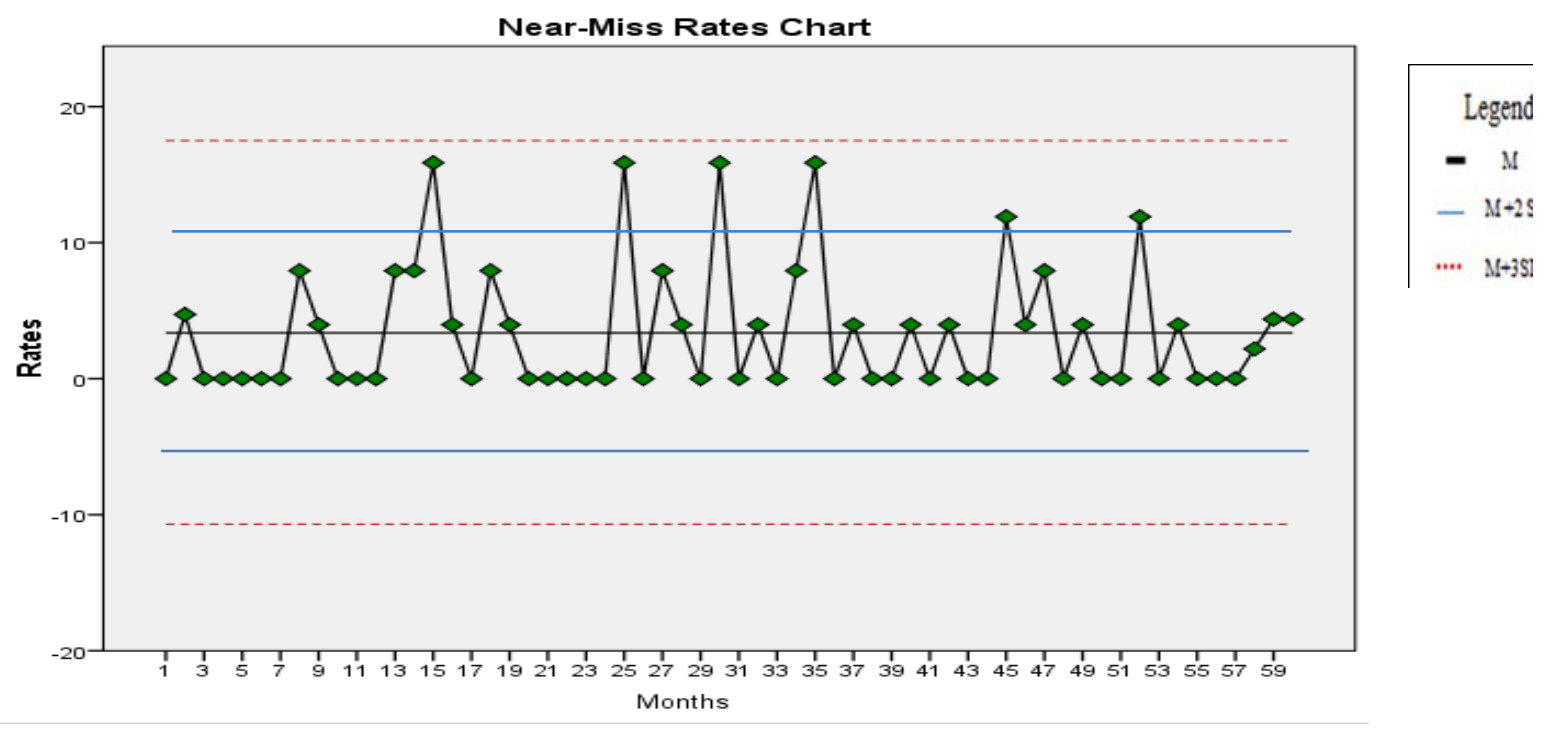

Figure 0.5: Process Control Chart of Near-Misses

The process seems to be in control, and there is no data beyond 3standard deviations and the data are all well distributed around the mean and no concerning patterns could be observed.

\subsection{Correlational Analysis}

Univariate correlation analyses were performed to assess the relationship between each incident's factors (dependent variables) and the independent variables (BBS outcomes). A total of fifteen regressions were performed.

\subsubsection{Dependent Variable Total Incident Rates (TE)}

\section{Regression 1}

Dependent Variable: Total Incident Rates (TE)

Independent Variable: Safe Behaviors Rate (KSafe)

The correlation between the two variables was examined and the results are shown in Table 5.6. 
Table 5.6: Correlation Results between Total Incident Rates and Safe Behaviors

\begin{tabular}{lccr}
\hline & & \multicolumn{2}{c}{ TE } \\
\hline \multirow{2}{*}{ Pearson Correlation } & TE & 1.000 & .264 \\
& KSafe & .264 & 1.000 \\
Sig. (1-tailed) & TE &. & .021 \\
& KSafe & .021 & \\
$\mathrm{~N}$ & TE & 60 & 60 \\
& KSafe & 60 & 60 \\
\hline
\end{tabular}

The relationship between the Total Incident Rates (TE) and the Safe Behaviors observed (KSafe) was assessed. The Pearson moment coefficient computed was $r=0.264$ at $p<0.05$, suggesting the existence of a significant positive relationship between the two variables. However the association was rather small. The R square values obtained are shown in Table 5.7.

Table 5.7: R-Values of the Correlation between Total Incidents and Safe Behaviors

\begin{tabular}{llrcc}
\hline Model & $\mathrm{R}$ & R Square & Adjusted R Square & Std. Error of the Estimate \\
\hline 1 & $.264^{\mathrm{a}}$ & .070 & .054 & 6.62773 \\
\hline
\end{tabular}

A regression of Incident Rates on Safe Behaviors was performed as shown in Table 5.8 and Table 5.9. 
Table 5.8: ANOVA Results between Total Incident Rates and Safe Behaviors

\begin{tabular}{|c|c|c|c|c|c|c|}
\hline \multicolumn{2}{|c|}{ Model } & \multirow{2}{*}{$\begin{array}{c}\text { Sum of Squares } \\
191.607\end{array}$} & \multirow{2}{*}{$\frac{\mathrm{df}}{1}$} & \multirow{2}{*}{$\frac{\text { Mean Square }}{191.607}$} & \multirow{2}{*}{$\frac{F}{4.362}$} & \multirow{2}{*}{$\begin{array}{l}\text { Sig. } \\
.041\end{array}$} \\
\hline & Regression & & & & & \\
\hline \multirow[t]{2}{*}{1} & Residual & 2547.753 & 58 & 43.927 & & \\
\hline & Total & 2739.360 & 59 & & & \\
\hline
\end{tabular}

Table 5.9: Regression Coefficients of Total Incident Rates on Safe Behaviors

\begin{tabular}{|c|c|c|c|c|c|c|}
\hline \multirow[t]{2}{*}{ Model } & \multicolumn{2}{|c|}{ Unstandardized Coefficients } & $\begin{array}{l}\text { Standardized } \\
\text { Coefficients }\end{array}$ & \multirow[t]{2}{*}{$\mathrm{t}$} & \multirow[t]{2}{*}{ Sig. } & \multirow{2}{*}{$\begin{array}{c}95.0 \% \\
\text { Confidence } \\
\text { Interval for B } \\
\text { Lower Bound }\end{array}$} \\
\hline & B & Std. Error & Beta & & & \\
\hline (Constant) & 1.283 & 3.448 & & .372 & .711 & -5.618 \\
\hline \multicolumn{7}{|l|}{1} \\
\hline KSafe & 68.804 & 32.944 & .264 & 2.089 & .041 & 2.860 \\
\hline
\end{tabular}

Dependent variable: TE

Independent variable :KSafe

$\underline{\text { Discussion }}$

A simple regression analysis was applied to investigate how well the rate of Total Incidents (TE) could be predicted from the Rate of Safe Behaviors observed (KSafe). The results were statistically significant $\mathrm{F}(1,58)=4.36$ at $\mathrm{p}<.05$. The regression equation obtained to explain the relationship was $\mathrm{TE}=1.28+68.804 * \mathrm{KSafe}$. The adjusted $\mathrm{R}$ square value was 0.054 meaning that about 5.4 percent of the variances in Total Incidents (TE) could be explained by Safe Behaviors (KSafe). 


\section{Regression 2}

Dependent variable: Total Incidents (TE)

Independent variable: At-Risk Behaviors (KRisk)

The correlation between the two variables was assessed as illustrated in Table 5.10.

Table 5.10: Correlation Results between Total Incident Rates and At-Risk Behaviors

\begin{tabular}{llcr}
\hline & & TE & KRisk \\
\hline & TE & 1.000 & .218 \\
Pearson Correlation & KRisk & .218 & 1.000 \\
& & & .047 \\
Sig. (1-tailed) & TE & .047 & \\
& KRisk & & \\
& & 60 & 60 \\
$\mathrm{~N}$ & TE & 60 & 60 \\
\hline
\end{tabular}

The relationship between the Total Incident (TE) and the At-Risk Behaviors observed (KRisk) was assessed; the Pearson moment coefficient computed was $r=0.218$ at $p<0.05$ suggesting the existence of a significant positive relationship between the two variables. The values of the correlation coefficients are shown in Table 5.11.

Table 5.11: R-Values of the Correlation between Incident Rates and At-Risk Behaviors

\begin{tabular}{|c|c|c|c|c|}
\hline Model & $\mathrm{R}$ & R Square & Adjusted R Square & $\begin{array}{c}\text { Std. Error of the } \\
\text { Estimate }\end{array}$ \\
\hline 1 & $.218^{\mathrm{a}}$ & .047 & .031 & 6.70732 \\
\hline
\end{tabular}


A regression of Total Incident Rates on the Rate of At-Risk Behaviors was performed and the results are illustrated in Table 5.12 and Table 5.13.

Table 5.12: ANOVA Results between Total Incident Rates and At-Risk Behaviors

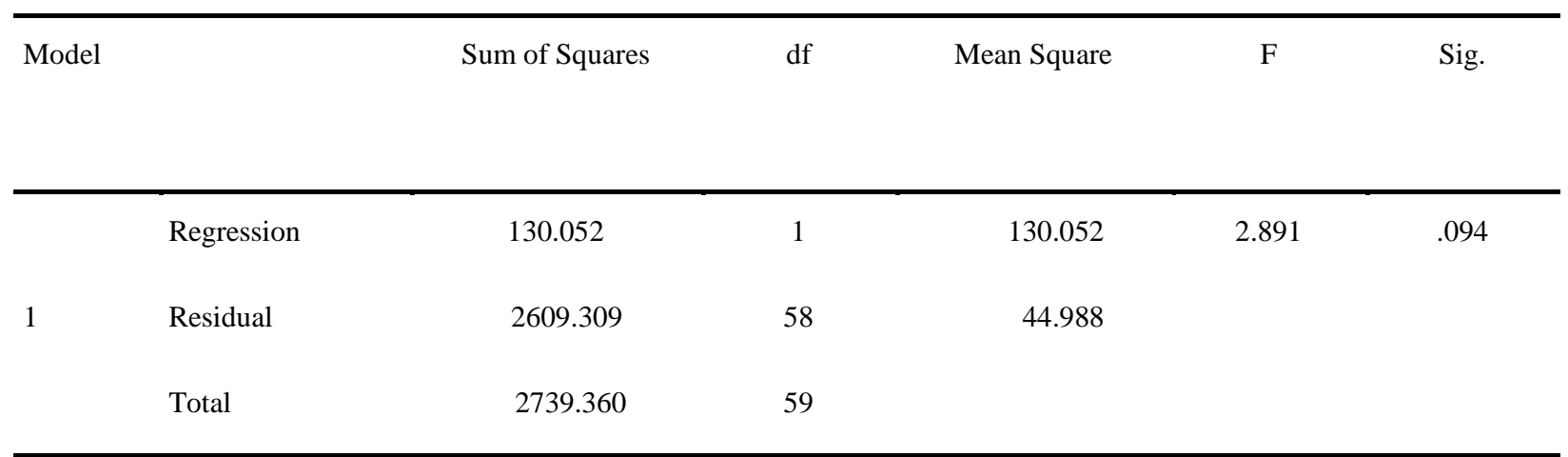

Dependent variable: TE

Independent variable: KRisk

Table 5.13: Regression Coefficients of Total Incident Rates on At-Risk Behaviors

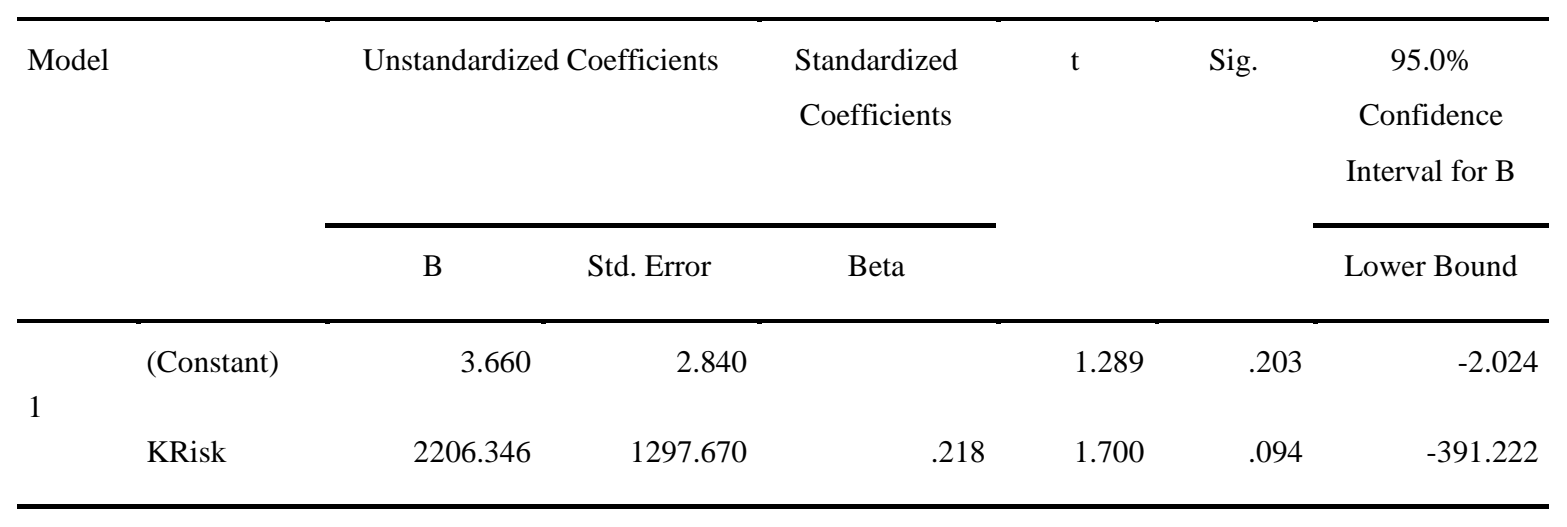


A simple regression was applied to investigate how well Total Incident Rates (TE) could be predicted from the At-Risk Behaviors observed (KRisk). The results were not statistically significant $F(1,58)=2.89$ at $p=0.09$ The regression equation drawn to explain the relationship was Total Incidents $=3.66+2206.35 *$ ( KRisk). The adjusted R square value was 0.031 meaning that about 3.1 percent of the variances in Total Incident Rates could be explained by the Rate of Safe Behaviors.

\section{Regression 3}

The association between Total Incident Rates and the Rate of Observation Sessions was examined and the results are shown in Table 5.14.

Dependent variable: Total Incidents (TE)

Independent Variable: Observation Sessions (Obsheet)

Table 5.14: Correlation Results between Incident Rates and Observation Sessions

\begin{tabular}{llcc}
\hline & & TE & Obsheet \\
\hline \multirow{2}{*}{ Pearson Correlation } & TE & 1.000 & .295 \\
& Obsheet & .295 & 1.000 \\
Sig. (1-tailed) & TE &. & .011 \\
& Obsheet & .011 &. \\
$\mathrm{~N}$ & TE & 60 & 60 \\
& Obsheet & 60 & 60 \\
\hline
\end{tabular}


The relationship between the rate of Total Incident (TE) and the Observation Sessions performed (Obsheet) was assessed. The Pearson moment coefficient calculated was $r=0.295$ at $p<0.05$, suggesting the existence of a small significant positive relationship between the two variables. Regression analyses were also performed to assess how well the Rate of Total Incidents could be predicted by the Rate of Observation Sessions performed as illustrated in Table 5.15 and Table 5.16.

Table 5.15: R- Values of the Correlation between Total Incidents and Observation Sessions

\begin{tabular}{|c|c|c|c|c|c|}
\hline Model & $\mathrm{R}$ & R Square & Adjusted R Square & & $\begin{array}{l}\text { Std. Error } \\
\text { of the } \\
\text { Estimate }\end{array}$ \\
\hline 1 & $.295^{\mathrm{a}}$ & .087 & & .072 & 6.56556 \\
\hline
\end{tabular}

a. Predictors: (Constant), Obsheet

A regression of the Rate of Total Incidents on the Rate of Observation Sessions was performed and the results are presented on the Table 5.16 and Table 5.17.

Table 5.16: ANOVA Results between Total Incident Rates and Observation Sessions

\begin{tabular}{|c|c|c|c|c|c|c|}
\hline Model & & Sum of Squares & $\mathrm{df}$ & Mean Square & $\mathrm{F}$ & Sig. \\
\hline & Regression & 239.182 & 1 & 239.182 & 5.549 & .022 \\
\hline \multirow[t]{2}{*}{1} & Residual & 2500.178 & 58 & 43.107 & & \\
\hline & Total & 2739.360 & 59 & & & \\
\hline
\end{tabular}

Dependent variable: TE

Predictors: (Constant), Obsheet 
Table 5.17: Regression Coefficients of Total Incident Rates on Observation Sessions

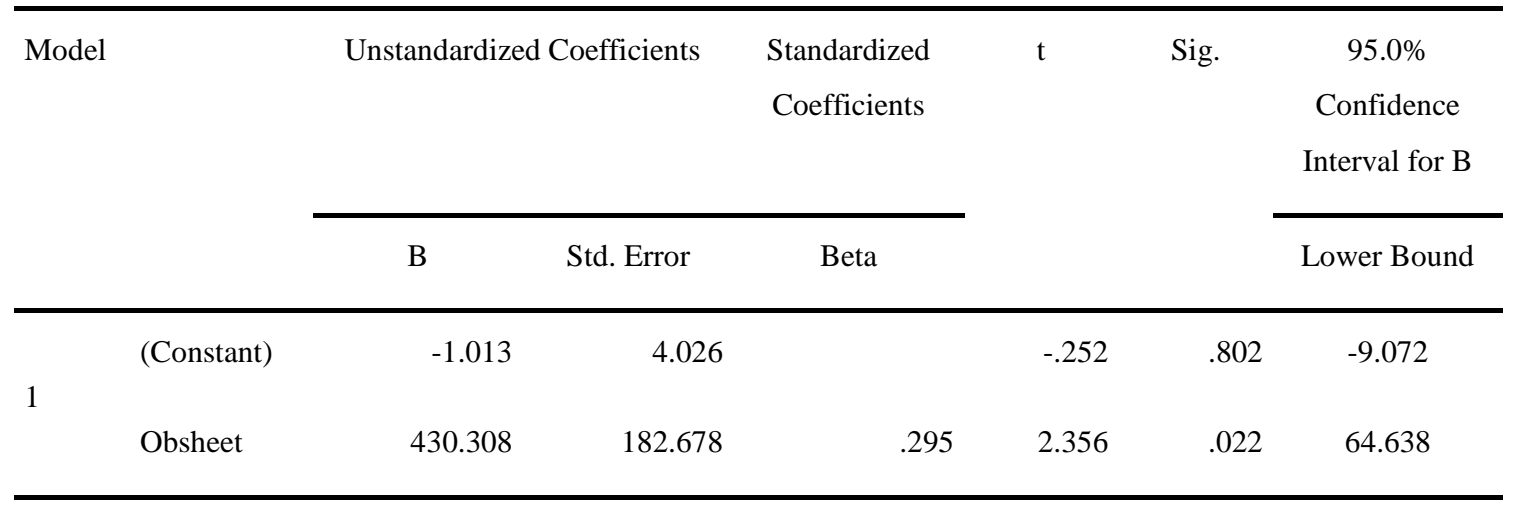

A simple regression was applied to investigate how well the Total Incidents Rates (TE) could be predicted by the observation sheets collected (Obsheet). The results were statistically significant: $\mathrm{F}(1,58)=5.55$ at $\mathrm{p}<0.05$. The regression equation drawn to explain the relationship was $Y=-1.013+430.308 \mathrm{X}$ suggesting that Total Incidents $=-1.013+430.308 *$ (Obsheet). The adjusted R square value was 0.072 meaning that about 7 percent of the variances in total incidents could be explained by safe behaviors.

\subsubsection{Dependent Variable: Near-Misses Rates (NN)}

\section{Regression 1}

Dependent variable: Near-Misses Rates (NN)

Independent variable: At-Risk Behaviors Rates (KRisk)

The correlation between the two variables was examined and the results are shown in Table 5.18 
Table 5.18: Correlation Results between Near-Miss Rates and At-Risk Behaviors

\begin{tabular}{lccr}
\hline & & NN & \multicolumn{2}{c}{ KRisk } \\
\hline \multirow{2}{*}{ Pearson Correlation } & NN & 1.000 & .119 \\
& KRisk & .119 & 1.000 \\
Sig. (1-tailed) & NN &. & .184 \\
& KRisk & .184 & \\
N & NN & & \\
& KRisk & 60 & 60 \\
\hline
\end{tabular}

The relationship between the Rate of Near-Miss (NN) and the At-Risk Behaviors (KRisk) was assessed. The Pearson moment coefficient computed was $r=0.119$. However, the relationship was not statically significant $\mathrm{p}>0.05$. Regression analyses were also performed and the results are shown in Table 5.19 and Table 5.20.

Table 5.19: R-Values of the Correlation between Near-Miss Rates and At-Risk Behaviors

\begin{tabular}{lrrrr} 
Model & R & R Square & Adjusted R Square & Std. Error of the Estimate \\
\hline 1 & .119 & .014 & -.003 & 4.68206 \\
\hline
\end{tabular}

Table 5.20: ANOVA Results between Near-Miss Rates and At-Risk Behaviors

\begin{tabular}{lrrrrrr}
\hline Model & & Sum of Squares & df & Mean Square & F & \multirow{2}{*}{ Sig. } \\
\hline \multirow{2}{*}{1} & Regression & 18.116 & 1 & 18.116 & .826 & .367 \\
& Residual & 1271.456 & 58 & 21.922 & & \\
& Total & 1289.572 & 59 & & & \\
\hline
\end{tabular}


The regression coefficients obtained are displayed in Table 5.21.

Table 5.21: Regression Coefficients of Near-Misses on At-Risk Behaviors

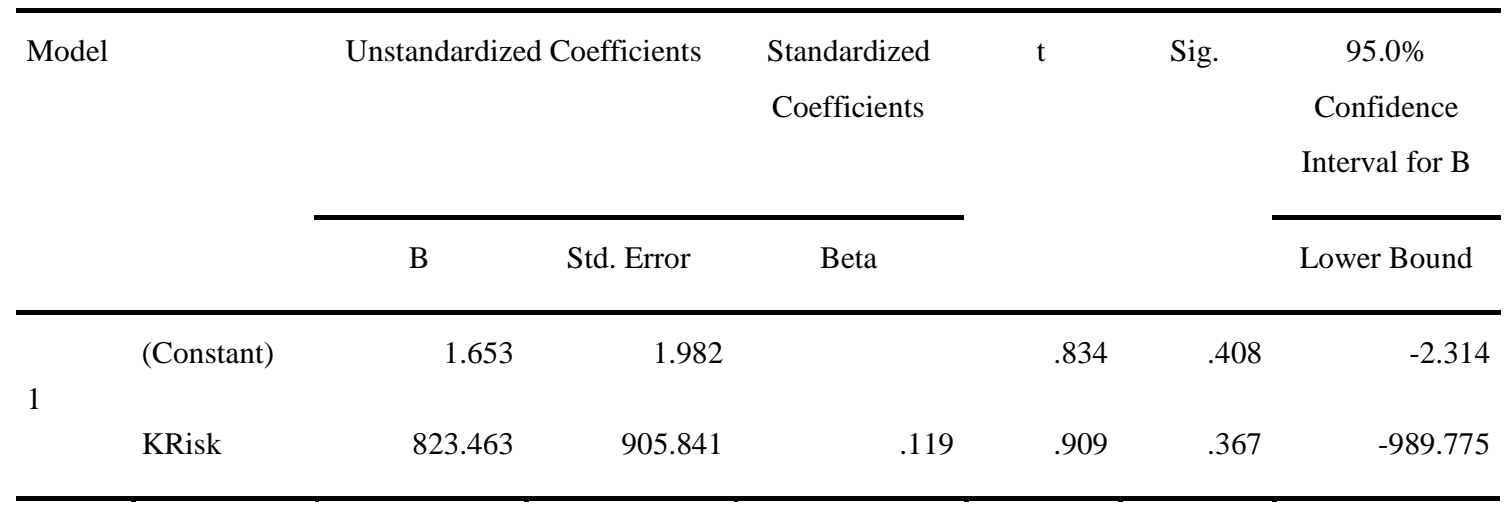

Dependent Variable: NN

\section{$\underline{\text { Discussion }}$}

A simple regression was applied to investigate how well Near-Miss Rates (NN) could be predicted from At-Risk Behaviors (KRisk). The results were not statistically significant:

$\mathrm{F}(1,58)=.826$ at $\mathrm{p}=.367$. The adjusted $\mathrm{R}$ square value was -003 meaning zero percent of the variances in Near-Misses could be explained by At-Risk Behaviors.

\section{Regression 2}

Dependent variable: Near-Misses (NN)

Independent variable: Safe Behaviors (KSafe)

The correlation between the two variables was examined and the results are shown in Table 5.22. 
Table 5.22: Correlation Results between Near-Miss and Safe Behavior Rates

\begin{tabular}{lccc}
\hline & & NN & KSafe \\
& & & \\
\hline & NN & 1.000 & .138 \\
Pearson Correlation & KSafe & .138 & 1.000 \\
& NN &. & .147 \\
Sig. (1-tailed) & KSafe & .147 &. \\
& NN & 60 & 60 \\
N & KSafe & 60 & 60 \\
\hline
\end{tabular}

The relationship between the Rate of Near-Misses (NN) and the Safe Behaviors Observed (KSafe) was assessed. The Pearson moment coefficient calculated was $r=.138$ at $p=.147$ suggesting that there is no statistically significant relationship between the two variables. The values of the coefficient of correlations are summarized in Table 5.23.

Table 5.23: R-Values of the Correlation between Near-Miss and Safe Behaviors

\begin{tabular}{llccc}
\hline Model & $\mathrm{R}$ & R Square & Adjusted R Square & $\begin{array}{c}\text { Std. Error of the } \\
\text { Estimate }\end{array}$ \\
\hline 1 & .138 & .019 & .002 & 4.67022 \\
\hline
\end{tabular}

A regression of the Rate of Near-Misses on the Rate of Safe Behaviors was performed and the results are presented in Table 24 and Table 25. 
Table 5.24: The ANOVA Results between Near-Miss and Safe Behavior Rates

\begin{tabular}{llrrrrr}
\hline Model & & Sum of Squares & df & Mean Square & F & \multicolumn{2}{l}{ Sig. } \\
\hline & Regression & 24.537 & 1 & 24.537 & 1.125 & .293 \\
1 & Residual & 1265.035 & 58 & 21.811 & & \\
& Total & 1289.572 & 59 & & & \\
\hline
\end{tabular}

Dependent variable: NN

Predictors: (Constant), KSafe

Table 5.25: Regression Coefficients of Near-Misses on Safe Behaviors

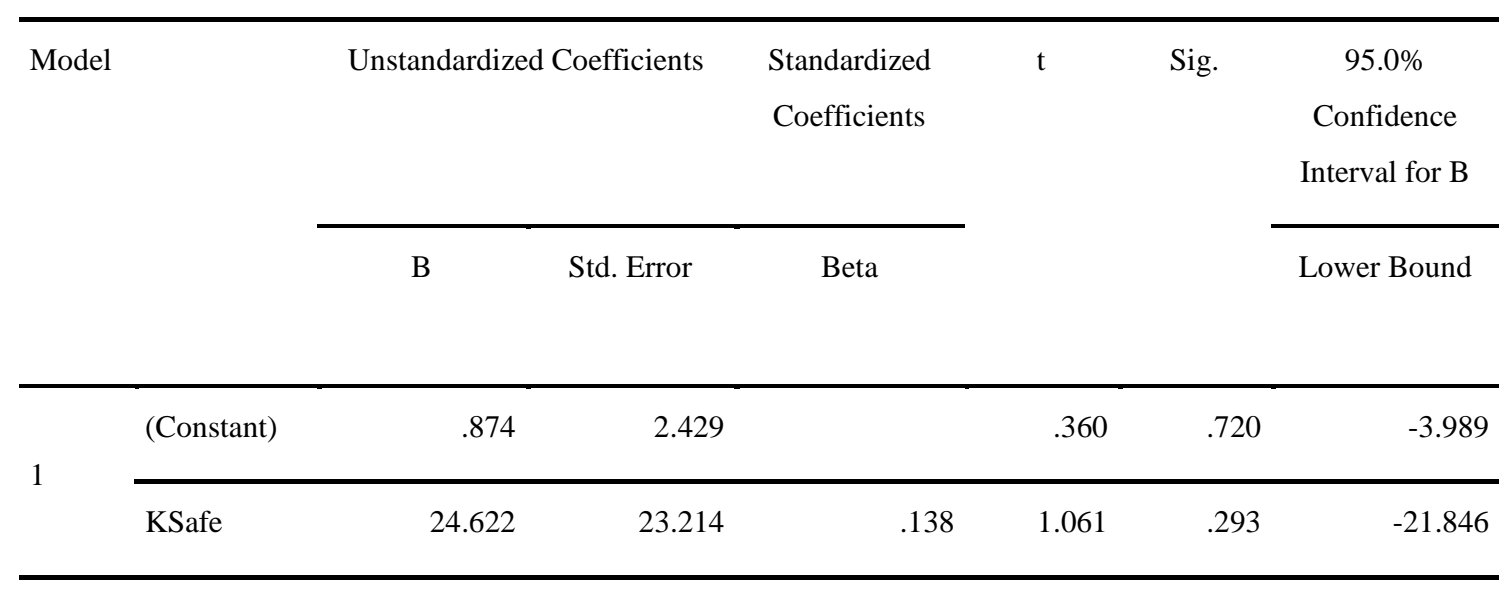

A simple regression was applied to investigate how well Near-Miss Rates (NN) could be predicted from Safe Behaviors (KSafe). The results were not statistically significant:

$\mathrm{F}(1,58)=1.125$ at $\mathrm{p}=.293$. The adjusted $\mathrm{R}$ square value was 002 meaning zero percent of the variances in Near-misses could be explained by Safe Behaviors.

\section{Regression 3}

Dependent variable: Near-Misses (NN)

Independent variable: Observation Sheets (Obsheet) 
The correlation between the two variables was examined and the results are shown in Table 5.26.

Table 5.26: Correlation Results between Near-Misses and Observation Sessions

\begin{tabular}{llcc}
\hline & & NN & Obsheet \\
\hline Pearson Correlation & NN & 1.000 & .131 \\
& Obsheet & .131 & 1.000 \\
Sig. (1-tailed) & NN &. & .159 \\
& Obsheet & .159 &. \\
$\mathrm{~N}$ & NN & 60 & 60 \\
& Obsheet & 60 & 60 \\
\hline
\end{tabular}

The relationship between the Rate of Near-Misses (NN) and the Rate of Observation Sessions performed (Obsheet) was assessed. The Pearson moment coefficient calculated was $r=.131$ at $\mathrm{p}=.159$ suggesting that there is no statistically significant relationship between the two variables. The results of the analyses performed are shown on the Table 5.27.

Table 5.27: R-Values of the Correlation between Near-Misses and Observation Sessions

\begin{tabular}{llrcc}
\hline Model & $\mathrm{R}$ & R Square & Adjusted R Square & Std. Error of the Estimate \\
\hline 1 & $.131^{\mathrm{a}}$ & .017 & .000 & 4.67455 \\
\hline
\end{tabular}

a. Predictors: (Constant), Obsheet

A regression of the Rate of Near-Misses on the Rate of Observation Sessions was performed, and the results are presented in Table 28 and Table 29. 
Table 5.28: ANOVA Results between Near-Misses and Observation Sessions

\begin{tabular}{llrrrrr}
\hline Model & & Sum of Squares & df & Mean Square & F & Sig. \\
\hline \multirow{2}{*}{1} & Regression & 22.189 & 1 & 22.189 & 1.015 & .318 \\
& Residual & 1267.383 & 58 & 21.851 & & \\
& & & & & \\
& Total & 1289.572 & 59 & & \\
\hline
\end{tabular}

Table 5.29: Regression Coefficients of Near-Misses on Observation Sessions

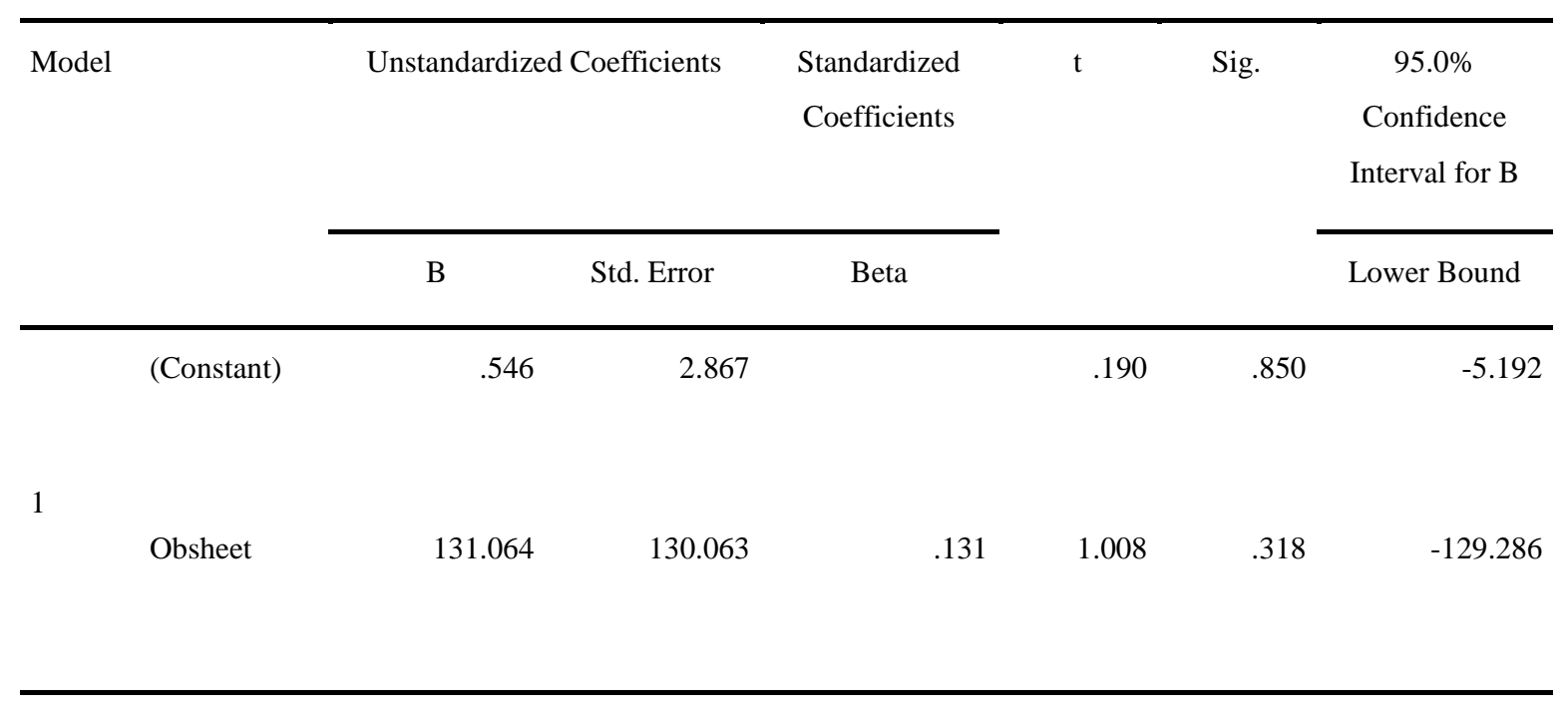

A simple regression was applied to investigate how well Near-Misses Rates (NN) could be predicted from the rate of Observation Sessions documented by the observation sheets collected (Obsheet). The results were not statistically significant: $F(1,58)=1.015, p=.318$. The adjusted R square value was .000 meaning zero percent of the variances in Near-misses could be explained by the observation sheets (Obsheet). 


\subsubsection{Dependent Variable: Injuries and Illnesses Rates (IN)}

\section{Regression 1}

Dependent variable: Injuries and Illness Rates (IN)

Independent variable: At-Risk Behaviors Rates (KRisk)

Table 5.30: Correlation Results between Injuries/Illness and At- Risk Behaviors

\begin{tabular}{lccc}
\hline & & IN & KRisk \\
\hline Pearson Correlation & IN & 1.000 & -.033 \\
& KRisk & -.033 & 1.000 \\
Sig. (1-tailed) & IN &. & .402 \\
& KRisk & .402 &. \\
$\mathrm{~N}$ & IN & 60 & 60 \\
& KRisk & 60 & 60 \\
\hline
\end{tabular}

The relationship between the Rate of Injuries/Illnesses (IN) and the At-Risk Behaviors observed (KRisk) was assessed. The Pearson moment coefficient calculated was $\mathrm{r}=.138$ at $\mathrm{p}=.402$ suggesting that there is no statistically significant relationship between the two variables. The $\mathrm{R}$ square values are shown in Table 5.31.

Table 5.31: R-Values of the Correlation between Injuries/Illnesses and At-Risk Behaviors

\begin{tabular}{ccccc}
\hline Model & $\mathrm{R}$ & R Square & Adjusted R Square & Std. Error of the Estimate \\
\hline 1 & .033 & .001 & -.016 & 1.72548 \\
\hline
\end{tabular}


A regression of the Rate of Injuries on At-Risk Behavior Rates was performed to investigate how well the Rate of injuries could be predicted from At-Risk Behavior Rates. The results obtained are shown in Table 5.32 and Table 5.33.

Table 5.32: ANOVA Results between Injuries/Illnesses and At-Risk Behaviors

\begin{tabular}{llrrrrr}
\hline Model & & Sum of Squares & df & Mean Square & F & Sig. \\
\hline \multirow{2}{*}{$\begin{array}{l}\text { Regression } \\
\text { Residual }\end{array}$} & .183 & 1 & .183 & .062 & .805 \\
& Total & 172.682 & 58 & 2.977 & & \\
& 172.865 & 59 & & & \\
\hline
\end{tabular}

Dependent variable: IN

Predictors: (Constant), KRisk

Table 5.33: Regression Coefficients of Injuries/Illnesses on At-Risk Behaviors

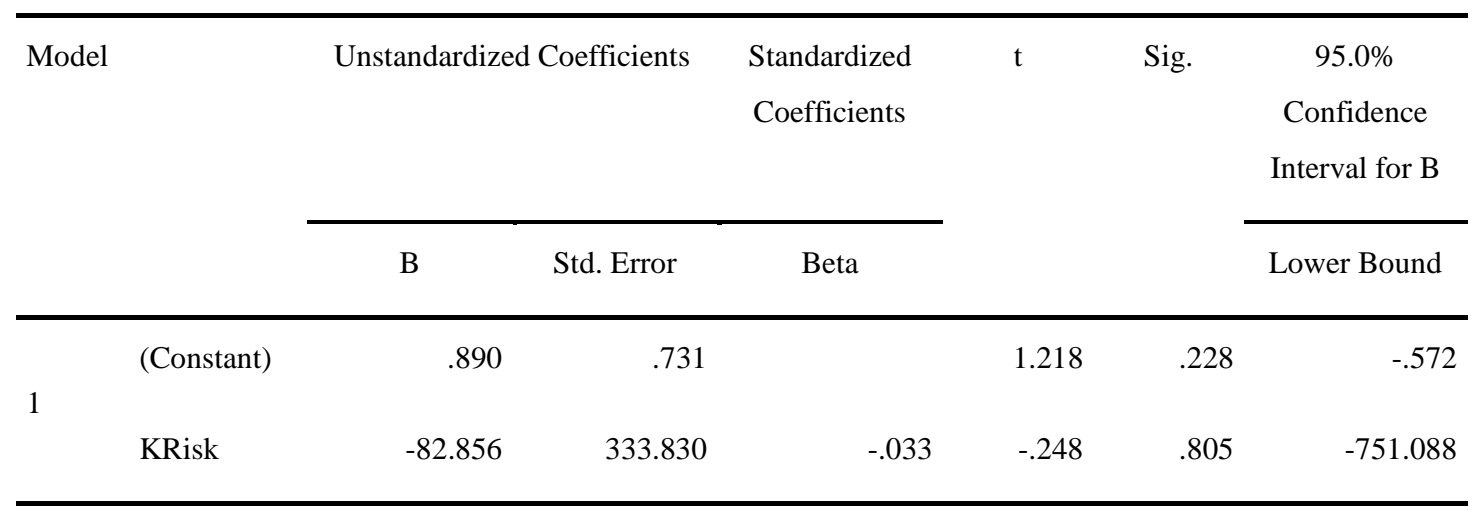

A simple regression was applied to investigate how well Injuries and Illness Rates (IN) could be predicted from At- Risk Behaviors (KRisk). The results were not statistically significant:

$\mathrm{F}(1,58)=.062$ and $\mathrm{p}=.805$. The adjusted $\mathrm{R}$ square value was .016 meaning that only 1.6 percent of the variances in Injury Rates could be explained by At-Risk Behaviors. 


\section{Regression 2}

Dependent variable: Injuries and Illness (IN)

Independent variable: Observation Sheets (Obsheet)

Table 5.34: Correlation Results between Injuries/Illnesses and Observation Sessions

\begin{tabular}{lccc}
\hline & & IN & Obsheet \\
\hline Pearson Correlation & IN & 1.000 & -.109 \\
& Obsheet & -.109 & 1.000 \\
& IN &. & .203 \\
Sig. (1-tailed) & Obsheet & .203 & $\cdot$ \\
& IN & 60 & 60 \\
$\mathrm{~N}$ & Obsheet & 60 & 60 \\
\hline
\end{tabular}

The relationship between the Rate of Injuries and Illnesses (IN) and the Observation Sessions performed (Obsheet) was assessed. The Pearson moment coefficient calculated was r= -.109 at $p=.203$ suggesting that there is no statistically significant relationship between the two variables. The values of the coefficients of correlation are summarized on Table 5.35.

Table 5.35: R-Values of the Correlation between Injuries/Illnesses and Observation Sessions

\begin{tabular}{lcccc}
\hline Model & $\mathrm{R}$ & $\mathrm{R}$ Square & Adjusted R Square & Std. Error of the Estimate \\
1 & .109 & .012 & -.005 & 1.71607 \\
\hline
\end{tabular}

Predictors: (Constant), Obsheet

A regression of the Rate of Injuries on the Rate of Observation Sessions was performed and the results are illustrated in Table 5.36 and 5.37. 
Table 5.36: ANOVA Results Between Injuries/Illnesses and Observation Sessions

\begin{tabular}{|c|c|c|c|c|c|c|}
\hline Model & & Sum of Squares & df & Mean Square & $\mathrm{F}$ & Sig. \\
\hline \multirow{3}{*}{1} & Regression & 2.061 & 1 & 2.061 & .700 & .406 \\
\hline & Residual & 170.805 & 58 & 2.945 & & \\
\hline & Total & 172.865 & 59 & & & \\
\hline
\end{tabular}

Dependent variable: IN

Predictors: (Constant), Obsheet

Table 3.37: Regression Coefficients of Injuries/Illnesses and Observation Sessions

\begin{tabular}{|c|c|c|c|c|c|c|c|}
\hline \multirow[t]{3}{*}{ Model } & & \multicolumn{2}{|c|}{ Unstandardized Coefficients } & \multirow{2}{*}{$\begin{array}{l}\text { Standardized } \\
\text { Coefficients }\end{array}$} & \multirow[t]{3}{*}{$\mathrm{t}$} & \multirow[t]{3}{*}{ Sig. } & $95.0 \%$ \\
\hline & & & & & & & Interval for B \\
\hline & & $\mathrm{B}$ & Std. Error & Beta & & & Lower Bound \\
\hline & (Constant) & 1.578 & 1.052 & & 1.499 & .139 & -.529 \\
\hline \multicolumn{8}{|l|}{1} \\
\hline & Obsheet & -39.940 & 47.748 & -.109 & -.836 & .406 & -135.517 \\
\hline
\end{tabular}

Dependent variable: IN

The correlation analysis performed suggested the existence of a small inverse relationship $(\mathrm{r}=-.109$ at $\mathrm{p}=0.203$ ) between the two variables; however, it was not statistically significant. A simple regression was applied to investigate how well Injuries Rates (IN) could be predicted from the Rate of Observation Sheets (Obsheet). The results were not statistically significant: $\mathrm{F}(1,58)=.700$ at $\mathrm{p}=.406$. The adjusted $\mathrm{R}$ square value was -.005 meaning that zero percent of the variances in Injuries Rates could be explained by the Rate of Observation Sheets. 


\section{Regression 3}

The relationship between the Rate of Injuries/ Illnesses and the Rate of Safe Behaviors was examined and the results of the correlational analysis are shown on Table 5.38.

Table 5.38: Correlations Results between Injuries/IIlnesses and Safe Behaviors

\begin{tabular}{llcr}
\hline & & IN & \multicolumn{2}{c}{ KSafe } \\
\hline \multirow{2}{*}{ Pearson Correlation } & IN & 1.000 & -.145 \\
& KSafe & -.145 & 1.000 \\
& IN & & .135 \\
Sig. (1-tailed) & KSafe & .135 &. \\
& IN & 60 & 60 \\
\hline N & KSafe & 60 & 60 \\
\hline
\end{tabular}

Dependent variable: Injuries/ Illnesses (IN)

Independent variable: Safe Behaviors (KSafe)

The relationship between the Rate of Injuries and Illnesses (IN) and the Safe Behaviors Observed (KSafe) was assessed. The Pearson moment coefficient computed was $r=-.145$ at $\mathrm{p}=.135$ suggesting that there is no statistically significant relationship between the two variables. The $\mathrm{R}$ square values are shown in Table 5.39.

Table 5. 39: R-Values of the Correlation between Injuries/Illnesses and Safe Behaviors

\begin{tabular}{llccc}
\hline Model & & R Square & Adjusted R Square & Std. Error of the Estimate \\
\hline 1 & .145 & .021 & .004 & 1.70823 \\
\hline
\end{tabular}


A regression of the Rate of Injuries and Illnesses on the Rate of Safe Behaviors was performed and the results are illustrated in Table 5.40 and Table 5.41.

Table 5.40: ANOVA Results between Injuries/Illnesses and Safe Behaviors

\begin{tabular}{llrcccc}
\hline Model & & $\begin{array}{c}\text { Sum of } \\
\text { Squares }\end{array}$ & df & Mean Square & F & Sig. \\
\hline & Regression & 3.618 & 1 & 3.618 & 1.240 & .270 \\
1 & Residual & 169.248 & 58 & 2.918 & \\
& Total & 172.865 & 59 & & \\
\hline
\end{tabular}

Dependent variable: IN

Predictors: (Constant), KSafe

The Regression coefficients are shown in Table 5.41.

Table 5.41: Regression Coefficients of Injuries/Illnesses on Safe Behaviors

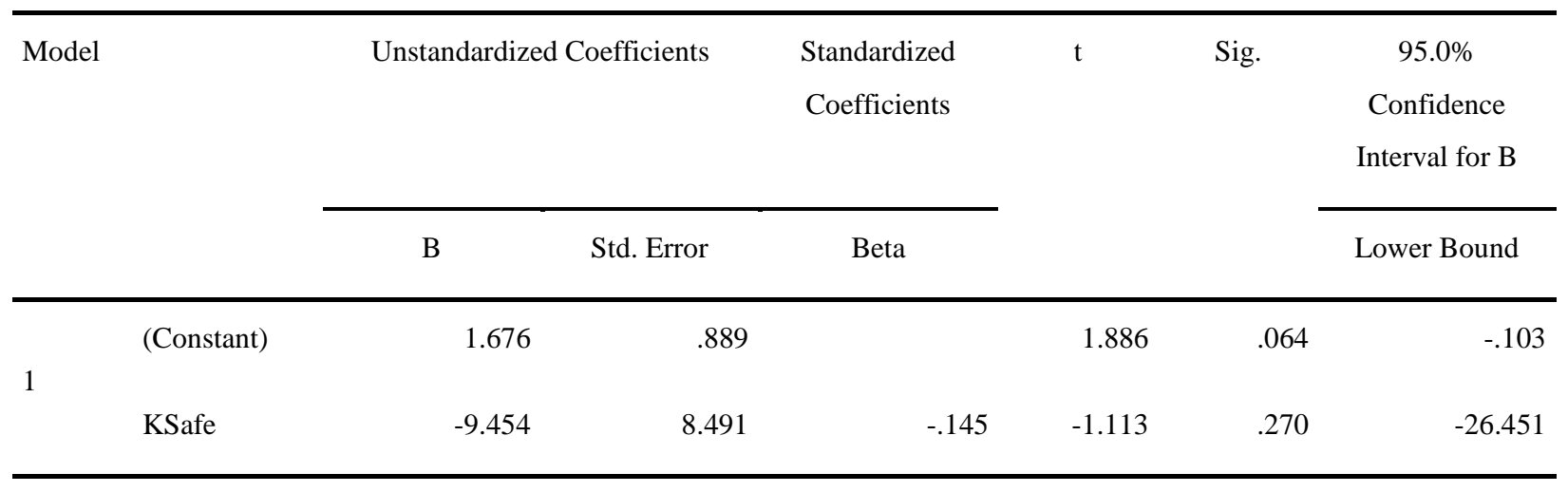

\subsubsection{Dependent Variable: Spill (SP)}

\section{Regression 1}

A regression of Spill Rates was performed on the Rate of At-Risk Behaviors in order to assess how well Spill Rates could be predicted from the Rate of At-Risk Behaviors. The results are illustrated the Table 5.42. 
Table 5.42: Correlation Results between Spills and Safe Behaviors

\begin{tabular}{lccc}
\hline & & SP & KRisk \\
\hline \multirow{2}{*}{ Pearson Correlation } & SP & 1.000 & .221 \\
& KRisk & .221 & 1.000 \\
Sig. (1-tailed) & SP &. & .045 \\
& KRisk & .045 &. \\
N & SP & 60 & 60 \\
& KRisk & 60 & 60 \\
\hline
\end{tabular}

The relationship between Spill Rates (SP) and At-Risk Behaviors observed (KRisk) was assessed. The Pearson moment coefficient calculated was $r=0.221$ at $\mathrm{p}<0.05$ suggesting the existence of a small significant positive relationship between the two variables. The R square Values are shown in Table 5.43.

Table 5.43: R-Values of the Correlation between Spills and At-Risk Behaviors

\begin{tabular}{llccc}
\hline Model & $\mathrm{R}$ & R Square & Adjusted R Square & Std. Error of the Estimate \\
\hline 1 & .221 & .049 & .032 & 3.91371 \\
\hline
\end{tabular}

Predictors: (Constant), KRisk 
The results of the regression analysis are illustrated in Table 5.44 and Table 5.45.

Table 5.44: ANOVA Results between Spill and At-Risk Behavior Rates

\begin{tabular}{llrrrrr}
\hline Model & & Sum of Squares & df & Mean Square & F & Sig. \\
\hline \multirow{2}{*}{ Regression } & 45.628 & 1 & 45.628 & 2.979 & .090 \\
& Residual & 888.395 & 58 & 15.317 & & \\
1 & & & & & \\
& Total & 934.022 & 59 & &
\end{tabular}

Dependent variable : SP

Predictors ( Constant),KRisk

Table 5.45: Regression Coefficients of Spill Rates on At-Risk Behavior Rates

\begin{tabular}{|c|c|c|c|c|c|c|}
\hline \multirow[t]{4}{*}{ Model } & \multicolumn{2}{|c|}{ Unstandardized Coefficients } & \multirow{3}{*}{$\begin{array}{l}\text { Standardized } \\
\text { Coefficients }\end{array}$} & \multirow[t]{4}{*}{$\mathrm{t}$} & \multirow[t]{4}{*}{ Sig. } & \multirow{4}{*}{$\begin{array}{c}95.0 \% \\
\text { Confidence } \\
\text { Interval for B } \\
\text { Lower Bound }\end{array}$} \\
\hline & & & & & & \\
\hline & & & & & & \\
\hline & B & Std. Error & Beta & & & \\
\hline (Constant) & .262 & 1.657 & & .158 & .875 & -3.055 \\
\hline KRisk & 1306.862 & 757.189 & .221 & 1.726 & .090 & -208.816 \\
\hline
\end{tabular}

a. Dependent variable: SP

A simple regression was applied to investigate how well spills rate (SP) could be predicted from the At-risk behaviors observed (KRisk). The results were not statistically significant $F(1,58)=$ 2.979 and $p=.090$. The regression equation drawn to explain the relationship was Spills $=262+$ $1306.862 *$ KRisk (At-Risk Behaviors). The adjusted R square value was 0.032 meaning that about 3.2 percent of the variances in Spill Rates could be explained by At-Risk Behaviors. 


\section{Regression 2}

The association between Spill Rates and the Rate of Observation Sessions was examined and the results are illustrated in Table 5.46.

Table 5.46: Correlation Results between Spills and Observation Sessions

\begin{tabular}{llcc}
\hline & & SP & Obsheet \\
\hline \multirow{2}{*}{ Pearson Correlation } & SP & 1.000 & .333 \\
& Obsheet & .333 & 1.000 \\
& SP &. & .005 \\
Sig. (1-tailed) & Obsheet & .005 &. \\
& SP & 60 & 60 \\
N & Obsheet & 60 & 60 \\
\hline
\end{tabular}

The relationship between the Rate of Spill (SP) and the Observation Sessions performed

(Obsheet) was assessed. The Pearson moment coefficient calculated was $\mathrm{r}=0.333$ at $\mathrm{p}<0.01$

suggesting the existence of a small significant positive relationship between the two variables.

The R square values are shown in Table 5.47.

Table 5.47: R-Values of the Correlations between Spills and Observation Sessions

\begin{tabular}{lrrrr}
\hline Model & R & R Square & Adjusted R Square & \multicolumn{2}{l}{ Std. Error of the Estimate } \\
\hline 1 & .333 & .111 & .096 & 3.78325
\end{tabular}

Dependent variable: Spills (SP)

Independent variable: Observation Sheets (Obsheet) 
A regression of Spill Rates on the Rate of Observation Sessions was performed and the results are presented in Table 48 and Table 49.

Table 5.48: ANOVA Results between Spills and Observation Sessions

\begin{tabular}{llrrrrr}
\hline Model & & Sum of Squares & df & Mean Square & F & Sig. \\
\hline & Regression & 103.868 & 1 & 103.868 & 7.257 & .009 \\
1 & Residual & 830.154 & 58 & 14.313 & & \\
& & & & & \\
& Total & 934.022 & 59 & & \\
\hline
\end{tabular}

Depended variable: SP

Predictors: (Constant), Obsheet

Table 5.49: Regression Coefficients of Spills on Observation Sessions

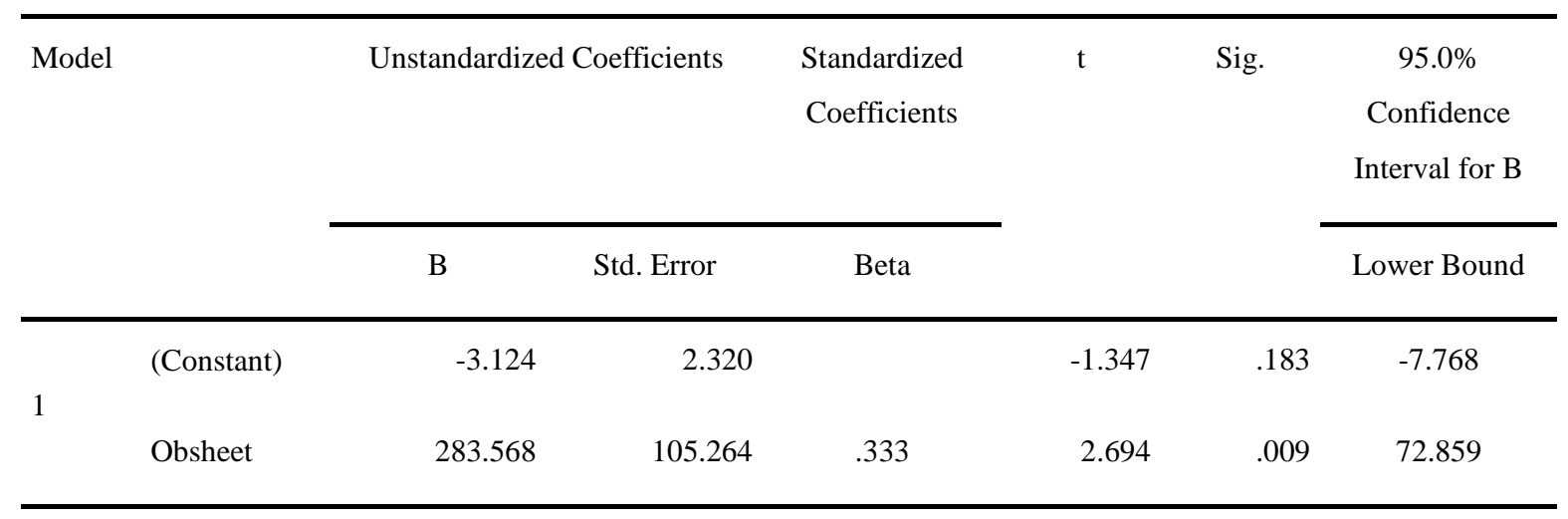

\section{Regression 3}

The association between Spill Rates and the Rate of Safe Behaviors was examined and the results are illustrated in Table 5.50. 
Table 5.50: Correlation Results between Spills and Safe Behaviors

\begin{tabular}{lccc}
\hline & \multicolumn{2}{c}{ SP } & \multicolumn{2}{c}{ KSafe } \\
\hline \multirow{2}{*}{ Pearson Correlation } & SP & 1.000 & .335 \\
& KSafe & .335 & 1.000 \\
& SP &. & .004 \\
Sig. (1-tailed) & KSafe & .004 &. \\
& SP & 60 & 60 \\
N & KSafe & 60 & 60 \\
\hline
\end{tabular}

Dependent variable: Spill (SP)

Independent variable: Safe Behaviors (KSafe).

The relationship Between Spill Rates (SP) and the Rate of Safe Behaviors observed (KSafe) was assessed. The Pearson moment coefficient computed was $\mathrm{r}=0.335$ at $\mathrm{p}<0.05$ suggesting the existence of a small significant positive relationship between the two variables. The Pearson correlation coefficient obtained may suggest a weak association between the two variables. The R square values are shown in Table 5.51.

Table 5.51: R-Values between Spills and Safe Behaviors

\begin{tabular}{lcccc}
\hline Model & $\mathrm{R}$ & R Square & Adjusted R Square & $\begin{array}{c}\text { Std. Error of the } \\
\text { Estimate }\end{array}$ \\
\hline 1 & .335 & .112 & .097 & 3.78098 \\
& & & \\
\hline
\end{tabular}


A regression of Spill Rates on the Rate of Safe Behaviors was performed in order to assess how well Spill Rates could be predicted from the Rate of Safe Behaviors. The results of the regression are shown in Table 5.52 and Table 5.53.

Table 5.52: ANOVA Results between Spills and Safe Behaviors

\begin{tabular}{lrrrrrr}
\hline Model & & Sum of Squares & df & Mean Square & F & Sig. \\
\hline \multirow{2}{*}{ Regression } & 104.866 & 1 & 104.866 & 7.335 & .009 \\
& Residual & 829.156 & 58 & 14.296 & & \\
1 & & & & & \\
& Total & 934.022 & 59 & &
\end{tabular}

Dependent variable: SP

Predictors: (Constant), KSafe

Table 5: 53: Regression Coefficients of Spills on Safe Behaviors

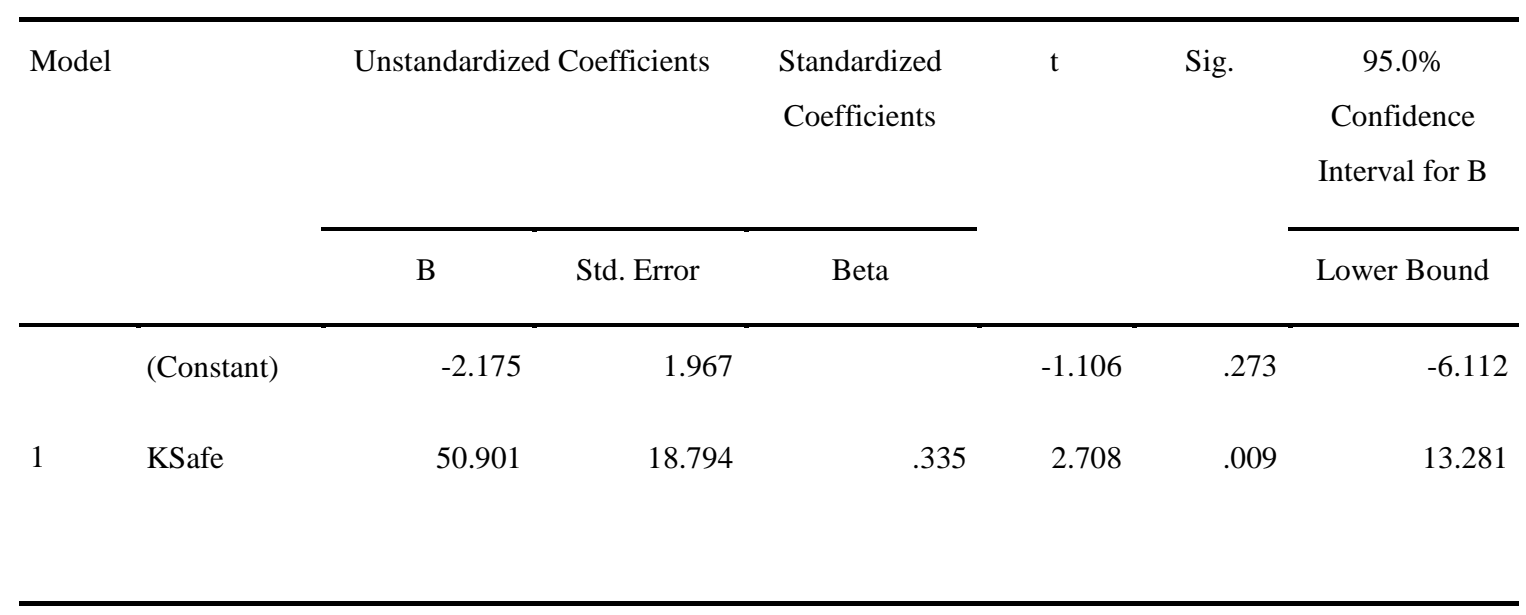

Dependent variable: SP 
A simple regression was applied to investigate how well Spill Rates (SP) could be predicted from the Rate of Safe Behaviors observed (KSafe). The results were statistically significant: $\mathrm{F}(1,58)=7.335$ at $\mathrm{p}<.05$. The regression equation drawn to explain the relationship was Spill Rates $=-2.175+50.9 *$ (Safe Behaviors). The adjusted R square value was 0.097 meaning that about 9.7 percent of the variances in Spill Rates could be explained by the Rate of Safe Behaviors.

\subsubsection{Dependent Variable: Fire Rates (FI)}

\section{Regression 1}

A regression of Fire Rates on the Rate of At-Risk Behaviors was performed in order to assess how well Fire Rates could be predicted from the Rate of At-Risks Behaviors. The results are shown in Table 5.54 .

Table 5.54: Correlation Results between Fires and At-Risk Behaviors

\begin{tabular}{llrr}
\hline & & \multicolumn{2}{c}{ FI KRisk } \\
\hline Pearson Correlation & FI & 1.000 & -.029 \\
& KRisk & -.029 & 1.000 \\
Sig. (1-tailed) & FI &. & .413 \\
& KRisk & .413 & \\
& & & \\
$\mathrm{~N}$ & FI & 60 & 60 \\
\hline
\end{tabular}


The relationship between the Rate of Fires and the Rate of At-Risk Behaviors observed was assessed. The Pearson moment coefficient calculated was $r=-.029$ suggesting the existence of a weak negative relationship; however, it was not statistically significant $\mathrm{p}<0.05$. The $\mathrm{R}$ square values are shown in Table 5.55.

Table 5.55: R-Values of the Correlation between Fires and At-Risk Behaviors

\begin{tabular}{ccccc}
\hline Model & $\mathrm{R}$ & $\mathrm{R}$ Square & Adjusted R Square & Std. Error of the Estimate \\
\hline 1 & .029 & .001 & -.016 & 1.27194 \\
\hline
\end{tabular}

A regression of Fire Rates on the Rate of At-Risk Behaviors was performed and the results are presented in Table 5.56 and Table 5.57.

Table 5.56: ANOVA Results between Fires and At-Risk Behaviors

\begin{tabular}{llccccc}
\hline Model & & Sum of Squares & df & Mean Square & F & Sig. \\
\hline \multirow{2}{*}{1} & Regression & .078 & 1 & .078 & .048 & .826 \\
& Residual & 93.834 & 58 & 1.618 & & \\
& Total & 93.912 & 59 & & & \\
\end{tabular}

Dependent variable: KRisk

Independent variable: FI 
The Regression Coefficients of the Rate of Fires on the Rate of At-Risk Behaviors are shown in Table 5.57.

Table 5.57: Regression Coefficients of Fires on At-Risk Behaviors

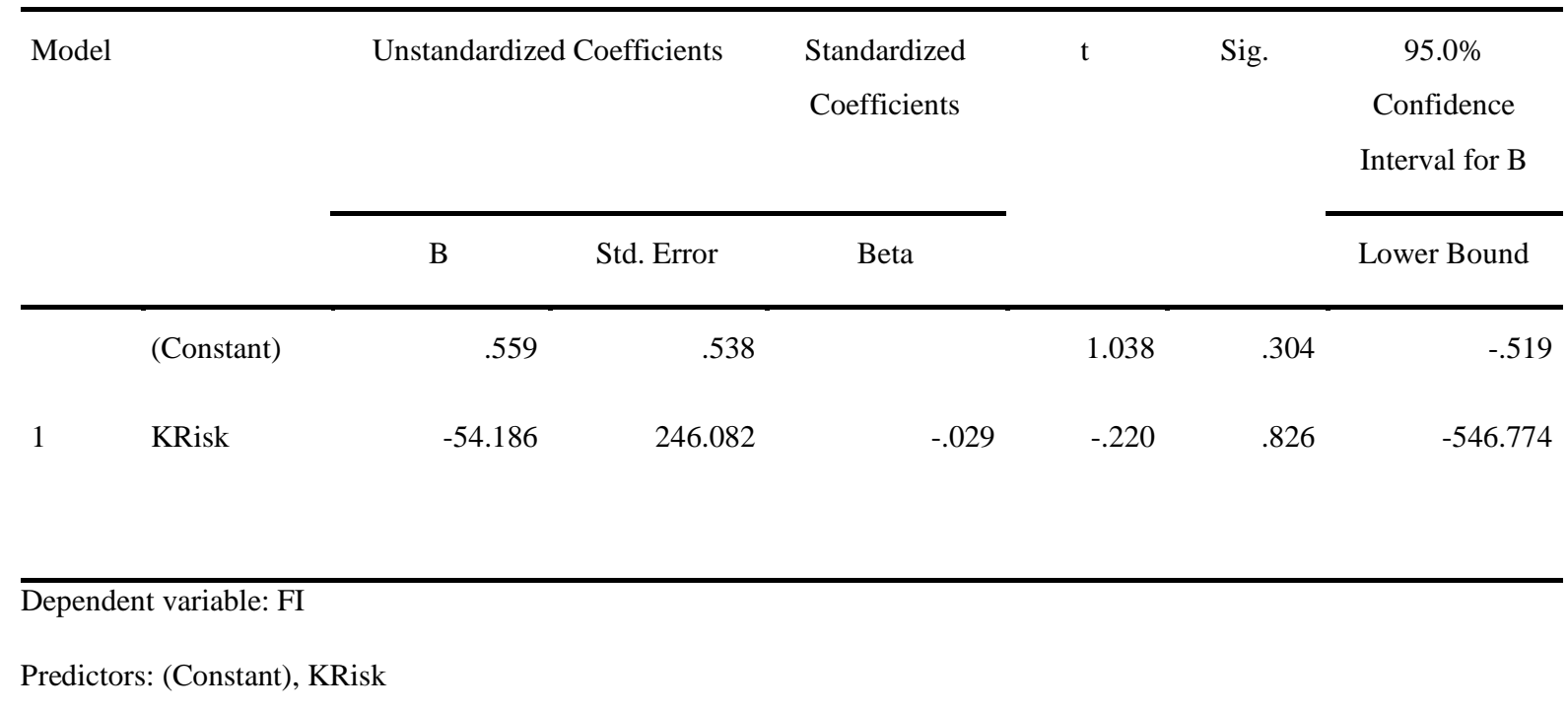

A simple regression was applied to investigate how well the Rate of Fires (FI) could be predicted from At- Risk Behaviors (KRisk). The results were not statistically significant:

$\mathrm{F}(1,58)=.048$ at $\mathrm{p}=.826$. The adjusted $\mathrm{R}$ square value was -.016 meaning that only 1.6 percent of the variances in Fire Rates could be explained by At-Risk Behaviors.

\section{Regression 2}

The association between the Rate of Fires and the Rate of the Observation Sessions performed was assessed. The results are shown in Table 5.58. 
Table 5.58 Correlation Results between Fires and Observation Sessions Behaviors

\begin{tabular}{llcr}
\hline & & FI & \multicolumn{2}{c}{ Obsheet } \\
\hline \multirow{2}{*}{ Pearson Correlation } & FI & 1.000 & -.076 \\
& Obsheet & -.076 & 1.000 \\
& FI &. & .281 \\
Sig. (1-tailed) & Obsheet & .281 & \\
& FI & & \\
& Obsheet & 60 & 60 \\
& & 60 & 60 \\
\hline
\end{tabular}

Dependent variable: Fire (FI)

Independent variable: Observation Sheets (Obsheet)

The relationship between the Rate of Fires (FI) and the Observation Sessions performed

(Obsheet) was assessed. The Pearson moment coefficient calculated was $r=-.076$ at $\mathrm{p}=.281$

suggesting that there is no statistically significant relationship between the two variables. The $\mathrm{R}$ square values are shown in Table 5.59

Table 5.59: R-Values of the Correlation between Fires and Observation Sessions

\begin{tabular}{lrrrr}
\hline Model & R & R Square & Adjusted R Square & Std. Error of the Estimate \\
\hline 1 & .076 & .006 & -.011 & 1.26875 \\
\hline
\end{tabular}

A regression of Fire Rates on Observation Session Rates was performed and the results are presented in Table 5.60 and Table 5.61. 
Table 5.60: ANOVA Results between Fires and Observation Sessions

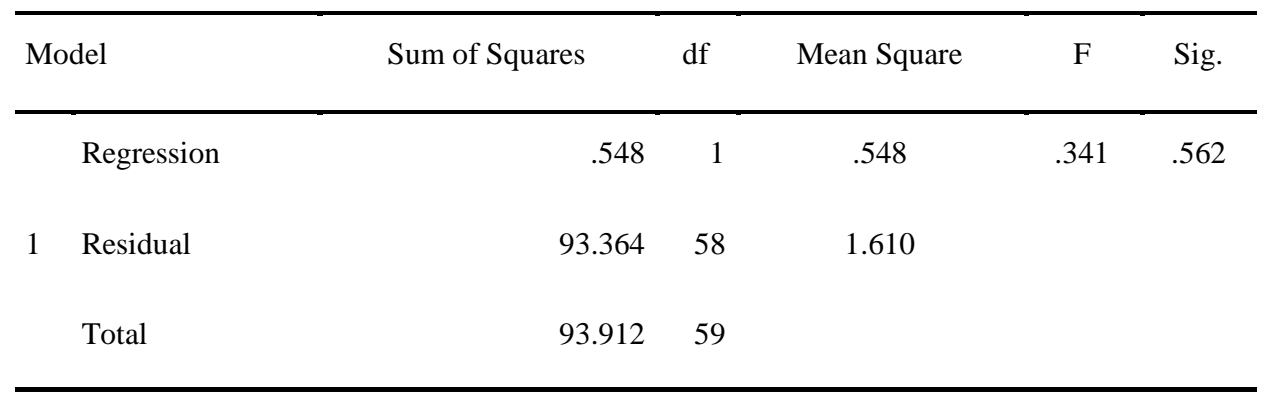

Independent variable : Obsheet

Dependent variable : FI

Table 5.61: Regression Coefficients of Fires on Observation Sessions

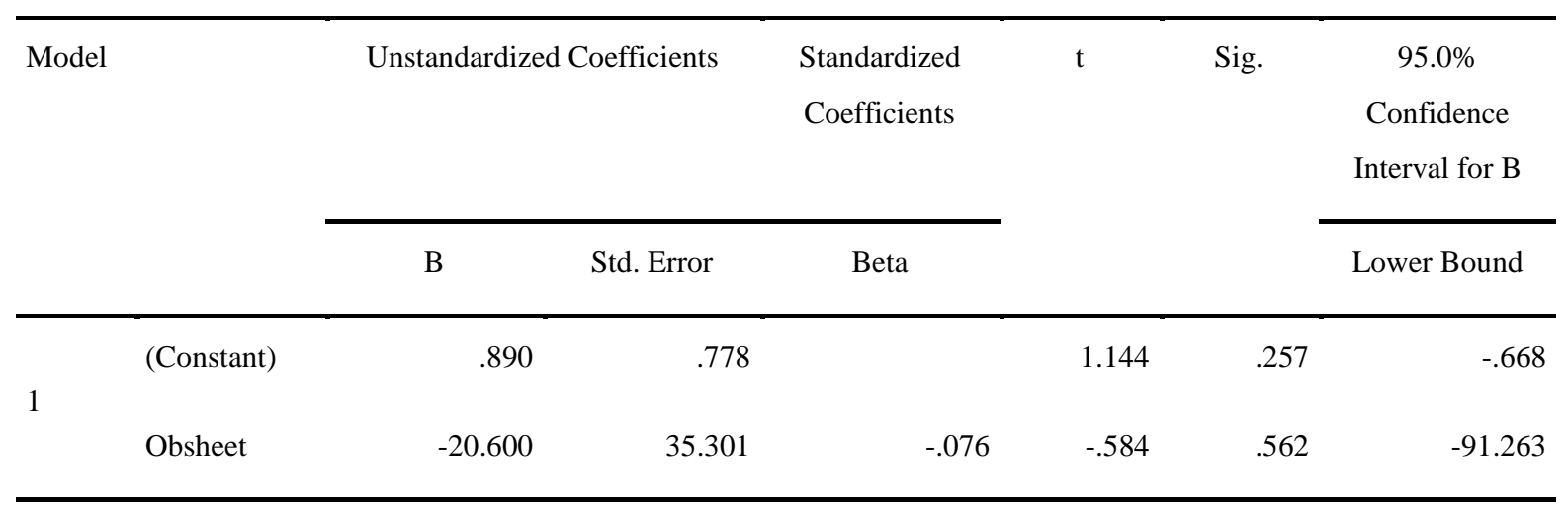

A simple regression was applied to investigate how well the Rate of Fires (FI) could be predicted from the Rate of Observation Sessions (Obsheet). The results were not statistically significant:

$\mathrm{F}(1,58)=.341$ at $\mathrm{p}=.562$, the adjusted $\mathrm{R}$ square value was -.011 meaning that only 1.1 percent of the variances in Fire Rates could be explained by the Rate of Observation Sessions (Obsheet).

\section{Regression 3}

Dependent variable: Fire Rates (FI)

Independent variable: Safe Behavior Rates (KSafe) 
The association between the Rates of Fires and Safe Behaviors observed was examined; the Pearson correlation coefficient was computed as illustrated on the Table 5.62.

Table 5.62: Correlation Results between Fire and Safe Behaviors

\begin{tabular}{|c|c|c|c|}
\hline & & FI & KSafe \\
\hline \multirow{2}{*}{ Pearson Correlation } & FI & 1.000 & -.098 \\
\hline & KSafe & -.098 & 1.000 \\
\hline Sig. (1-tailed) & FI & . & .228 \\
\hline \multirow{2}{*}{$\mathrm{N}$} & FI & 60 & 60 \\
\hline & KSafe & 60 & 60 \\
\hline
\end{tabular}

The relationship between the Rate of Fires (FI) and the Rate of Safe Behaviors (KSafe) was assessed. The Pearson moment coefficient calculated was $r=-.098$ at $p=.228$, suggesting that there is no statistically significant relationship between the two variables. The R square values are shown in Table 5.63.

Table 5.63: R-Values of the Correlation between Fires and Observation Sessions

\begin{tabular}{|c|c|c|c|c|}
\hline Model & $\mathrm{R}$ & R Square & Adjusted R Square & $\begin{array}{l}\text { Std. Error of the } \\
\text { Estimate }\end{array}$ \\
\hline 1 & $.098^{\mathrm{a}}$ & .010 & -.007 & 1.26633 \\
\hline
\end{tabular}


A regression of Fire Rates on the Rate of Safe Behaviors was performed and the results are presented in Table 5.64 and Table 5.65.

Table 5.64: ANOVA Results between Fires and Safe Behaviors

\begin{tabular}{|c|c|c|c|c|c|c|}
\hline Model & & Sum of Squares & $\mathrm{df}$ & Mean Square & $\mathrm{F}$ & Sig. \\
\hline \multirow{3}{*}{1} & Regression & .904 & 1 & .904 & .564 & .456 \\
\hline & Residual & 93.008 & 58 & 1.604 & & \\
\hline & Total & 93.912 & 59 & & & \\
\hline
\end{tabular}

Dependent variable: FI

Predictors: (Constant), KSafe

The Regression coefficients are shown in Table 5.65.

Table 5.65: Regression Coefficients of Fires on Safe Behaviors

\begin{tabular}{|c|c|c|c|c|c|c|}
\hline \multirow[t]{2}{*}{ Model } & & \multicolumn{2}{|c|}{ Unstandardized Coefficients } & Standardized & \multirow[t]{2}{*}{$\mathrm{t}$} & \multirow[t]{2}{*}{ Sig. } \\
\hline & & $\mathrm{B}$ & Std. Error & Beta & & \\
\hline \multirow{2}{*}{1} & (Constant) & .925 & .659 & & 1.404 & .166 \\
\hline & KSafe & -4.726 & 6.294 & -.098 & -.751 & .456 \\
\hline
\end{tabular}

A simple regression was applied to investigate how well the Rate of Fires (FI) could be predicted from Safe Behaviors (KSafe). The results were not statistically significant: $F(1,58)=.564$ at $\mathrm{p}=.456$. The adjusted $\mathrm{R}$ square value was -.007 meaning that zero percent of the variances in Fire Rates could be explained by the Rate of Safe Behaviors. 


\subsubsection{Correlation between the Rate of Observation Sessions and the Rate of Safe Behaviors}

One of the questions evolved from this study was to investigate the impact on BBS of performing BBS observations on worker's safety-related behaviors. Does the frequency of observations promote work related safe behaviors? The scatter plot drawn suggested the existence of a linear relationship between Observation Sessions and the Safe Behaviors observed. The slope of the line also suggested that the nature of the relationship is positive.

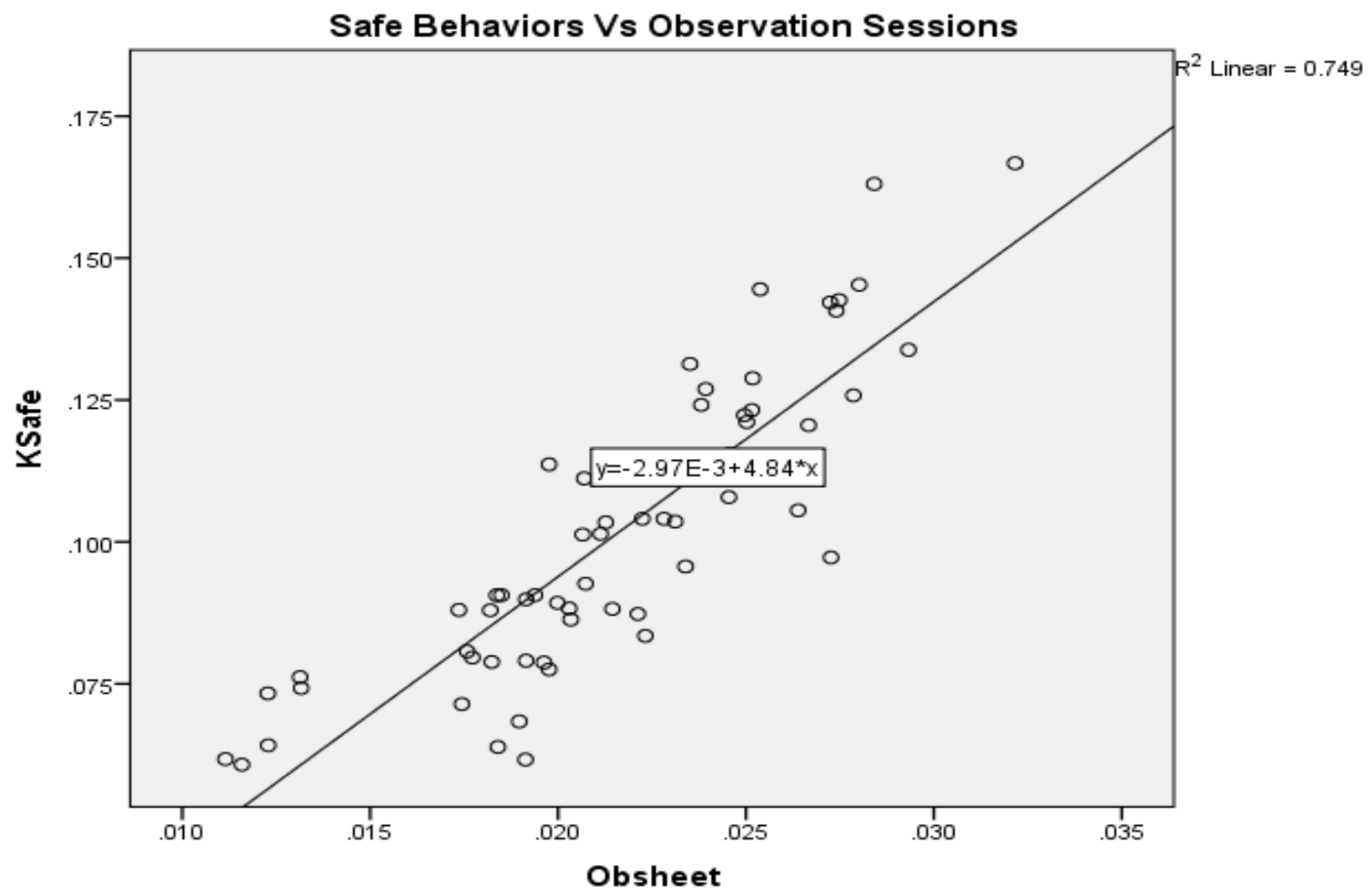

Figure 0.6: Scatter Plots of the Relations between Safe Behaviors and Observations Sessions

In addition to the scatter plot, a correlation analysis was performed between the two variables to explore the nature of their relationship. Results are illustrated in Table 5.66. 
Table 5.66: Correlation Results between Observation sessions and Safe Behavior Rates

\begin{tabular}{llrr}
\hline & & KSafe & Obsheet \\
\hline \multirow{2}{*}{ KSafe } & Pearson Correlation & 1 & .865 \\
& Sig. (2-tailed) & & .000 \\
& $N$ & 60 & 60 \\
Obsheet & Pearson Correlation & .865 & 1 \\
& Sig. (2-tailed) & .000 & \\
& $N$ & 60 & 60 \\
\hline
\end{tabular}

The correlation analysis was performed and suggested the existence of a strong positive statistically significant relationship between the Rate of Observation Sessions and Safe Behaviors observed, $\mathrm{p}$ value $<0.01$ and the Pearson coefficient $\mathrm{r}=0.865$. This result implies that when the rate of observation session increases, the rate of safe behaviors tend to increase.

\subsubsection{Conclusion}

Correlation and regression analyses were performed to explore the nature of the relationship between Behavior-Based Safety outcomes and incident rates in XYZ Oil Company. Among the 15 correlations examined, six of them were statistically significant. Actually, these significant correlations were related to two type of relationships: the one between BBS and the total incident rates and the one between BBS and oil spill rates. In the first case, when the relationship between BBS and the total incident rates was examined, a statistically significant p value $<0.05$ correlation was found between the Rate of At-Risk Behaviors observed (KRisk) and Total Incidents (TE). The Pearson moment coefficient $r=.218$ value suggested the existence of a small positive correlation between the two variables, meaning that when the rate of at-risk 
behaviors observed increases, the total incidents rate also increases. In addition, the regressions performed revealed an adjusted R square value of 0.031 suggesting that only $3.1 \%$ of the variances in incident rates can be explained by the independent variable. These results also suggested the existence of other variables, not identified by this study, that may modify or impact the relationship between the two variables. For example, other organizational safety elements such as supervisor's safety leadership, organizational capability, and work shift management may impact the relationship. Also, the quality of observation sessions performed such as feedback may also modify the nature of the relationship.

Another trend that could be observed was the existence of a small positive significant relationship between Incident Rates (TE) and both the Rate of Observation Sessions performed (Obsheet) and Safe Behaviors observed (KSafe); on the other hand, Obsheet and KSafe were also strongly corrected. These positive correlations suggest that when the rate of observation sessions performed increases, the rate of incidents also increases. Even if the Pearson coefficient of correlation was rather small, the possibility of the incident's occurrence influencing the trend of observations performed is not to be discarded since a causal relationship may not be established through correlational studies alone. It appears that when incident rates increase, BBS is overly emphasized leading to an increase of observation sessions; however, when the rate of incidents decreases, this emphasis no longer exists, therefore the rate of observation sessions performed also decreases.

In the second case, when the relationship between BBS and oil Spill rates was examined, similar correlations were found. The rate of At-Risk Behaviors was significantly correlated to Spill Rates with $r=0.221 \mathrm{P}<0.05$. Also, a small positive significant relationship was revealed 
between Spill Rates (SP) and both the Rate of Observation Sessions performed (Obsheet), $\mathrm{r}=0.333$ at $\mathrm{p}<0.05$ and the Rate of Safe Behaviors observed (KSafe), $\mathrm{r}=0.335$ at $\mathrm{p}<0.05$. However, it is important to notice that Spill Rates (SP) constitute a large part of the total incidents and was found to be strongly correlated to Incident Rates $r=0.631$ at $\mathrm{p}<0.01$. Therefore only the results of the correlations related to Total Incidents (TE) were considered.

Additionally, the impact of performing observations on workers' safety-related behaviors was also assessed. A strong positive relationship was observed between the Rate of Safe Behaviors (KSafe) and the Rate of Observation Sessions (Osheet), meaning that when the rate of observation sessions increases, the rate of safe behaviors observed also increases. While a causal relationship may not be determined, this correlation may suggest that the more people are observed, the more safe behaviors are recorded.

Regression analyses were also performed to investigate whether or not XYZ Incident Rates could be predicted by BBS outcomes. Only the statistically significant correlations were considered for the regressions analysis. The regression models obtained are listed below.

- $\quad \mathrm{TE}=3.66+2206.35 *$ KRisk. For this regression, the adjusted $\mathrm{R}$ square value was 0.031 meaning that about 3.1 percent of the variances in total incidents could be explained by the rate of At-Risk behaviors

- $\mathrm{TE}=-1.013+430.308 *$ Obsheet. For this regression the adjusted $\mathrm{R}$ square value was 0.072 meaning that about 7 percent of the variances in total incidents could be explained by the rate of observation sessions performed. 
- $\mathrm{TE}=1.28+68.804 *$ KSafe. For this regression, the adjusted R square value was 0.054 meaning that about 5.4 percent of the variances in total incidents (TE) could be explained by the Rate of Safe Behaviors (KSafe).

- $\quad \mathrm{SP}=262+1306.862 *$ KRisk. For this regression, the adjusted $\mathrm{R}$ square value was 0.032 meaning that about 3.2 percent of the variances in Spill Rates (SP) could be explained by the Rate of At-Risk Behaviors.

- $\mathrm{SP}=3.124+283.57 *$ Obsheet. For this regression, the adjusted R square value was .096 meaning that about 9.6 percent of the variances in Spills Rate (SP) could be explained by the Rate of Observation sessions performed.

- $\mathrm{SP}=-2.175+50.9 *$ Safe Behaviors. The adjusted $\mathrm{R}$ square value was 0.097 meaning that about 9.7 percent of the variances in Spill Rates (SP) could be explained by the Rate of Safe Behaviors

The predictive models resulting from these regression analyses were rather weak, suggesting that BBS outcomes alone may not be good predictors of incident rates. In fact, the better model could only explain $9.7 \%$ of the variances in Incident Rates. This suggests that additional variables should be considered for stronger predictive models. Chapter 6 summarizes the study's recommendations and conclusions. 


\section{Chapter 6: Discussion and Conclusions}

\subsection{Limitation and Future Works}

Despite the relevance of this study in the area of occupational safety interventions and the safety literature in general, the following conditions may be regarded as possible limitations of this work. This study considered the data from a production department in the XYZ Oil Company and therefore may not be readily generalized to other areas of the company nor may it be easily extended to other oil production companies. Secondly, the lack of control group made it hard to determine whether the safety performance outcomes measurement would be different without BBS intervention since causal effects were not determined. Additionally, even if BBS could be recognized as the most relevant safety intervention applied at that time, this study did not consider the interaction of BBS intervention with other incident prevention strategies applied at XYZ Oil Company.

Finally, this study evaluates the effectiveness of BBS intervention as a whole; thus, it did not allow for determining the causal role or impact of individual components of the BBS process. Also, being mainly a summative evaluation research, this work does not focus on the process quality per se. Thus, potential qualitative process variance may affect the study’s results.

Despite the intent of behavior-based safety intervention being to decrease incident rates, unintended outcomes may result as it usually occurs with any process intervention. For instance, a BBS intervention can potentially affect non-targeted safety-related behaviors or other company’s business aspects such as productivity. Moreover, it may be that BBS intervention differently affects all safety performance when it is considered together with other safety 
programs, an event sometimes referred to as effect modifiers. Further research may consider exploring these possibilities.

This study involves continuous scale variables which were assumed as normally and independently distributed. Also, first order regression equations were considered in this research.

\subsection{Occupational Application}

The results of this work have several applications to the work environment. The study performed indicates that Behavior-Based Safety is a valuable tool for fostering safety-related behaviors in workplaces. However, merely implementing the BBS process will not suffice to lower incident rates. BBS is definitely not a magic bullet against incidents, as many consulting companies selling the program tend to suggest, since the best BBS predictive model could only explain less than $10 \%$ of the incidents' variation. However BBS may work together with other safety programs to effectively lower incidents rates.

The study also suggested that BBS outcomes were not good predictors of incidents rates, and other organizational factors may need to be considered such as the supervisors' safety leadership, work shift management, and organizational capability. In addition, the quality of BBS sessions such as feedback and the promptness of an action plan may also impact the effectiveness of the BBS process. Many organizations tend to focus on the number of BBS observations performed and the rate of safe behaviors instead of the quality of the observations sessions, however this study revealed that these are not good indicators of the safety performance. 
At-risk behaviors should be given more attention because it was revealed to be statistically and significantly correlated to the incident rates, what Tomas Krause called the critical mass of incidents. However it should not be the only focus for injury prevention strategies. In fact, the traditional accident pyramid, which usually involves at-risk behaviors, may not be the only critical path to accidents for all types of industries. For high risk industries such as oil production companies, a latent path may exist escaping the traditional safety triangle path, and leading directly to the major incidents.

In relation to XYZ Company, it can be recommended that other safety programs be given attention since this study suggests that BBS impact on incidents rates is rather small. Therefore, other safety strategies should be emphasized and the resources allocated to BBS activities should be reconsidered in order to optimize company resources. Furthermore, from this study, it appears that the BBS process in XYZ Oil Company tended to work in a cyclical mode. The proactive merit of the BBS process will be limited if the process is either overly or hardly emphasized according to the incident trends. Hence, BBS activities should be performed steadily and consistently.

\subsection{Conclusions}

The aim of this study was to evaluate the effectiveness of the BBS process in decreasing incident rates in XYZ Oil Company in order to help optimizing the resources allocated to incident prevention strategies. For this purpose, the nature of the relationship between BBS outcomes and incident rates was examined; the impact of BBS process on incident rates was quantified and its predictability assessed. Based on BBS conceptual design and theoretical studies reviewed, 3 main hypotheses guided this work. The first hypothesis was that a positive 
statistically significant relationship existed between at-risk behaviors and incidents rates, meaning that when more at-risk behaviors are observed, the incident rates tend to increase. A correlation analysis was performed to test this hypothesis and study results revealed the existence of a positive statistically significant relationship $(\mathrm{p}<0.05)$ between the rates of at-risk behaviors and total incidents. However, the association was rather weak.

The second hypothesis suggested the existence of a negative correlation between the rate of safe behaviors and incident rates. Similar analyses were performed and the results revealed the existence of a statistically significant positive relationship between safe behaviors and total incident rates, therefore the null hypothesis was not rejected and the alternative hypothesis was not supported. Similarly, the third hypothesis, suggesting the existence of a negative relationship between the rate of observation sessions performed and the incident rates, was tested. The results revealed the existence of a statistically significant positive relationship between the rate of observation sessions and total incident rates; therefore, the null hypothesis was not rejected. The test results related to the second and third hypothesis suggested that the BBS process may be working on a cyclical or crisis mode. It appears that when incident rates increase, more BBS observations are performed and the contrary occurs when incident rates decrease. It is hoped that future studies may be performed to investigate a causal relationship between these variables.

Two study questions framed this work. The first one asked whether incident rates could be predicted from BBS outcomes. The regression analyses performed on the statistically significant correlation revealed that the best regression model drawn could only explain less than $10 \%$ of the incident rates variance, suggesting that BBS outcomes were not good predictors of incident rates. The second question was whether performing more observation sessions could 
increase workers' safe behaviors. A simple scatter plot suggested that the rate of safe behaviors tend to increase when the rate of observation sessions performed increases. The findings of this research led to the conclusion that the BBS process can foster safe behaviors in workplaces.

However, its effects on incident rates are rather modest. 


\section{References}

Alvero, A. M., \& Austin, J. (2004). The effects of conducting behavioral observations on the behavior of the observer. Journal of Applied Behavior Analysis, 4(4), 457-468.

Brauer, R. L. (2006). Safety and health for engineers $\left(2^{\text {nd }}\right.$ ed.). Hoboken, NJ: John Wiley \& Sons, Inc

Carder, B. (1994). Quality theory and the measurement of safety systems. Professional 39, $23-$ 28.

Carder, B., \& Ragan, P. W. (2003). A survey-based system for safety measurement and improvement. Journal of Safety Research, 34(2), 157-165.

Carder, B., \& Ragan, P. W. (1994). Systems theory and safety. Professional Safety, 39, 22.

Chen, D., \& Tian, H. (2012). Behavior-based safety for accidents prevention and positive study in China construction project. Procedia Engineering, 43, 528-534.

Cooper, M. D. (2006). Exploratory analyses of the effects of managerial support and feedback consequences on behavioral safety maintenance. Journal of Organizational Behavior Management, 26(3), 1-41.

Cooper, M. D., \& Phillips, R. A. (2004). Exploratory analysis of the safety climate and safety behavior relationship. Journal of Safety Research, 35(5), 497-512.

Cooper, M. D., Phillips, R. A., Sutherland, V. J., \& Makin, P. J. (1994). Reducing accidents with goal-setting and feedback: A field study. Journal of Occupational and Organizational Psychology, 67, 219-240. 
Cooper, S. E., \& Newbold R. C. (1994). Combining external and internal behavioral systems. Consulting Psychology Journal: Practice and Research, 46(3), 32-41.

Creswell, J. W. (2008). Educational research: Planning, conducting, and evaluating quantitative and qualitative research (3rd ed.). Upper Saddle River, NJ: Pearson.

DeJoy, D. (1996). Theoretical models of health behavior and workplace self-protective behavior. Journal of Safety Research, 27, 61-72.

Dyreborg, J., Nielsen, K., Kines, P., Rasmussen, K., Olsen, O., \& Hester, L. J. (2011) Safety interventions for the prevention of accidents in the work place. Retrieved from http://www.campbellcollaboration.org

Flin, R., Mearns, K., O'Connor, P., \& Bryden, R. (2000). Measuring safety climate: Identifying the common features. Safety Science, 34, 177-92.

Fullarton, C., \& Stokes, M. (2006). The utility of a workplace injury instrument in prediction of workplace injury. Accident Analysis and Prevention, 39, 28-37.

Geller, E. S. (2005). Behavior-based safety and occupational risk management. (Unpublished doctoral dissertation). Virginia Polytechnic Institute and State University, Blacksburg, VA.

Geller, E. S. (1996). The psychology of safety. Radnor, PA: Chilton Book Company.

Godbey, J. (2006). The effects of behavior-based safety techniques on behavior variation, targeted and non-targeted safe behaviors, and productivity and quality in manufacturing facilities. (Unpublished doctoral dissertation). Auburn University, Auburn, Alabama.

Retrieved from http://etd.auburn.edu/etd/bitstream/handle/10415/1297/godbey_jessie_56.pdf?sequence= 1 
Goetsch, D. L. (2008). Occupational safety and health for technologist, engineers and managers (6 th ed.). Upper Saddle River, NJ: Pearson.

Guastello, S. J. (1993). Do we really know how well our occupational accident prevention programs work? Safety Science, 16(3-4), 445-463.

Haddix, A. C., Teutsch, S. M., \& Corso, P. S. (2003). Prevention effectiveness: A guide to decision analysis and economic evaluation. Oxford, UK: Oxford University Press.

Haight, M. J., Agraz-Boeneker, R. \& Groves, W. A. (2007). An examination of observations and incidence rates for a behavior-based safety program. Journal of Safety Health\& Environment Research, 4(3), 2-22.

Haight, M. J., \& Thomas, R. E. (2003). Intervention effectiveness research: A review of literature on leading indicators. Chemical Health and Safety, March/April, 10(2), 21-25l.

Hart, M. B., Neumann, M. C., \& Veltri, T. A. (2009). Hand injury prevention training: Assessing knowledge, attitude and behavior. American Society of Safety Engineers, 6(1), 2-23.

Haynes, R. S., Pine, R. C., \& Fitch, H. G. (1982). Reducing accident rates with organizational behavior modification. The Academy of Management Journal, 25(2), 407-416.

Heinrich, H. W. (1931). Industrial accident prevention. New York: McGraw-Hill.

Heinrich, H. W., Petersen, D., \& Roos, N. (1980). Industrial accident prevention (5th ed.). New York: McGraw-Hill.

Hermann, J. A., Ibarra, G. B., \& Hopkins, B. L. (2010). A safety program that integrated behavior-based safety and traditional safety methods and its effects on injury rates of manufacturing workers. Journal of Organizational Behavior Management, 30(1), 6-25. 
Hopkins, A. (2006). What are we to make of safe behaviour programs? Safety Science, 44 (7), 583-597. Retrieved from http://dx.doi.org.www.libproxy.wvu.edu/10.1016/j.ssci.2006.01.001

Iyer, P. S., Haight, M. J., Del Castillo, E., Tink, B.W., \& Hawkins, P.W. (2004). Intervention effectiveness research: Understanding and optimizing industrial safety programs using leading indicators. Chemical Health \& Safety, 11(2), 9-19.

Janicak, C. (2003). Safety metrics: Tools and techniques for measuring safety performance. Lanham, Maryland 20706, Government Institutes.

Johnston, M. R., \& Hayes, L. J. (2005). Use of a simulated work setting to study behavior-based safety. Journal of Organizational Behavior Management, 25(1), 1-34.

Jones, S., Kirchsteiger, C., \& Bjerke, W. (1999). The importance of near miss reporting to further improve safety performance. Journal of Loss Prevention in the Process Industries, 12(1), 59-67.

Kidd, P., Reed, D., Weaver, L., Westneat, S., \& Rayenss, M. K. (2003). The theoretical model of change in adolescents: Implications for injury prevention. Journal of Safety Research, 34, 281-288.

Komaki, J., \& Goltz, S. (2001). Within-group research designs: Going beyond program evaluation questions. In C. M. Johnston,W. K. Redmon, \& T. C. Mawhinney (Eds.), Handbook of organizational performance: Behavior analysis and management (pp. 81-137). Binghamton, NY: The Haworth Press, Inc.

Krause, T. R. (1995). Employee-driven systems for safe behavior: Integrating behavioral and statistical methodologies. Library of Congress Catalog. 
LaMontagne, A. D., \& Needleman, C. (1996). Overcoming practical challenges in intervention research in occupational health and safety. American Journal of Industrial Medicine, 29(4), 367-372

McDavid, C. J. (2005). Research designs for program evaluations (2nd ed.). California, Sage Publications.

Mearns, K. (2009). From reactive to proactive - can LPIs deliver? Safety Science, 47, 491-492.

Morgan, G. A., Leech, N. L., Gloeckner, G. W., \& Barrett, K. C. (2012). IBM SPSS for introductory statistics: Use and interpretation (5th ed.). New York, NY: Routledge Academy.

Neal, A., \& Griffin, M. A. (2006). A study of the lagged relationships among safety climate, safety motivation, safety behavior, and accidents at the individual and group levels. Journal of Applied Psychology, 91(4), 946-995.

Nielsen, K. J., Carstensen, O., \& Rasmussen, K. (2006). The prevention of occupational injuries in two industrial plants using an incident reporting scheme. Journal of Safety Research, 37, 479-486.

NIOSH. (2010). Engineering controls. Centers for Disease Control and Prevention. Retrieved from http://www.cdc.gov/niosh/topics/engcontrols

Paul, P. S., \& Maiti, J. (2007). The role of behavioral factors on safety management in underground mines. Safety Science, 45(4), 449-471.

Pawson, R., \& Tilley, N. (2004). Realist evaluation. Washington, DC: Sage Publications.

Petersen, D. (2003). Techniques of safety management: A systems approach (4th ed.). Des Plaines, IL: American Society of Safety Engineers. 
Razi, S. (2006). The organizational culture impact on accidents: A secondary analysis of the relationship between culture and safety. (Published doctoral dissertation). Capella University, ProQuest, UMI Dissertations Publishing, 2006. 3206384. Retrieved from http://search.proquest.com.www.libproxy.wvu.edu/docview/304909829?accountid=2837

Reber, R. A., Wallin, J. A., \& Chhokar, J. S. (1984). Reducing industrial accidents: A behavioral experiment. Industrial Relations, 23(1), 119-125.

Robson, L. S., Judith, C.A., Cullen, K., Bielecky, A., Severin, C., Bigelow, P. L., Irvin, E., Culyer, A., \& Mahood, Q. (2007). The effectiveness of occupational health and safety management system interventions: A systematic review. Safety Science, 45(3), 329-353.

Robson, L. S., Shannon, H. S., Goldenhar, L. M., \& Hale, A. R. (2001). Guide to evaluating the effectiveness of strategies for preventing work injuries: How to show whether a safety intervention really works. Centers for Disease Control and Prevention DHHS (NIOSH) Publication No. 2001-119.

Saari, J. (1994). When does behaviour modification prevent accidents? Leadership \& Organization Development Journal, 25(1), 1-34.

Shannon, H. S., Robson, L. S., \& Guastello, S. J. (1999). Methodological criteria for evaluating occupational safety intervention research. Safety Science, 31(2), 161-179.

Skogdalen, E., Utne, B., \& Vinnem, E. J. (2011). Developing safety indicators for preventing offshore oil and gas deep water drilling blowouts. Safety Science, 49(8), 1187-1199. Sulzer-Azaroff, B., \& Austin, J. (2000). Behavior-based safety and injury reduction: A survey of the evidence. Professional Safety, 45(7), 19-24. 
U.S. Bureau of Labor Statistics. (2011). Incidence rates of nonfatal occupational injuries and illnesses by case type and ownership, selected industries. Retrieved from http://www.bls.gov/news.release/osh.t01.htm

Weinstein, M. B. (1997). Total quality safety management and auditing. Cleveland, OH: CRC Press.

Williams, S. J. (1927). The manual of industrial safety. Chicago \& New York, A.W. Shaw Co.; London, A.W. Shaw and Co., 1927 (OCoLC)609002101. Retrieved from http://www.worldcat.org/title/manual-of-industrial-safety/oclc/544528

Whitley, B., \& Kite, M. E. (2012). Principles of research in behavioral science (3rd ed.). New York, NY: Routledge, Taylor \& Francis Group.

Wirth, O., \& Sigurdsson, S. (2008). When workplace safety depends on behavior change: Topics for behavioral safety research. Journal of Safety Research, 39, 589-598.

Wurzelbacher, S., \& Jin, Y. (2011). A framework for evaluating OSH program effectiveness using leading and trailing metrics. Journal of Safety Research, 42, 199-207. 


\section{Appendix A: Five Years BBS Outcomes Spreadsheet}

\begin{tabular}{|c|c|c|c|c|c|c|c|c|c|c|}
\hline Count & ID & Months & Safe & $\begin{array}{l}\text { At- } \\
\text { Risk }\end{array}$ & total & $\begin{array}{l}\text { \# of } \\
\text { sessions }\end{array}$ & $\begin{array}{l}\text { Total } \\
\text { incident } \\
\text { rate }\end{array}$ & $\begin{array}{l}\text { At- } \\
\text { Risk } \\
\text { Rate }\end{array}$ & $\begin{array}{l}\text { Safe } \\
\text { Rate }\end{array}$ & $\begin{array}{l}\text { \# } \\
\text { Session } \\
\text { Rate }\end{array}$ \\
\hline 2008 & & & & & & & & & & \\
\hline 1 & 108 & Jan & 2,556 & 64 & 2,620 & 810 & 0.06 & 0.00 & 0.06 & 0.02 \\
\hline 2 & 208 & Feb & 2,656 & 48 & 2,704 & 779 & 0.06 & 0.00 & 0.06 & 0.02 \\
\hline 3 & 308 & Mar & 3,401 & 132 & 3,533 & 945 & 0.08 & 0.00 & 0.08 & 0.02 \\
\hline 4 & 408 & Apr & 3,550 & 50 & 3,600 & 879 & 0.07 & 0.00 & 0.07 & 0.02 \\
\hline 5 & 508 & May & 4,360 & 76 & 4,436 & 875 & 0.09 & 0.00 & 0.09 & 0.02 \\
\hline 6 & 608 & Jun & 4,351 & 94 & 4,445 & 1081 & 0.09 & 0.00 & 0.09 & 0.02 \\
\hline 7 & 708 & Jul & 5,174 & 72 & 5,246 & 1121 & 0.10 & 0.00 & 0.10 & 0.02 \\
\hline 8 & 808 & Aug & 3,905 & 64 & 3,969 & 989 & 0.08 & 0.00 & 0.08 & 0.02 \\
\hline 9 & 908 & Sep & 4,280 & 71 & 4,351 & 1025 & 0.09 & 0.00 & 0.08 & 0.02 \\
\hline 10 & 1008 & Oct & 3,917 & 68 & 3,985 & 965 & 0.08 & 0.00 & 0.08 & 0.02 \\
\hline 11 & 1108 & Nov & 3,416 & 30 & 3,446 & 956 & 0.07 & 0.00 & 0.07 & 0.02 \\
\hline 12 & 1208 & Dec & 4,744 & 78 & 4,822 & 1179 & 0.10 & 0.00 & 0.09 & 0.02 \\
\hline Total & & Year & 43,754 & 783 & 44,537 & 11,604 & 0.88 & 0.02 & 0.87 & 0.23 \\
\hline 2009 & & & & & & & & & & \\
\hline 13 & 109 & Jan & 5,947 & 129 & 6,076 & 1344 & 0.12 & 0.00 & 0.12 & 0.03 \\
\hline 14 & 209 & Feb & 5,139 & 81 & 5,220 & 1165 & 0.10 & 0.00 & 0.10 & 0.02 \\
\hline 15 & 309 & Mar & 4,255 & 145 & 4,400 & 1115 & 0.09 & 0.00 & 0.08 & 0.02 \\
\hline
\end{tabular}




\begin{tabular}{|l|l|l|l|l|l|l|l|l|l|l|}
\hline 16 & 409 & Apr & 5,919 & 185 & 6,104 & 1261 & 0.12 & 0.00 & 0.12 & 0.03 \\
\hline 17 & 509 & May & 6,009 & 157 & 6,166 & 1258 & 0.12 & 0.00 & 0.12 & 0.02 \\
\hline 18 & 609 & Jun & 5,618 & 110 & 5,728 & 996 & 0.11 & 0.00 & 0.11 & 0.02 \\
\hline 19 & 709 & Jul & 5,487 & 130 & 5,617 & 1290 & 0.11 & 0.00 & 0.11 & 0.03 \\
\hline 20 & 809 & Aug & 5,094 & 119 & 5,213 & 1072 & 0.10 & 0.00 & 0.10 & 0.02 \\
\hline 21 & 909 & Sep & 4,548 & 121 & 4,669 & 1045 & 0.09 & 0.00 & 0.09 & 0.02 \\
\hline 22 & 1009 & Oct & 4,349 & 100 & 4,449 & 1023 & 0.09 & 0.00 & 0.09 & 0.02 \\
\hline 23 & 1109 & Nov & 3,966 & 102 & 4,068 & 886 & 0.08 & 0.00 & 0.08 & 0.02 \\
\hline 24 & 1209 & Dec & 3,794 & 45 & 3,839 & 662 & 0.08 & 0.00 & 0.08 & 0.01 \\
\hline Total & & Year & 60,125 & 1424 & 61,549 & 13,117 & 1.22 & 0.03 & 1.19 & 0.26 \\
\hline 2010 & & & & & & & & & & \\
\hline 25 & 110 & Jan & 5,007 & 98 & 5,105 & 1041 & 0.10 & 0.00 & 0.10 & 0.02 \\
\hline 26 & 210 & Feb & 3,900 & 113 & 4,013 & 893 & 0.08 & 0.00 & 0.08 & 0.02 \\
\hline 27 & 310 & Mar & 8,033 & 185 & 8,218 & 1432 & 0.16 & 0.00 & 0.16 & 0.03 \\
\hline 28 & 410 & Apr & 6,276 & 121 & 6,397 & 1206 & 0.13 & 0.00 & 0.12 & 0.02 \\
\hline 29 & 510 & May & 4,991 & 120 & 5,111 & 1065 & 0.10 & 0.00 & 0.10 & 0.02 \\
\hline 30 & 610 & Jun & 4,479 & 87 & 4,566 & 926 & 0.09 & 0.00 & 0.09 & 0.02 \\
\hline 31 & 710 & Jul & 6,090 & 121 & 6,211 & 1268 & 0.12 & 0.00 & 0.12 & 0.03 \\
\hline 34 & 810 & Aug & 6,968 & 125 & 7,093 & 1381 & 0.14 & 0.00 & 0.14 & 0.03 \\
\hline & 1110 & Nov & 5,144 & 102 & 5,246 & 1150 & 0.10 & 0.00 & 0.10 & 0.02 \\
\hline 35 & Sep & 5,708 & 111 & 5,819 & 1237 & 0.12 & 0.00 & 0.11 & 0.02 \\
\hline
\end{tabular}




\begin{tabular}{|l|l|l|l|l|l|l|l|l|l|l|}
\hline 36 & 1210 & Dec & 6,191 & 150 & 6,341 & 1404 & 0.13 & 0.00 & 0.12 & 0.03 \\
\hline Total & & Year & 69,118 & 1495 & 70,613 & 14,272 & 1.40 & 0.03 & 1.37 & 0.28 \\
\hline 2011 & & & & & & & & & & \\
\hline 37 & 111 & Jan & 5,188 & 132 & 5,320 & 1330 & 0.11 & 0.00 & 0.10 & 0.03 \\
\hline 38 & 211 & Feb & 5,294 & 143 & 5,437 & 1237 & 0.11 & 0.00 & 0.11 & 0.02 \\
\hline 39 & 311 & Mar & 3,869 & 105 & 3,974 & 919 & 0.08 & 0.00 & 0.08 & 0.02 \\
\hline 40 & 411 & Apr & 4,398 & 101 & 4,499 & 1007 & 0.09 & 0.00 & 0.09 & 0.02 \\
\hline 41 & 511 & May & 4,467 & 100 & 4,567 & 932 & 0.09 & 0.00 & 0.09 & 0.02 \\
\hline 42 & 611 & Jun & 4,467 & 100 & 4,567 & 977 & 0.09 & 0.00 & 0.09 & 0.02 \\
\hline 43 & 711 & Jul & 4,442 & 88 & 4,530 & 965 & 0.09 & 0.00 & 0.09 & 0.02 \\
\hline 44 & 811 & Aug & 4,316 & 117 & 4,433 & 917 & 0.09 & 0.00 & 0.09 & 0.02 \\
\hline 45 & 911 & Sep & 3,831 & 77 & 3,908 & 996 & 0.08 & 0.00 & 0.08 & 0.02 \\
\hline 46 & 1011 & Oct & 4,792 & 110 & 4,902 & 1374 & 0.10 & 0.00 & 0.10 & 0.03 \\
\hline 47 & 1111 & Nov & 7,156 & 127 & 7,283 & 1279 & 0.14 & 0.00 & 0.14 & 0.03 \\
\hline 48 & 1211 & Dec & 6,130 & 126 & 6,256 & 1200 & 0.12 & 0.00 & 0.12 & 0.02 \\
\hline Total & & Year & 58,350 & 1326 & 59,676 & 13,133 & 1.18 & 0.03 & 1.16 & 0.26 \\
\hline 2012 & & & & & & & & & & \\
\hline 49 & 112 & Jan & 6,624 & 121 & 6,745 & 1478 & 0.13 & 0.00 & 0.13 & 0.03 \\
\hline 50 & 212 & Feb & 8,282 & 120 & 8,402 & 1621 & 0.17 & 0.00 & 0.16 & 0.03 \\
\hline 51 & 312 & Mar & 7,036 & 151 & 7,187 & 1385 & 0.14 & 0.00 & 0.14 & 0.03 \\
\hline & Apr & 7,191 & 132 & 7,323 & 1412 & 0.15 & 0.00 & 0.14 & 0.03 \\
\hline & & & & & & & & & & \\
\hline
\end{tabular}




\begin{tabular}{|l|l|l|l|l|l|l|l|l|l|l|}
\hline 54 & 612 & Jun & 6,521 & 99 & 6,620 & 1185 & 0.13 & 0.00 & 0.13 & 0.02 \\
\hline 55 & 712 & Jul & 5,507 & 97 & 5,604 & 1043 & 0.11 & 0.00 & 0.11 & 0.02 \\
\hline 56 & 812 & Aug & 5,545 & 97 & 5,642 & 1019 & 0.06 & 0.00 & 0.06 & 0.01 \\
\hline 57 & 912 & Sep & 5,441 & 112 & 5,553 & 1059 & 0.06 & 0.00 & 0.06 & 0.01 \\
\hline 58 & 1012 & Oct & 5756 & 109 & 5,865 & 1123 & 0.06 & 0.00 & 0.06 & 0.01 \\
\hline 59 & 1112 & Nov & 6,562 & 138 & 6,700 & 1122 & 0.07 & 0.00 & 0.07 & 0.01 \\
\hline 60 & 1212 & Dec & 6,655 & 131 & 6,786 & 1203 & 0.07 & 0.00 & 0.07 & 0.01 \\
\hline Total & & Year & 78,166 & 1,427 & 79,593 & 15,023 & 1.49 & 0.03 & 1.46 & 0.28 \\
\hline
\end{tabular}




\section{Appendix B: XYZ Oil Company Incident Rates from 2008-2005}

\begin{tabular}{|c|c|c|c|c|c|c|c|c|}
\hline Count & ID & Month & $\begin{array}{l}\text { Incident } \\
\text { category in } \\
\text { rates }\end{array}$ & & & & & \\
\hline & & & $\begin{array}{l}\text { Near-Miss } \\
\text { Rate }\end{array}$ & Spill Rate & $\begin{array}{l}\text { Injury \& illness } \\
\text { Rate }\end{array}$ & $\begin{array}{l}\text { Fires } \\
\text { Rate }\end{array}$ & $\begin{array}{l}\text { Property } \\
\text { dam/Rate }\end{array}$ & Total/Rate \\
\hline 1 & 108 & Jan & 0 & 9.448224 & 0 & 4.724112 & 4.724112 & 18.89645 \\
\hline 2 & 208 & Feb & 4.724112 & 0 & 4.724112 & 0 & 0 & 9.448224 \\
\hline 3 & 308 & Mar & 0 & 0 & 0 & 0 & 0 & 0 \\
\hline 4 & 408 & Apr & 0 & 0 & 0 & 3.968254 & 3.968254 & 7.936508 \\
\hline 5 & 508 & May & 0 & 0 & 0 & 0 & 0 & 0 \\
\hline 6 & 608 & Jun & 0 & 0 & 0 & 0 & 0 & 0 \\
\hline 7 & 708 & Jul & 0 & 0 & 0 & 0 & 0 & 0 \\
\hline 8 & 808 & Aug & 7.936508 & 3.968254 & 0 & 0 & 0 & 11.90476 \\
\hline 9 & 908 & Sep & 3.968254 & 0 & 0 & 0 & 0 & 3.968254 \\
\hline 10 & 1008 & Oct & 0 & 7.936508 & 0 & 0 & 0 & 7.936508 \\
\hline 11 & 1108 & Nov & 0 & 0 & 0 & 0 & 0 & 0 \\
\hline 12 & 1208 & Dec & 0 & 0 & 0 & 0 & 0 & 0 \\
\hline Total & & & & & & & & 55.55556 \\
\hline 2009 & & & Nmis & Spil & Inj & Fires & Proprt & Total \\
\hline 13 & 109 & Jan & 7.936508 & 0 & 0 & 0 & 3.968254 & 11.90476 \\
\hline 14 & 209 & Feb & 7.936508 & 3.968254 & 0 & 0 & 3.968254 & 15.87302 \\
\hline 15 & 309 & Mar & 15.87302 & 0 & 0 & 0 & 0 & 15.87302 \\
\hline 16 & 409 & Apr & 3.968254 & 0 & 0 & 0 & 0 & 3.968254 \\
\hline 17 & 509 & May & 0 & 7.936508 & 3.968254 & 3.968254 & 0 & 15.87302 \\
\hline 18 & 609 & Jun & 7.936508 & 0 & 0 & 0 & 0 & 7.936508 \\
\hline 19 & 709 & Jul & 3.968254 & 0 & 0 & 0 & 0 & 3.968254 \\
\hline 20 & 809 & Aug & 0 & 0 & 0 & 0 & 0 & 0 \\
\hline 21 & 909 & Sep & 0 & 0 & 0 & 0 & 3.968254 & 3.968254 \\
\hline 22 & 1009 & Oct & 0 & 0 & 0 & 0 & 0 & 0 \\
\hline 23 & 1109 & Nov & 0 & 0 & 0 & 0 & 0 & 0 \\
\hline 24 & 1209 & Dec & 0 & 3.968254 & 0 & 0 & 0 & 3.968254 \\
\hline Total & & & & & & & & 83.33333 \\
\hline 2010 & & & Nmis & Spill & Inj & Fires & Propt & Total \\
\hline 25 & 110 & Jan & 15.87302 & 0 & 0 & 0 & 0 & 15.87302 \\
\hline 26 & 210 & Feb & 0 & 0 & 0 & 0 & 0 & 0 \\
\hline 27 & 310 & Mar & 7.936508 & 11.90476 & 0 & 0 & 0 & 19.84127 \\
\hline 28 & 410 & Apr & 3.968254 & 0 & 0 & 0 & 0 & 3.968254 \\
\hline 29 & 510 & May & 0 & 3.968254 & 0 & 3.968254 & 3.968254 & 11.90476 \\
\hline
\end{tabular}




\begin{tabular}{|c|c|c|c|c|c|c|c|c|}
\hline 30 & 610 & Jun & 15.87302 & 0 & 3.968254 & 3.968254 & 0 & 23.80952 \\
\hline 31 & 710 & Jul & 0 & 15.87302 & 0 & 0 & 7.936508 & 23.80952 \\
\hline 32 & 810 & Aug & 3.968254 & 0 & 0 & 0 & 0 & 3.968254 \\
\hline 33 & 910 & Sep & 0 & 3.968254 & 0 & 0 & 0 & 3.968254 \\
\hline 34 & 1010 & Oct & 7.936508 & 3.968254 & 0 & 0 & 3.968254 & 15.87302 \\
\hline 35 & 1110 & Nov & 15.87302 & 3.968254 & 0 & 0 & 0 & 19.84127 \\
\hline 36 & 1210 & $\mathrm{Dec}$ & 0 & 7.936508 & 0 & 0 & 0 & 7.936508 \\
\hline Total & & & & & & & & 150.7937 \\
\hline 2011 & & & Nmiss & Spill & Inj & Fires & Prop Da & Total \\
\hline 37 & 111 & Jan & 3.968254 & 3.968254 & 3.968254 & 0 & 3.968254 & 15.87302 \\
\hline 38 & 211 & Feb & 0 & 3.968254 & 0 & 0 & 0 & 3.968254 \\
\hline 39 & 311 & Mar & 0 & 0 & 3.968254 & 0 & 0 & 3.968254 \\
\hline 40 & 411 & Apr & 3.968254 & 11.90476 & 0 & 0 & 0 & 15.87302 \\
\hline 41 & 511 & May & 0 & 0 & 7.936508 & 0 & 0 & 7.936508 \\
\hline 42 & 611 & Jun & 3.968254 & 3.968254 & 0 & 0 & 0 & 7.936508 \\
\hline 43 & 711 & Jul & 0 & 3.968254 & 0 & 0 & 0 & 3.968254 \\
\hline 44 & 811 & Aug & 0 & 0 & 0 & 0 & 0 & 0 \\
\hline 45 & 911 & Sep & 11.90476 & 3.968254 & 0 & 0 & 0 & 15.87302 \\
\hline 46 & 1011 & Oct & 3.968254 & 3.968254 & 3.968254 & 0 & 0 & 11.90476 \\
\hline 47 & 1111 & Nov & 7.936508 & 3.968254 & 0 & 0 & 0 & 11.90476 \\
\hline 48 & 1211 & $\mathrm{Dec}$ & 0 & 3.968254 & 0 & 0 & 0 & 3.968254 \\
\hline Total & & & & & & & & 103.1746 \\
\hline 2012 & & & Nmiss & Spill & Inj & Fires & Prop Da & Total \\
\hline 49 & 112 & Jan & 3.968254 & 11.90476 & 0 & 0 & 0 & 15.87302 \\
\hline 50 & 212 & Feb & 0 & 7.936508 & 0 & 0 & 3.968254 & 11.90476 \\
\hline 51 & 312 & Mar & 0 & 7.936508 & 3.968254 & 3.968254 & 0 & 15.87302 \\
\hline 52 & 412 & Apr & 11.90476 & 0 & 0 & 0 & 0 & 11.90476 \\
\hline 53 & 512 & May & 0 & 3.968254 & 0 & 0 & 0 & 3.968254 \\
\hline 54 & 612 & Jun & 3.968254 & 3.968254 & 0 & 0 & 0 & 7.936508 \\
\hline 55 & 712 & Jul & 0 & 0 & 0 & 0 & 0 & 0 \\
\hline 56 & 812 & Aug & 0 & 0 & 4.376751 & 0 & 0 & 4.376751 \\
\hline 57 & 912 & Sep & 0 & 0 & 0 & 2.188375 & 0 & 2.188375 \\
\hline 58 & 1012 & Oct & 2.188375 & 0 & 0 & 0 & 0 & 2.188375 \\
\hline 59 & 1112 & Nov & 4.376751 & 0 & 2.188375 & 0 & 0 & 6.565126 \\
\hline 60 & 1212 & Dec & 4.376751 & 10.94188 & 0 & 0 & 0 & 15.31863 \\
\hline Total & & & 37.43636 & 52.4109 & 14.97454 & 7.487272 & 3.743636 & 116.0527 \\
\hline
\end{tabular}




\section{Appendix C: Sample of BBS Observation Sheet}

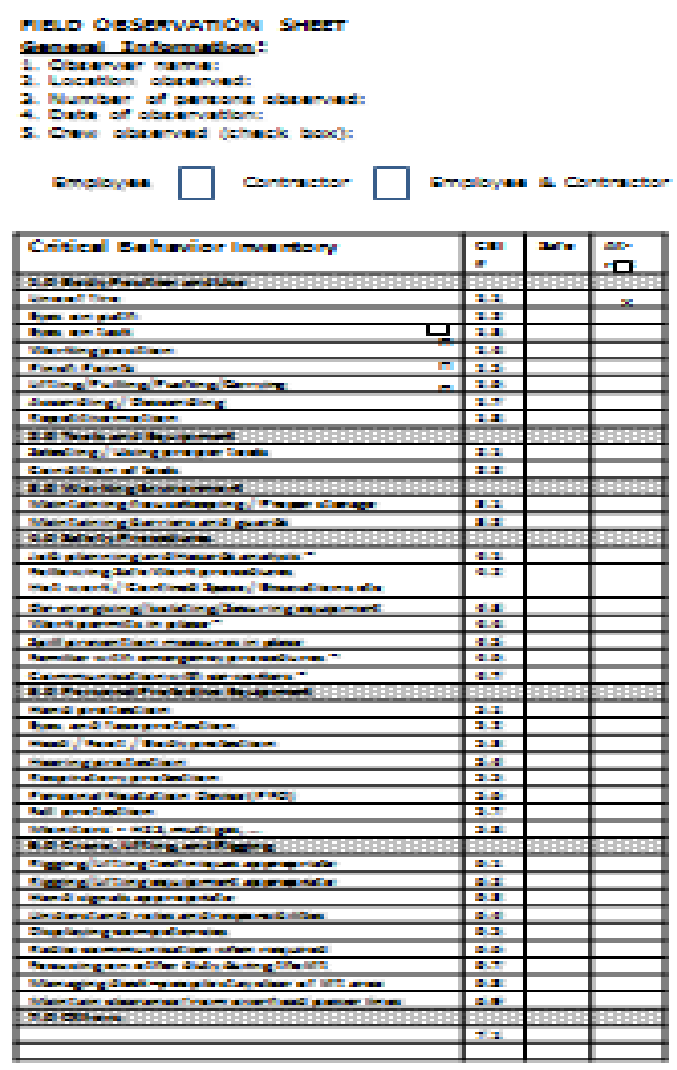

$\square$

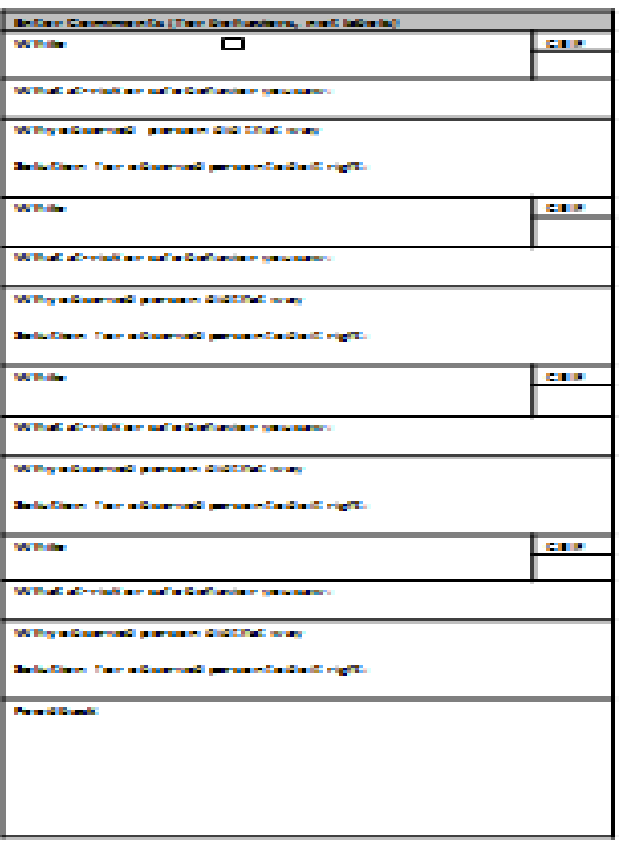

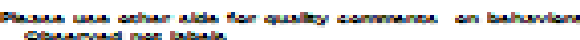




\section{Appendix D: Sample of Critical Behaviors Inventory and Definitions in XYZ Oil Company}

\subsection{Body Use and Position}

\section{$\underline{1.1}$ Line of fire}

Q.-Does the person place all parts of his/her body so that they will not be pinned, crushed, struck, sprayed or trapped by energy releases of any kind (electrical, hydraulic, pneumatic, chemical, moving equipment suspended loads etc.)?

Q.-Does the person place all parts of his/her body so that if something gives way, lets go, releases, sprays, leaks, spillage, flashes, arcs, or falls, he/she will not be contacted (electrical, pneumatic and hydraulic, chemical, suspended loads)?

\section{Examples of safe behaviors:}

- $\quad$ Stand to the side or stay out of the area of suspended loads.

- Hold tool to avoid trapping hand between tool and other object if the tool slips or binds.

- When using a cutting tool, cut with a motion that is moving away from your body.

- When accessing or working at height ensures that no items are carried or stored in such a way so they may fall or be dropped.

- When disconnecting hoses, make sure all pressure is relieved.

- When clearing or cleaning lines, stand to the side.

- When opening door of pig trap receiver, stand to the side

- When opening valves, always stay to the side

- When pouring hot coffee, pour over the top of the counter.

- When using a paper cutter, make sure that hands and fingers are placed safely away form the cutting action of the blade, before lowering the cutting blade.

- When walking by doors that open out into the hallway, walk on the far side of hallway

\section{$\underline{1.2 \text { Eyes on path }}$}

Q.-Does the person look in the direction they are walking, moving, or operating mobile equipment or vessel?

Q.-Is the person's vision unobstructed when in motion?

Q.-Does the person clear obstructions out of the way, move or walk around them? 
Q.-Does the person moves at a safe pace appropriate for conditions?

Q.-Does the person use walkways, stairways and/or catwalks provided for access to working area and

Avoid shortcuts, uneven, slippery, and cluttered surfaces and areas with tight clearances?

Q.-Does the person look for hazards in the path below, above and to the sides?

Q.-Does the person watches above, below and to the sides of where he/she is moving?

Q.-Does the person walk around slipping/tripping hazards?

Q.-Does the person clear vision when walking?

Q.-Does the person use ceiling mirror at intersections where available?

\section{Examples of safe behaviors:}

- When walking, use sidewalks or designated walkways (avoid shortcuts across green space or through machinery).

- When walking on ice, snow covered, wet, oily or slippery surfaces take small flat-footed steps.

- Avoid areas where floor is being cleaned, under construction or repair.

- Before opening door fully into hallway, partially open door and look both ways

- Walk down the corridor (instead of running).

- When walking across your intended path, yield to others.

- While walking/moving keep eyes on path to avoid bumping objects such as magnetic doors, overhead obstacles utility lines, duct work, low ceilings and exposed sharp surfaces.

\section{$\underline{1.3 \text { Eyes on task }}$}

Q.-Does the people keep their eyes on the work being performed?

Q.-Does the person have an unobstructed view of the work?

Q.-Does the people ignore distractions while doing the task?

Q.-Does the people look around for sharp or hot objects, corners, machinery, and equipment. before moving or changing position in tight spaces 


\section{Examples of safe behaviors:}

- When using hammer ensures that eyes are focused on striking area.

- Keep your eyes on the work and pay attention where you place your hands

- When carrying out task ensures that any distractions are ignored until the job is complete or is made safe.

- If moving large objects such as ladders or poles, check clearances before performing tasks

- When using mechanical lift, identify and avoid overhead obstacles.

- When working around hot surfaces, keep arms length away.

- When working in blind spots, visually inspect area prior to placing hands, legs or arms.

- When reaching into boxes, inspect prior to placing hands inside.

\subsection{Working position}

Q.-Does the person stands or sits on level, stable, solid surface that provides good traction?

Q.-Does the person set up the work on a level, stable, solid surface?

Q.-Does the person position his/her feet flat and shoulder- width apart?

Q.-Does the person balance weight equally over both feet?

\section{Examples of safe behaviors:}

- When using stool, ladder or climbing device set on level stable surface.

- Use a step stool rather than a box, chair, etc. and support body with hand on a secured object.

- When setting up ladder, place ladder one foot out for every four feet up.

- When placing an extension ladder ensures that the ladder is tied off at the top onto secure equipment or is extended three feet contact point.

- When exiting machinery, place feet on level surface.

\subsection{Pinch Points}

Q.-Does the person keep fingers, hands, feet, other body parts or the entire body away from tight clearances or areas where equipment, machinery pieces or parts come together? (Primarily fingers in tight clearances.)

Q.-Does the person avoid creating a pinch point, when moving equipment or materials? 


\section{Examples of safe behaviors:}

- Keep fingers away from tight areas such as hinges and doors, as they move.

- Keeping hands from between objects being moved and slings or fixed surfaces.

- When aligning equipment to work on it ensures that body parts are kept clear of any pinch points.

- Keep hands or fingers out of moving or unstable equipment.

- When closing drawers, use handles provided.

- When moving furniture, keep your body away from doors, walls and corners.

- Holding tools to avoid trapping hands, fingers between tool and other object if tool slips or binds.

\subsection{Lifting/Pulling/Pushing/Carrying}

Q.-Does the person use legs and keep back straight when lifting and lowering loads?

Q.-Is the lifting done in a smooth motion?

Q.-Is the load held close to the body?

Q.-Is the weight appropriate for person/s to lift?

Q.-Is the object secure when lifted?

Q.-Does the person keeps the load close to body, avoiding extending to arm length and bending at waist?

Q.-Does the person maintain a balanced body position when pushing/pulling?

Q.-Does the person push instead of pulling when possible?

Q.-Does the person pulls or pushes with legs instead of back?

Q.-Does the person "tests" or "sizes up" the load before lifting?

Q.-Does the person uses a continuous motion instead of "jerking" to pull or push?

Q.-Does the person pushes with legs and entire body instead of arms only?

\section{Examples of safe behaviors:}

- When lifting or lowering bend at the knees (keeping the back and neck straight) instead of bending at the waist

- Lift heavy objects with two hands and carry load within his/her forearm distance of the body.

- When lifting large jugs of water to the cooler, get assistance. 
- Lift within the safety zone between the knees and shoulders.

- When moving welding carts, push instead of pull.

- When pushing pallet jack, keep body balanced and feet square with shoulders.

- When pulling winch cable, balance body so that if the cable comes free the body will not fall.

\subsection{Ascending/Descending}

Q.-Does the person use stairs, ladders or other climbing devices intended for ascending/descending, rather than climbing on equipment, piping, etc?

Q.-Does the person walk up and down stairs one step at a time using handrails? Do not run on stairs.

Q.-Does the person stands at or below designated top rung on a step stool or ladder?

Q.-Does the person takes one step at a time instead of skipping stairs or ladder rungs?

Q.-Does the person keeps the body within the rails of the ladder?

Q.-Does the person step from truck, machinery, equipment instead of jumping?

Q.-Are tools secured while ascending and descending?

\section{Examples of safe behaviors:}

- When ascending/descending ladders ensures that three-point contact is maintained.

- When ascending/descending ladders ensures that tools/equipment is not hand-carried.

- When ascending/descending ensures the person face the ladder.

- When getting in or out of machinery use the handle.

- When walking up or down stairs hang on to the hand rail.

- Place the foot fully on the stair or ladder instead of stepping on the ball of the foot or the toes.

\subsection{Repetitive motion}

Q.-When exposed to ergonomic risks (static or repetitive work, awkward or forceful work) does the person deliberately break up the stress by changing positions, moving, stopping or rotating activity or stretching?

Q.-Does the person modifies and/or adjusts their equipment or tools to help them achieve neutral and/or supported wrist, neck, back or legs posture? 


\section{Examples of safe behaviors:}

- When performing a repetitive task, e.g. tightening of screws, jack hammering, ensures that stress is reduced by changing positions, moving or rotating jobs to use different muscle groups, taking breaks or stretching.

- When working at a workstation, (e.g. computer or work-bench), ensures equipment or tools are placed in order to achieve neutral or supported body position.

- When the job requires doing the same motion repeatedly, ensures varying the way the job is done, or alternating tasks and or taking regular breaks to rest and stretch.

\subsection{Tools and equipment}

\subsection{Selecting and using proper tools}

Q.-Does the person select the correct tool or equipment for the job?

Q.-Does the person use the tool/equipment as it was designed to be used?

Q.-Is the equipment correctly certified for the area in which it is to be used?

\section{Examples of safe behaviors:}

- When opening/closing valve ensures that correct size wheel key is used.

- When transporting samples ensures that a closed container is used.

- When appropriate ensures that equipment is correctly certified for the area to be worked in.

- When removing staples, use a staple remover.

- Never use a wrench for hammer

- Never use a screwdriver for a chisel or pry bar

- Follow operating instructions for specialized tools

\subsection{Condition of tools}

Q.-Have tools or equipment not been modified?

Q.-Is there no defective tool in use?

Q.-Is the tool or equipment clean and free from obvious defects and in good working order with no damage? 


\section{Examples of safe behaviors:}

- When using power tools, check condition of plugs and cords prior to use.

- When operating equipment, ensure that guards are in place prior to using.

- Before using tools/equipment ensure they are free of non-approved modifications.

- Wire rope slings free of wicker's / burrs

- Nylon slings are not excessively soiled or frayed

- Jaws on wrenches and vises are clean and in good condition.

\subsection{Working Environment}

\subsection{Maintaining housekeeping/proper storage}

Q.-Has the person cleared the area of slipping/tripping hazards?

Has the person cleared passages and work area of obstructions and clutter such as boxes, flats, pallets, hoses?

Q.-Does the person clean and organize work area before, during and after the task involved?

Q.-Has person stored equipment, tools, materials, chemicals securely and labeled chemicals?

\section{Examples of safe behaviors:}

- When slippery surfaces are found ensures that the situation is reported, removed or otherwise rectified.

- Remove oils/chemicals from floors, handrails, etc.

- Remove debris from floor before leaving area.

- Wipe up spilled coffee from the floor.

- Close drawers and cabinets after use.

- Move boxes, chairs, trashcans, etc. out of the walkway.

- Keep computer, telephone, and power cords, trash cans, stools and stepladders out of the way so they do not become a tripping hazard.

- When storing equipment in the workplace ensure that it is not stored on stairways, at the base of ladder access or in access-ways.

- Store tools out of the immediate work space when not in use.

\subsection{Maintaining barriers and guards}

Q.-Has the person placed barricades and signs around work areas when hazards exist? 
Q.-Are there barricades and guards in place to prevent entry into temporary hazardous areas?

Q.-Are barricades and warnings kept around permanent hazards effectively and in good condition?

Q.-Is the correct type of barricade or warning device used?

Q.-Does the barricade or warning explains the hazard and action to be taken?

Q.-Is the barricade/warning removed when the hazard is clear?

\section{Examples of safe behaviors:}

- When floor gratings have been lifted and are open ensure that "Do not enter" signs and chain barricades are in place.

- When radiography takes place ensure that yellow/black tape and warning triangles are in place to prevent unauthorized entry to area.

- When creating local high noise areas ensure that ear protection signs are erected.

- Place cones, tape, tents, signs, etc. around temporary hazards (puddles, holes, low clearances, overhead work, etc.)

- When roofing, define buffer zone with tape or rope.

- Use guards on all belts, couplings, or grinders.

- When there are spills, wet floors or obstructions to walkways place cones around hazards.

- When working behind a door that has no window, place a cone in front of the door.

- When filing in open filing cabinets (that you can't keep closed) place cones in walkway.

\subsection{Safety Procedures}

\subsection{Job planning and hazards analysis}

Q.-Has the person completed the Job Safety Analysis (JSA) for the work being performed

Q.-Has the person inspected the area for and responding to possible hazards - asking how could I get hurt and mitigating that risk?

Q.-Has the person assess the work area and equipment, reading labels and manuals before starting work?

Q.-Has the person considered the health and environmental aspects in the JSA? 


\section{Examples of safe behaviors:}

- $\quad$ Prior to starting a job, complete a Job Safety Analysis (JSA), involving the right parties.

- Prior to starting the work, inspect the area for potential hazards.

- Team consider to review JSA when exposures change

- Critical tasks that requires a qualified operator to be in the control room during task has been identified

And personnel identified

- All affected parties are notified of work in progress

\subsection{Following Safety work Procedures (Hot work/ Confined Space/ Excavations...)}

Q.-Is the person following Company standard procedures in relation to the task? $\underline{\text { Safe Practices }}$ Manual 8.0

Q.-Is the Person-In-Charge (PIC) helping to ensure that procedures are being adhered to?

Q.-Has scaffolding been inspected and tagged (green tag) as per SOP

Q.-Is the person approaching flare in the upwind side?

Q.-Are compressed gas cylinders away from flammables, with 20 feet (6mts) distance?

Q.-Is the person following all steps established per JSA?

Q.-Is the person following instructions of the MSDS when handling chemicals although using proper gloves?

Q.-Is the person following established SOP guidelines?

Q.-has the person verified that confined space is gas-free?

Q.-Is watch person carrying a radio for communication?

\section{Examples of safe behaviors:}

- When carrying out any task routine or non-routine, hazardous or not, ensure that persons are compliant

- With company standard operating procedures

- Ensuring that scaffold is appropriately tagged green and inspection date is updated before any task

- Use of a flare pistol to light all flares and ensuring proper direction of projectile.

- Keeping compressed gas cylinders away from oils or other flammable chemicals 
- When doing hot work, ensure that a competent fire watch (second person) is available in case of fire and ensure warning signs and shields/curtains are in place.

- Before entering confined space ensure there is a designated watch person

- Ensure name is on permit before entering confined space

- Ensure that all safety equipment is accessible for entrance/exit

\subsection{De - Energizing/ Isolating/ Securing Equipment}

Q.-Is the person locking and tagging out equipment he/she is working on with company issued lock and Tag?

Q.-Is the person identifying and isolating all energy sources? This may include cooling hot surfaces

Q.-Is the person locking, tagging, choking, blocking, venting or draining, etc. all energy sources before working on or around the equipment?

Q.-Is the person supporting equipment being mechanically disconnected?

Q.-Does the person secures all equipment (such as electrical panel) before restarting?

\section{Examples of safe behaviors:}

- When removing equipment jams, lock out prior to working on.

- When cleaning belts and moving parts in equipment, lock out/tag out prior to cleaning. Before working on the equipment, verify that the equipment will not start (has been isolated) by attempting to start/operate equipment

- Before working on equipment verify that it will not start (all power sources been isolated) by attempting to

Operate it while isolated as they might other sources of energy.

\subsection{Work Permit in place}

This is more of looking a footprint of a behavior. Observer needs to ask for them.

Q.-Has the person obtained and displayed approved work permit(s)?

Q.-Are all required permits on-site, have they appropriate signatures, and are up-to-date?

\section{Examples of safe behaviors:}

- Use of permits as required by Hot works/ confined space entry/ excavations/

- All work permits are duly completed 


\subsection{Spill prevention measures in place}

Q.-Is the person following procedures and taking precautions to prevent spills?

\section{Examples of safe behaviors:}

- When filling tanks or drums keep eye on fill line to ensure that they do not overflow

- When tanks and vessels sit idle, ensure they are emptied

- When transferring fluids between tanks, conduct during regular business hours.

- Has a drip tray available and in use when undoing hydraulic lines.

\section{$\underline{4.6 \text { Familiar with emergency procedures }}$}

Q.-Has the person received safety briefing upon arrival at platform or new site?

Q.-Does the person know the muster point of present area of work?

Q.-Does the person know and understand the emergency phone numbers in camp?

Ask him to tell you the numbers- should check: Fire Dept., Medical, Security

Q.-Has the person inspected the area for possible hazards and how to respond in emergency?

Q.-Is the person familiar with the site specific emergency procedures?

Q.-Has the person assess the work area and equipment, reading labels and manuals before starting work?

Q.-Has the person considered the health and environmental aspects in the JHA?

\section{Examples of safe behaviors:}

- Prior to start a job; complete a Job Safety Analysis (JSA), involving the right parties.

- Prior to starting the work, inspect the area for potential hazards and look to understand how you respond in case of emergency

- Prior to start a job in an unfamiliar site, inquire for emergency procedures applicable in the area

\subsection{Communication with co-workers}

Q.-Is the person communicating with co-workers through distinct words or signals, the hazards, unsafe material or impending action? 
Q.-Are members of the team within sight so that each can see others actions?

Q.-Is there a line of communication in place for an employee working alone?

Q.-Has everyone acknowledged the content of JSA and signed it so that all involved persons know the steps?

Q.-Have changes in JSA been communicated to everybody on the spot?

\section{Examples of safe behaviors:}

- When starting machines or equipment, communicate with all others to ensure your coworkers are clear of the way.

- When using mobile equipment, use horn when needed to communicate and alert coworkers of your presence.

- When working alone, carry radio to use for communication as necessary.

- Communicate necessary changes to JSA whenever needed like when exposure changes

\subsection{Personal Protective Equipment}

\subsection{Hand Protection}

Q.-Is the appropriate hand protection being worn for the task?

Q.-Is it in good condition?

Q.-Is it being worn correctly?

\section{Examples of safe behaviors:}

- Wear gloves/sleeves made of material designed to protect from the risks of the job.

- When handling sharp objects wear leather gloves.

- When pouring or working with chemicals, wear chemical gloves.

- When welding wear welding gloves and sleeves.

- When working close to hot surfaces ensures that wrist and other exposed areas are protected.

\subsection{Eyes and Face Protection}

Q.-Is the eye/face protection appropriate for the task being performed? 
Q.-Is it in good condition?

Q.-Is it being worn as designed?

\section{Examples of safe behaviors:}

- Wear safety glasses with side shields when working in areas with risk of dust, particles, etc. in the eyes.

- Wear face shield and/or goggles where flying particles (e.g., dust, metal shavings, splashing hazardous liquids or welding arcs) are generated or when handling corrosive chemicals.

- When welding, use welding hood.

- When grinding wear goggles.

- When working with chemicals wear face shield.

\subsection{Head / Foot / Body Protection}

Q.-Is head protection being worn in designated areas?

Q.-Is it in good condition?

Q.-Is it being worn as designed?

Q.-Is appropriate foot protection for the job or work area being worn?

Q.-Is foot protection appropriate for the risk?

Q.-Is it in good condition?

Q.-Is it being worn correctly and as designed?

Q.-Is the appropriate body protection being worn for the task?

Q.-Is it in good condition?

Q.-Is it being worn correctly?

Examples of safe behaviors:

- Wear coveralls, apron or other work clothing to protect from the risks of the present job.

- Wear the appropriate clothing if performing electrical job.

- Wear disposable long sleeve white suit when handling greasy material or chemicals 
- Wear steel-toed shoes when working with heavy objects or material handling equipment.

- When walking on ice, snow-covered and wet surfaces, wear flat (not high heel) shoes with slip-resistance soles.

- Wear boots when handling chemicals.

- When working in process areas, construction areas, and other designated areas ensures that head protection is worn.

- When head protection is required ensures that it is in good condition and within expiry date.

- Where head protection is required ensures that it is worn correctly.

\section{$\underline{5.4 \text { Hearing Protection }}$}

Q.-Is hearing protection worn in designated areas?

Q.-Is it in good condition and cleans?

Q.-Is it worn correctly and as designed?

\section{Examples of safe behaviors:}

- Wear ear muffs or earplug in areas posted as high noise area.

- When jack hammering wear ear protection.

- When working around loud equipment/vehicles wear hearing protection.

\subsection{Respiratory Protection}

Q.-Is respiratory protection for the job being worn?

Q.-Is respiratory protection appropriate for the task being performed?

Q.-Is it in good condition?

Q.-Is it being worn properly and as designed?

\section{Examples of safe behaviors:}

- Wear recommended respirator where there is risk of inhaling chemicals, corrosives, hazardous dust, mist, fumes, or hazardous gases.

- When working in dusty areas wear dust mask.

- When wearing respiratory protection ensures that it fits properly, seals against leaks and functions as designed.

- When using breathing apparatus ensures that all safety checks are completed successfully before moving into affected area. 


\subsection{Personal Floatation Device (PFD)}

Q.-Does the person wearing a personal floatation device (PFD) when traveling to and from sites Over water, such as platforms?

Q.-Is it in good condition?

Q.-Is it being worn correctly?

\section{Examples of safe behaviors:}

- Wear a PFD at all times when on boat, helicopter, or platform.

\subsection{Fall Protection}

Q.-Is a person working at height wearing a body harness?

Q.-Is it attached to a secure mount or secondary device (fall arrestor?)

Q.-Is the harness, secondary device and mounts in good condition?

Q.-Does the harness fit correctly?

Q.-Is it worn correctly?

\section{Examples of safe behaviors:}

- Wear safety harness when working above 6 feet (either on top of tank, on ladder, etc.)

- When wearing a lifeline and harness ensures that the lifeline is connected to a secure mount.

- When wearing a harness ensures that it is fit and properly fastened.

- Maintain the harness free of frays, holes, tears, tape, or modifications.

\subsection{Monitor $-\mathrm{H} 2 \mathrm{~S}$, multi gas}

Q.-Use during Hot work, confined space or when hazards exist that warrants its use?

Q.-Use personal monitors in designated H2S areas 


\subsection{Crane, Lifting and Rigging}

\section{$\underline{6.1 \text { Rigging and Lifting Techniques Appropriate }}$}

Q.-Is the crane being operated in a slow, smooth and controlled manner, or are the movements too fast and jerky causing the load to swing about in the air?

Q.-Are the people using the rigging gear taking care to use good ergonomics and body posture with a good secure footing, or are they stretching too far, or standing on an unsuitable/unstable platform such as a box etc.?

Q.-Is the lay down area is clear from obstruction before the initial lift in made, or are the crew trying to clear the area just as the load is about to be lowered?

\section{Examples of safe behaviors:}

- The work area is marked with barrier tape. (Where and when appropriate)

- Operator uses slow deliberate to lift load and slew crane into position

- Operator uses slow deliberate to lift load and slew crane into position.

- Operator waits until load has stopped swinging before trying to lower it to the deck/ground.

- The load has tag lines fitted to help control load from spinning during lift.

- Rigger is using good body posture.

- The lay down area is discussed and cleared before lift takes place.

\subsection{Rigging and Equipment Appropriate}

Q.-Is there enough rigging equipment to complete the task?

Q.-Is there enough rigging equipment to complete the task?

Q.-Is the rigging equipment marked with a serial number?

Q.-Is the rigging equipment marked with a valid color code?

Q.-Does the rigging equipment have a safe working load suitable for the task?

Q.-Does the rigging equipment seems to be in good condition?

Q.-Are there safety latches in the crane blocks or chain hoists?

Q.-Are daily check list for the crane up to date (these should be in crane cab)? 


\section{Examples of safe behaviors:}

- The rigging equipment is color coded with this years color. (You may need to check this with site supervisor to get the color code for the period)

- Only trained personal using equipment.

- No non- essential personal near the rigging or lifting operation.

- Rigging equipment is kept in good condition.

- Rigging equipment is stored in a suitable location, and in a neat and tidy manner.

\section{$\underline{6.3 \text { Hand Signals Appropriate }}$}

Q.-Are the hand signals being giving by the Signalman, to the clear crane operator clear?

Q.-Is there only one person giving the hand signals?

Q.-Is the signalman wearing a Hi-Viz vest - or some other means of clear identification - to make himself visible to the Crane operator?

\section{$\underline{6.4 \text { Understand Roles and Responsibilities }}$}

Q.-Is each person involved in the crane or lifting operation aware of their own particular role during the operation, and does they what is expected of them? (You may need to ask questions)

Q.-Is each person involved in the crane or lifting operation aware of their own particular responsibility during the operation, and does they what is expected of them? (You may need to ask questions)

\section{Examples of safe behaviors:}

- Willingness to use the SWA if need be.

- Inspection of crane by operator prior to lifting operation commencing, and reporting defects if any.

- Inspection of rigging gear by rigger prior to lift, and report defects if present.

- Ensuring people are kept clear of lifting operation.

- Setting out a good plan and discuss roles and responsibilities before work begins.

\section{$\underline{6.5 \text { Displaying Competencies }}$}

Q.-Are the people involved working with confidence, or do they look confused and bewildered by their surroundings?

Q.-Is the crew working in a controlled manner?

Q.-Do they answer any questions quickly and confidently, for example a question regarding the Current color code? 


\section{Examples of safe behaviors:}

- Crane loads moved in a controlled manner.

- The signalman is using deliberate, clear signals.

- Good rigging practices being used to sling loads

- The team is working in a confident manner and able to answer all rigging and lifting questions.

\subsection{Radio Communication when is required}

Q.-Is the crane lift being carried out a lift were the operator losses sight of the load, if so a radio should be used to communicate between crane operator and signalman?

Q.-Is the radio reception clear and understandable?

\section{Examples of safe behaviors:}

- Making sure radio batteries are charged.

- Carrying out radio check prior to lifting operation.

- Using a headset if noise levels are high.

\subsection{Focusing on other duty during the Lift}

Q.-Is the team being distracted by other simultaneous ongoing operations nearby?

Q. - How are the signalman and rigger doing each other's duties?

Q.-Is the crane operator watching the load and signalman directions, or is he watching what's happening on the drill floor etc.?

\section{Examples of safe behaviors:}

- Work group is focused on the task in hand.

- People are adhering to their own specific roles during the lifting operation.

- Crane operator is vigilant at all times.

\subsection{Managing deck-people stay clear of lift area}

Q.-Are there peoples other than the team within the lay down area, or the rigging area whilst a lifting or rigging operation is taking place? 
Q.-Is there sufficient barriers in place to stop others walking in to the 'line of fire' area?

Q.-Are the signalman and rigger policing the area to keep people clear if no barriers are in place?

\section{Examples of safe behaviors:}

- Use of barriers to keep people out of the lifting area.

- Inform others of imminent lifting operations. (Can use platform/sites PA system)

- Try to plan lift during a quieter time of the day.

- Stopping job and asking someone to leave area if someone enters lift area.

\subsection{Maintain clearance from overhead power lines}

Q.-Are there any power lines in the near vicinity of the crane lifting operation, if so, is it possible for the crane boom, or crane wire rope to come in to contact with them?

\section{Examples of safe behaviors:}

- Ensure crane can rotate 360deg and still have a 10 foot clearance from the power lines at all time.

- Have a Heavy Equipment or Facility Inspector present to act as spotter. (The spotter can leave the site once satisfied that there is enough clearance.

- Get the power line insolated (tag out/lock out if possible-approved person only)

- Insulate/shield the power line (approved person only)

- Install grounding systems for the power lines and make with red flag or tape to aid visibility. (Approved person only)

\subsection{Others}

7.1_enter here any other behavior or Critical Behavior CBI ${ }^{\circledR}$ that is not covered above

7.2 enter here any other behavior or Critical Behavior $\mathrm{CBI}{ }^{\circledR}$ that is not covered above 